\title{
Development of a computer based total productive maintenance model for electrical motors
}

Aruna Muniswamy

West Virginia University

Follow this and additional works at: https://researchrepository.wvu.edu/etd

\section{Recommended Citation}

Muniswamy, Aruna, "Development of a computer based total productive maintenance model for electrical motors" (2008). Graduate Theses, Dissertations, and Problem Reports. 4407.

https://researchrepository.wvu.edu/etd/4407

This Thesis is protected by copyright and/or related rights. It has been brought to you by the The Research Repository @ WVU with permission from the rights-holder(s). You are free to use this Thesis in any way that is permitted by the copyright and related rights legislation that applies to your use. For other uses you must obtain permission from the rights-holder(s) directly, unless additional rights are indicated by a Creative Commons license in the record and/ or on the work itself. This Thesis has been accepted for inclusion in WVU Graduate Theses, Dissertations, and Problem Reports collection by an authorized administrator of The Research Repository @ WVU. For more information, please contact researchrepository@mail.wvu.edu. 
Development of a Computer Based Total Productive Maintenance

\title{
Model for Electrical Motors
}

\section{By}

\author{
Aruna Muniswamy \\ Thesis submitted to the College of Engineering and Mineral Resources \\ at West Virginia University \\ in partial fulfillment of the requirements \\ for the degree of \\ Master of Science \\ in \\ Industrial Engineering
}

Dr. Bhaskaran Gopalakrishnan, P.E

Dr. Majid Jaraeidi

Dr. Edward Crowe

Industrial and Management Systems Engineering

\section{Morgantown, West Virginia 2008}

Keywords: Total Productive Maintenance, Electrical Motor, Periodic Maintenance, Predictive Maintenance

Copyright 2008 Aruna Muniswamy 


\title{
ABSTRACT
}

\section{Development of a Computer Based Total Productive Maintenance Model for Electrical Motors}

\author{
By Aruna Muniswamy
}

Electrical motors are the major energy consuming equipment in US industries. They drive an innumerable number of processes that keep the industry running resulting in production of various consumer goods. A large number of motors (more than $40 \%$ ) fail before reaching their design life.

Maintenance of motors is an important area of concern. A total productive maintenance model is designed and developed in Microsoft Access for electrical motors. The model takes input from the user regarding motor information, predictive tests data etc. The received data is processed and the output is displayed in the report. The report has a set of periodic recommendations providing guidelines on what to do and how often to do, it will have test results indicating the condition of the motor and giving appropriate recommendations. The report will also give maintenance cost details, periodic maintenance cost and predictive maintenance cost separately. The model also keeps track

of the motor history by saving the previous test data in the database and displaying in the report.

The model can predict problems within the motor before the actual failure. This feature will go a long way in helping the industry personnel in preventing sudden failures, thereby reducing costs incurred due to stoppage of production. The periodic maintenance recommendations given by the model, when adhered to, will ensure that the motor life is taken closer to design life as much as possible. 


\section{ACKNOWLEDGEMENTS}

I would like to wholeheartedly thank my advisor Dr. B. Gopalakrishnan for his continued support, guidance and encouragement during the course of this research. I also wish to thank Dr. Majid Jaraiedi and Dr. Edward Crowe, my committee members, for their advice and support. I wish to extend my special thanks to my brother Mr. Anil M. Kumar for his invaluable help and support for the success of this project.

Above all, I wish to thank God, my spiritual master and my family for their constant support and blessings, enabling my success and happiness in all my pursuits and endeavors in life. 


\section{Table of Contents}

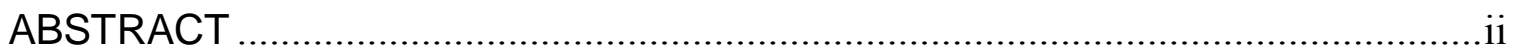

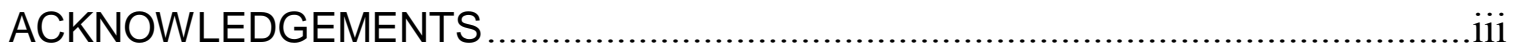

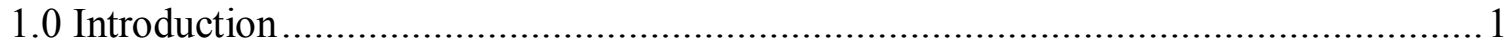

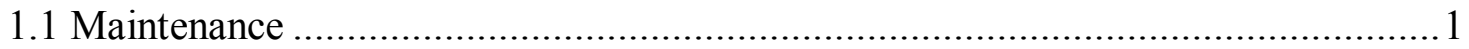

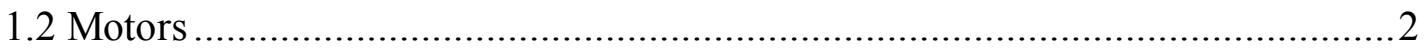

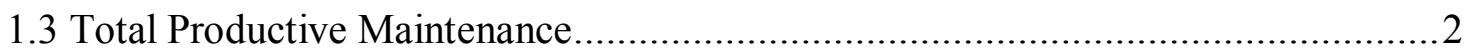

1.3.1 Concept of Total Productive Maintenance ………......................................

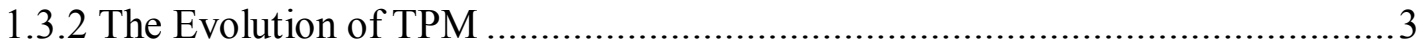

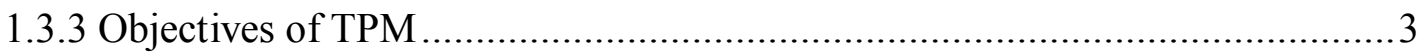

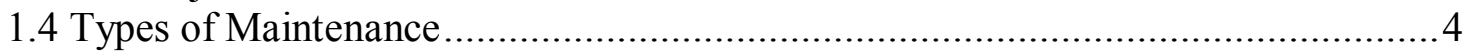

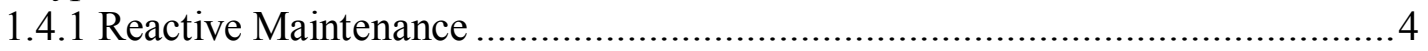

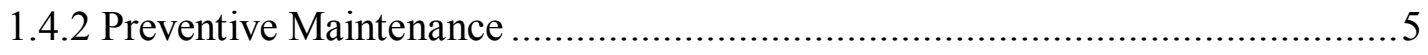

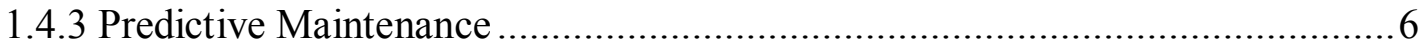

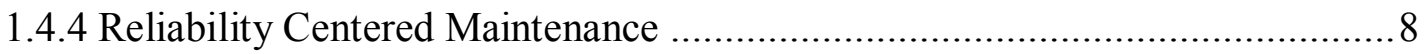

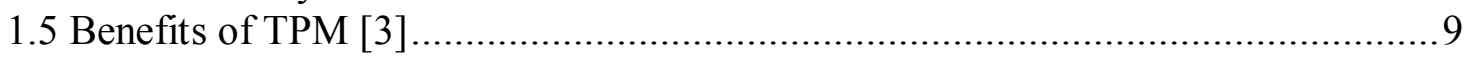

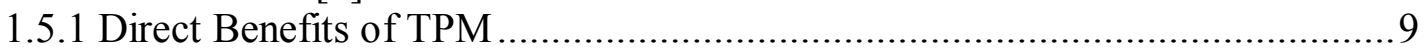

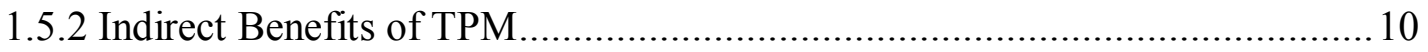

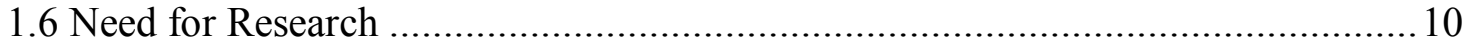

1.6.1 Current Poor Motor Maintenance Practices ………...................................... 10

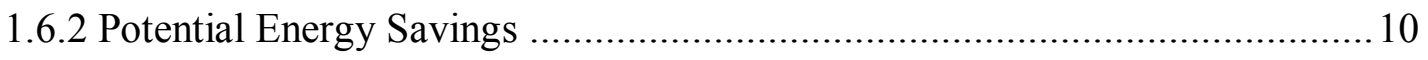

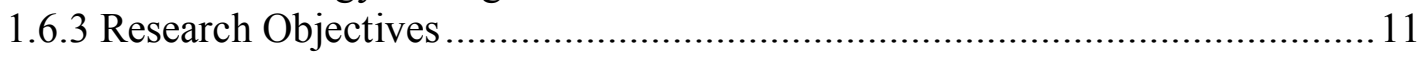

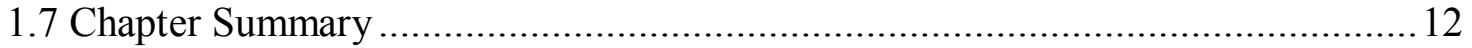

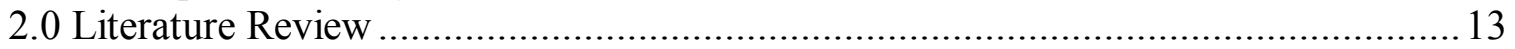

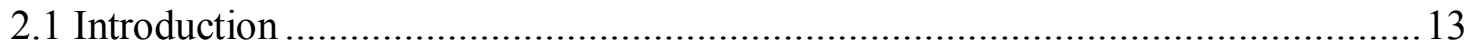

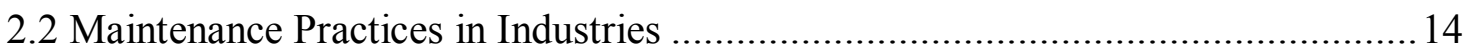

2.3 Total Productive Maintenance of Equipments in Industries .................................. 14

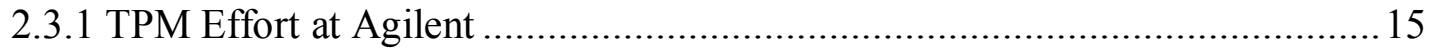

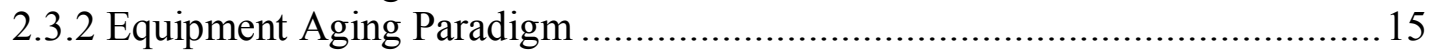

2.4 Total Productive Maintenance for Electrical Motors ……..................................... 16

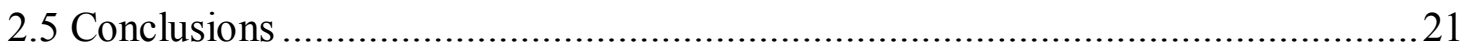

3.0 Design of Total Productive Maintenance (TPM) Model for Electrical Motors..........22

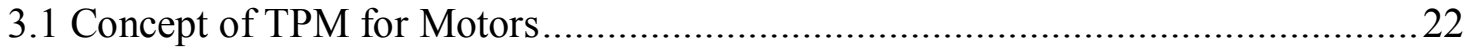

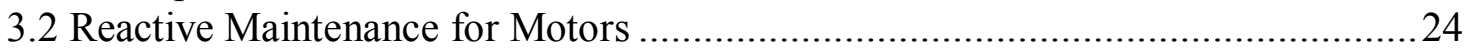

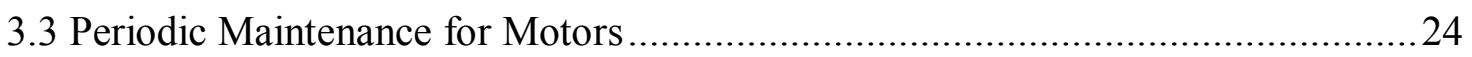

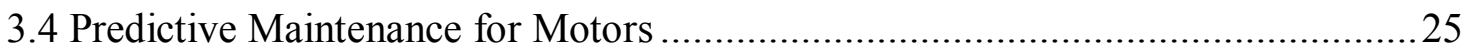

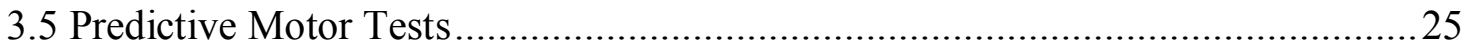

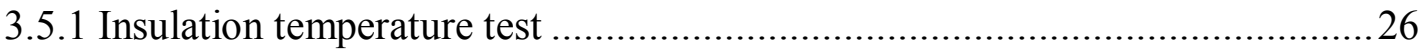

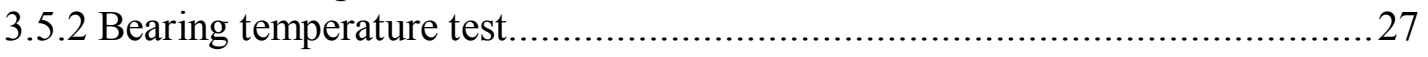

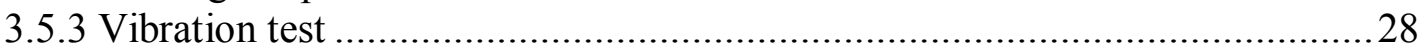

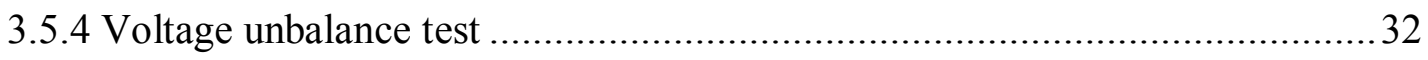

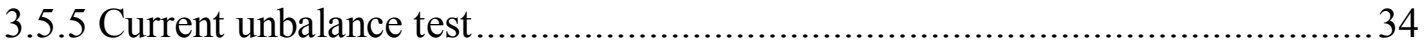

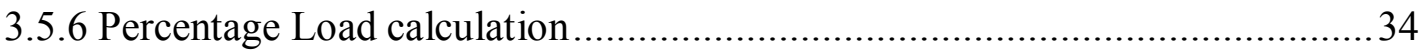

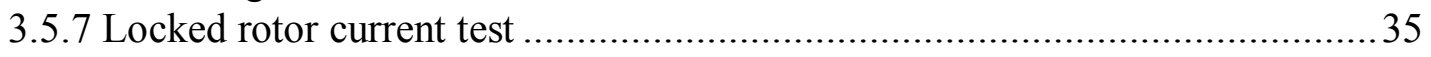

3.5.8 Effective service factor (ESF) calculation ..................................................39 


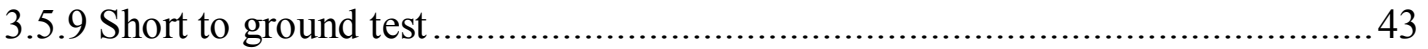

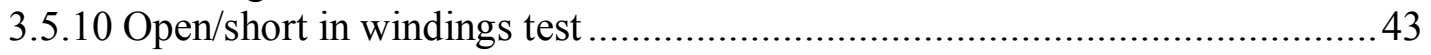

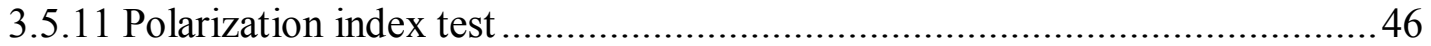

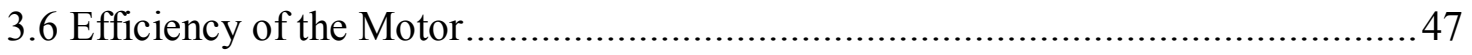

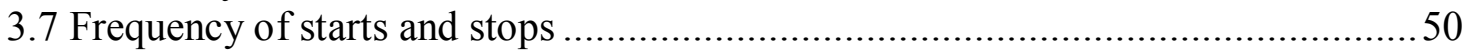

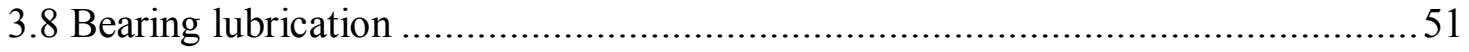

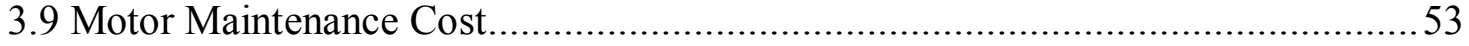

3.10 History of Motor Testing .........................................................................56

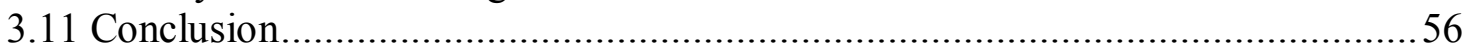

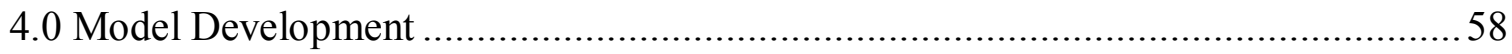

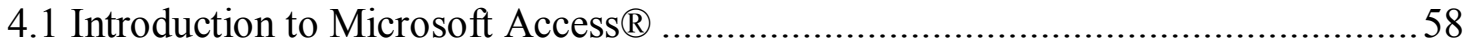

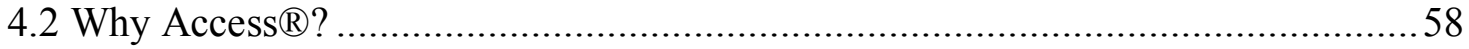

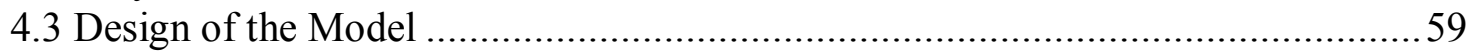

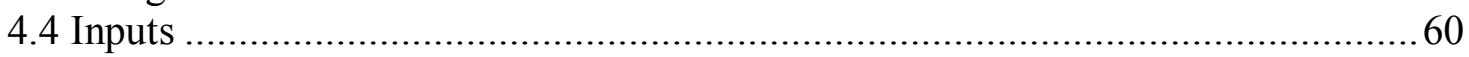

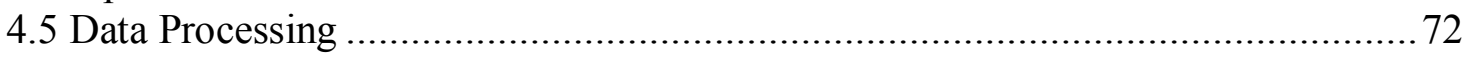

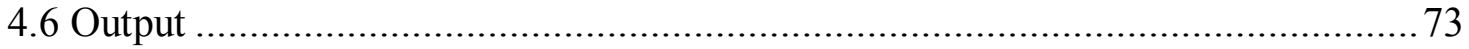

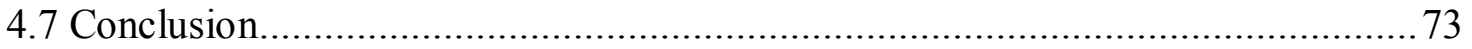

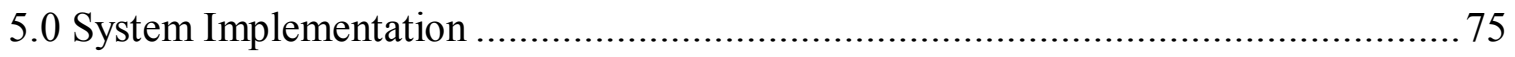

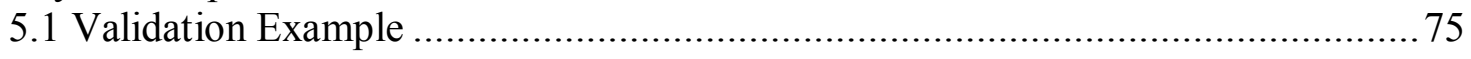

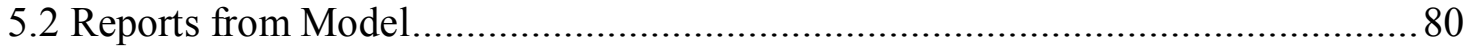

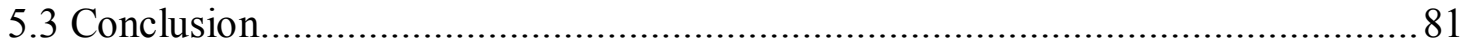

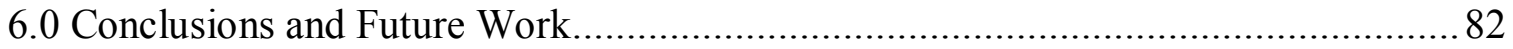

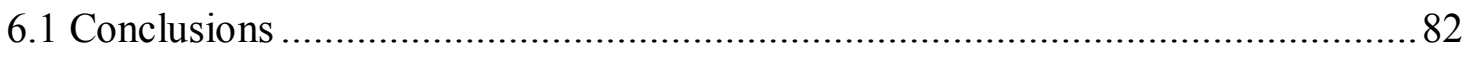

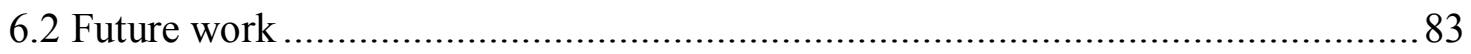

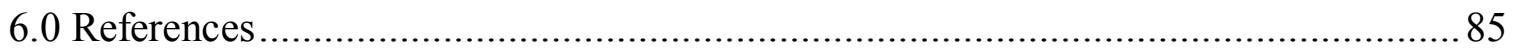

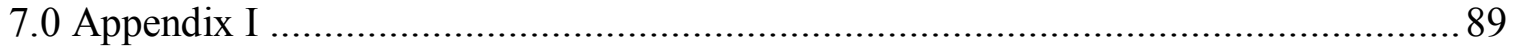

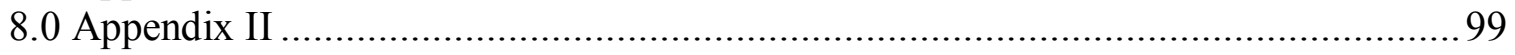

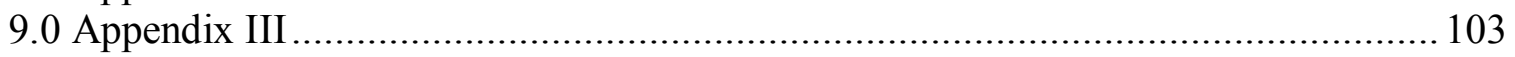




\section{$\underline{\text { List of Figures }}$}

Figure $3.1:$ : Flowchart showing the sequence of steps in the TPM model for motors....23

Figure 3.2: Flowchart showing the sequence of steps in insulation and bearing

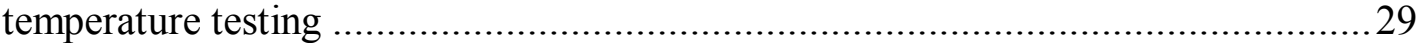

Figure 3.3: Vibration readings for different classes [29] …….................................... 30

Figure 3.4: Flowchart showing the sequence of steps in vibration testing .......................31

Figure 3.5: Flowchart showing the sequence of steps in voltage unbalance test.............. 33

Figure 3 6: Flowchart showing the sequence of steps in current unbalance test. ..............36

Figure 3.7: showing the sequence of steps in current unbalance test...............................37

Figure 3.8: Flowchart showing the sequence of steps in LRC test.................................40

Figure 3.9: showing the sequence of steps in ESF test. ............................................42

Figure 3.10: Flowchart showing the sequence of steps in short to ground test...............44

Figure 3.11: Flowchart showing the sequence of steps in open/short in windings test. ...45

Figure 3.12: Flowchart showing the sequence of steps in polarization index test ...........48

Figure 3.13: Flowchart showing the sequence of steps in efficiency calculation.............49

Figure 3.14: Flowchart showing the details of frequency of starts and stops..................50

Figure 3.15: Flowchart showing information on amount of lubrication. ………..............53

Figure 3.16: Flowchart showing information on frequency of lubrication. .....................54

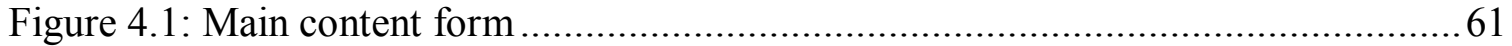

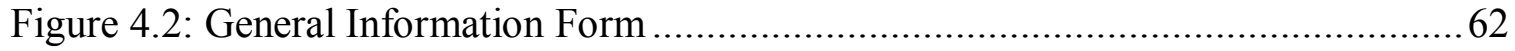

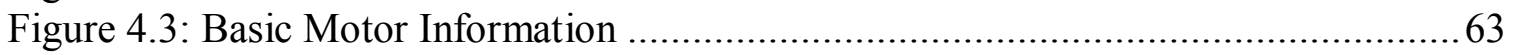

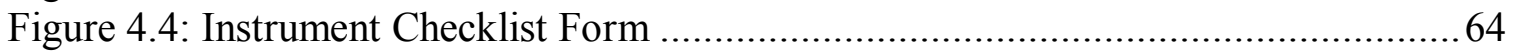

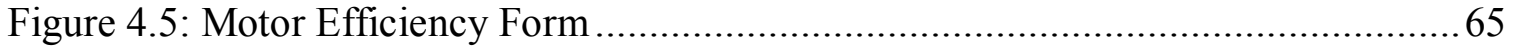

Figure 4.6: Temperature and Vibration Test Form ....................................................66

Figure 4.7: Voltage, Ammeter, \% Load and Locked Rotor Current Test Form ................68

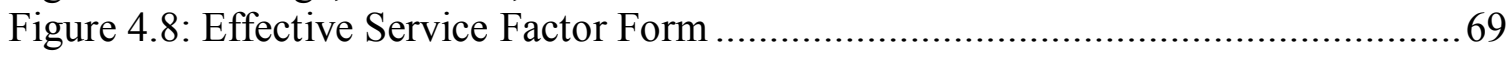

Figure 4.9: $\mathrm{Ohm}$ meter test and polarization index test form .....................................70

Figure 4.10: Frequency of Starts \& Stops Form ....................................................... 71

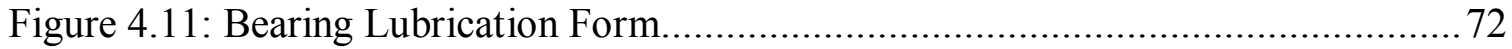

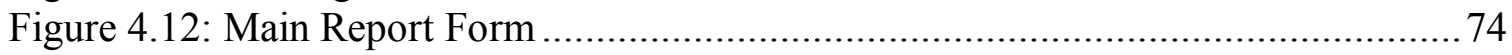




\section{$\underline{\text { List of Tables }}$}

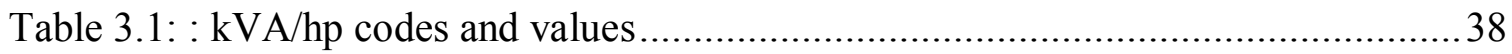

Table 3.2: Standard Locked Rotor current Values............................................................ 39

Table 3.3: Derating factors for $\%$ voltage unbalances .................................................... 41

Table 3.4: Information for frequency of starts and stops ...........................................51

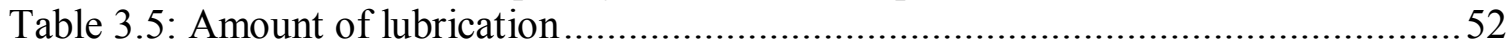

Table 3.6: Frequency of lubrication ........................................................................5

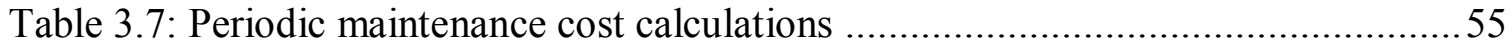

Table 3.8: Predictive maintenance cost calculations ....................................................56

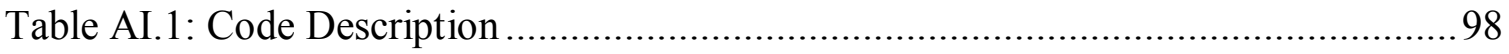

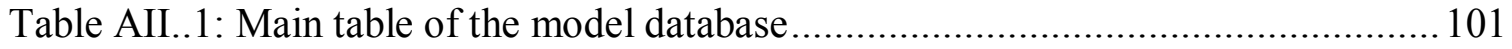

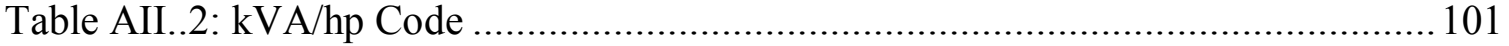




\subsection{Introduction}

\subsection{Maintenance}

What is maintenance and why is it performed? Past and current maintenance practices in both the private and government sectors would imply that maintenance is the action associated with equipment repair after it is broken [1]. The dictionary defines maintenance as follows: "the work of keeping something in proper condition; upkeep." This would imply that maintenance should be actions taken to prevent a device or component from failing or to repair normal equipment degradation experienced with the operation of the device to keep it in proper working order. Unfortunately, data obtained in many studies over the past decade indicates that most private and government facilities do not expend the necessary resources to maintain equipment in proper working order [1]. Rather, they wait for equipment failure to occur and then take whatever actions are necessary to repair or replace the equipment. Nothing lasts forever and all equipment has associated with it some predefined life expectancy or operational life. For example, equipment may be designed to operate at full design load for 5,000 hours and may be designed to go through 15,000 start and stop cycles [1].

The design life of most equipment requires periodic maintenance. Belts need adjustment, alignment needs to be maintained, and proper lubrication on rotating equipment is required, and so on. In some cases, certain components need replacement, e.g., a wheel bearing on a motor vehicle, to ensure the main piece of equipment (in this case a car) last for its design life. Anytime we fail to perform maintenance activities intended by the equipment's designer, we shorten the operating life of the equipment. But what options do we have? Over the last 30 years, different approaches to how maintenance can be performed to ensure equipment reaches or exceeds its design life have been developed in the United States [1]. In addition to waiting for a piece of equipment to fail (reactive maintenance), we can utilize preventive maintenance, predictive maintenance, or reliability centered maintenance. 


\subsection{Motors}

Motor systems consume about $70 \%$ of all the electric energy used in the manufacturing sector of the United States [2]. To date, most public and private programs to improve motor system energy efficiency have focused on the motor component. This is primarily due to the complexity associated with motor-driven equipment and the system as a whole. The electric motor itself, however, is only the core component of a much broader system of electrical and mechanical equipment that provides a service (e.g., refrigeration, compression, or fluid movement).

Numerous studies [2] have shown that opportunities for efficiency improvement and performance optimization are actually much greater in the other components of the system-the controller, the mechanical system coupling, the driven equipment, and the interaction with the process operation. Despite these significant system-level opportunities, most efficiency improvement activities or programs have focused on the motor component or other individual components.

There is an absolute necessity in today's highly competitive manufacturing world to have all the equipment in the facility operating effectively. For this, all equipment needs to be maintained very well with sound maintenance practices in place. This is where the concept of Total Productive Maintenance (TPM) comes into limelight. In the following section, the concept and benefits of TPM will be discussed.

\subsection{Total Productive Maintenance}

\subsubsection{Concept of Total Productive Maintenance}

Total Productive Maintenance (TPM) can be considered as the medical science of machines. TPM is a program which involves a newly defined concept for maintaining plants and equipment. The goal of the TPM program is to increase production while, at the same time, increasing employee morale and job satisfaction.

TPM brings maintenance into focus as a necessary and vitally important part of the business. It is no longer regarded as a non-profit activity. Down time for maintenance is scheduled as a part of the manufacturing day and, in some cases, as an integral part of the manufacturing process. The goal is to hold emergency and unscheduled maintenance to a minimum. 


\subsubsection{The Evolution of TPM}

TPM is an innovative Japanese concept. The origin of TPM can be traced back to 1951 when preventive maintenance was introduced in Japan. However the concept of preventive maintenance was taken from the USA. Nippondenso was the first company to introduce plant wide preventive maintenance in 1960 [3]. Preventive maintenance is the concept wherein, operators produced goods using machines and the maintenance group was dedicated with work of maintaining those machines, however with the automation of Nippondenso, maintenance became a problem as more maintenance personnel were required [3]. So the management decided that the routine maintenance of equipment would be carried out by the operators. This is Autonomous Maintenance, one of the features of TPM .

Thus Nippondenso which already followed preventive maintenance also added Autonomous Maintenance done by production operators. The maintenance crew was released of their routine maintenance task and they carried out equipment modification for improving reliability and maintainability. The modifications were made or incorporated in new equipment. These tasks are aimed at unnecessary maintenance prevention. Thus preventive maintenance along with Maintenance prevention and Maintainability Improvement gave birth to Productive Maintenance (PM). The aim of productive maintenance was to maximize plant and equipment effectiveness to achieve optimum life cycle cost of production equipment.

By then, Nippondenso had made quality circles, involving the employees' participation. Thus all employees took part in implementing Productive Maintenance. Based on these developments Nippondenso was awarded the distinguished plant prize for developing and implementing TPM, by the Japanese Institute of Plant Engineers ( JIPE ). Thus Nippondenso of the Toyota group became the first company to obtain the TPM certification [3].

\subsubsection{Objectives of TPM}

TPM was introduced to achieve the following objectives:

- Avoid waste in a quickly changing economic environment.

- Producing goods without reducing product quality.

- Reduce cost. 
- Produce a low batch quantity at the earliest possible time.

- Goods sent to the customers must be non defective.

\subsection{Types of Maintenance}

\subsubsection{Reactive Maintenance}

Reactive maintenance is basically the "run it till it breaks" maintenance mode. No actions or efforts are taken to maintain the equipment as the designer originally intended to ensure design life is reached. Studies as recent as the winter of 2000 [4] indicate this is still the predominant mode of maintenance in the United States. The referenced study [4] breaks down the average maintenance program as follows:

- $>55 \%$ Reactive

- $31 \%$ Preventive

- $12 \%$ Predictive

- $2 \%$ Other.

Note that more than $55 \%$ of maintenance resources and activities of an average facility are still reactive.

Advantages to reactive maintenance can be viewed as a double-edged sword. If we are dealing with new equipment, we can expect minimal incidents of failure. If the maintenance program is purely reactive, we will not expend manpower dollars or incur capital cost until something breaks.

Since we do not see any associated maintenance cost, we could view this period as saving money. The downside is reality. When companies think they are saving maintenance and capital cost, they are really spending more dollars than they would have under a different maintenance approach. More dollars are spent associated with capital cost because, while waiting for the equipment to break, we are shortening the life of the equipment resulting in more frequent replacement. We may incur cost upon failure of the primary device associated with its failure causing the failure of a secondary device. This is an increased cost we would not have experienced if our maintenance program was more proactive. The labor cost associated with repair will probably be higher than normal because the failure will most likely require more extensive repairs than would have been required if the piece of equipment had not been run to failure. Chances are the piece of 
equipment will fail during off hours or close to the end of the normal workday. If it is a critical piece of equipment that needs to be back on-line quickly, we will have to pay maintenance overtime cost. Since we expect to run equipment to failure, we will require a large material inventory of repair parts. This is a cost we could minimize under a different maintenance strategy.

\section{Advantages}

- Low cost.

- Less staff.

\section{Disadvantages}

- Increased cost due to unplanned downtime of equipment.

- Increased labor cost, especially if overtime is needed.

- Cost involved with repair or replacement of equipment.

- Possible secondary equipment or process damage from equipment failure.

- Inefficient use of staff resources.

\subsubsection{Preventive Maintenance}

Preventive maintenance can be defined as follows: Actions performed on a timeor machine-run-based schedule that detect, preclude, or mitigate degradation of a component or system with the aim of sustaining or extending its useful life through controlling degradation to an acceptable level. The U.S. Navy pioneered preventive maintenance as a means to increase the reliability of their vessels [5]. By simply expending the necessary resources to conduct maintenance activities intended by the equipment designer, equipment life is extended and its reliability is increased. In addition to an increase in reliability, dollars are saved over that of a program just using reactive

maintenance. Studies [5] indicate that this savings can amount to as much as $12 \%$ to $18 \%$ on the average.

Depending on the facilities' current maintenance practices, present equipment reliability, and facility downtime, there is little doubt that many facilities purely reliant on reactive maintenance could save much more than $18 \%$ by instituting a proper preventive maintenance program. While preventive maintenance is not the optimum maintenance program, it does have several advantages over that of a purely reactive program. By 
performing preventive maintenance as the equipment designer envisioned, we will extend the life of the equipment closer to the design. Preventive maintenance (lubrication, filter change, etc.) will generally run the equipment more efficiently resulting in dollar savings. While we will not prevent equipment catastrophic failures, we will decrease the number of failures. Minimizing failures translate into maintenance and capital cost savings.

\section{Advantages}

- Cost effective in many capital intensive processes.

- Flexibility allows for the adjustment of maintenance periodicity.

- Increased component life cycle.

- Energy savings.

- Reduced equipment or process failure.

- Estimated $12 \%$ to $18 \%$ cost savings over reactive maintenance program [4].

\section{Disadvantages}

- Catastrophic failures still likely to occur.

- Labor intensive.

- Includes performance of unneeded maintenance.

- Potential for incidental damage to components in conducting unneeded maintenance.

\subsubsection{Predictive Maintenance}

Predictive maintenance can be defined as measurements that detect the onset of a degradation mechanism, thereby allowing causal stressors (the elements that cause stress) to be eliminated or controlled prior to any significant deterioration in the component physical state. Results indicate current and future functional capability. Basically, predictive maintenance differs from preventive maintenance by basing maintenance need on the actual condition of the machine rather than on some preset schedule. It may be recalled that preventive maintenance is time-based. Activities such as changing lubricant are based on time, such as calendar time or equipment run time. For example, most people change the oil in their vehicles every 3,000 to 5,000 miles traveled [4]. This is

effectively basing the oil change needs on equipment run time. No concern is given to the actual condition and performance capability of the oil. It is changed because it is time. 
This methodology would be analogous to a preventive maintenance task. If, on the other hand, the operator of the car discounted the vehicle run time and had the oil analyzed at some periodicity to determine its actual condition and lubrication properties, he/she may be able to extend the oil change until the vehicle had traveled 10,000 miles. This is the fundamental difference between predictive maintenance and preventive maintenance, whereby predictive maintenance is used to define needed maintenance task based on quantified material/equipment condition.

The advantages of predictive maintenance are many. A well-orchestrated predictive maintenance program will all but eliminate catastrophic equipment failures. It will be possible to schedule maintenance activities to minimize or delete overtime cost; minimize inventory and order parts, as required, well ahead of time to support the downstream maintenance needs. The operation of the equipment can be optimised, saving energy cost and increasing plant reliability. Past studies [4] have estimated that a properly functioning predictive maintenance program can provide a savings of $8 \%$ to $12 \%$ over a program utilizing preventive maintenance alone. Depending on a facility's reliance on reactive maintenance and material condition, it could easily recognize savings opportunities exceeding $30 \%$ to $40 \%$ [4]. In fact, independent surveys indicate the following industrial average savings resultant from initiation of a functional predictive maintenance program [4]:

- Return on investment: 10 times

- Reduction in maintenance costs: $25 \%$ to $30 \%$

- Elimination of breakdowns: $70 \%$ to $75 \%$

- Reduction in downtime: $35 \%$ to $45 \%$

- Increase in production: $20 \%$ to $25 \%$.

On the down side, to initially start into the predictive maintenance world is not inexpensive. Much of the equipment requires cost in excess of $\$ 50,000$. Training of inplant personnel to effectively utilize predictive maintenance technologies will require considerable funding. Program development will require an understanding of predictive maintenance and a firm commitment to make the program work by all facility organizations and management.

\section{Advantages}


- Increased component operational life/availability.

- Allows for preemptive corrective actions.

- Decrease in equipment or process downtime.

- Decrease in costs for parts and labor.

- Better product quality.

- Improved worker and environmental safety.

- Improved worker morale.

- Energy savings.

- Estimated $8 \%$ to $12 \%$ [4] cost savings over preventive maintenance program.

\section{Disadvantages}

- Increased investment in diagnostic equipment.

- Increased investment in staff training.

- Savings potential not readily seen by management.

\subsubsection{Reliability Centered Maintenance}

Reliability centered maintenance (RCM) magazine provides the following definition of RCM: "a process used to determine the maintenance requirements of any physical asset in its operating context."[5] Basically, RCM methodology deals with some key issues not dealt with by other maintenance programs. It recognizes that all equipment in a facility is not of equal importance to either the process or facility safety. It recognizes that equipment design and operation differs and that different equipment will have a higher probability to undergo failures from different degradation mechanisms than others. It also approaches the structuring of a maintenance program recognizing that a facility does not have unlimited financial and personnel resources and that the use of both need to be prioritized and optimized. In a nutshell, RCM is a systematic approach to evaluate a facility's equipment and resources to best mate the two and result in a high degree of facility reliability and cost-effectiveness. RCM is highly reliant on predictive maintenance but also recognizes that maintenance activities on equipment that is inexpensive and unimportant to facility reliability may best be left to a reactive maintenance approach. The following maintenance program breakdowns of continually 
top-performing facilities would echo the RCM approach to utilize all available maintenance approaches with the predominant methodology being predictive [5].

- $<10 \%$ Reactive

- $25 \%$ to $35 \%$ Preventive

- $45 \%$ to $55 \%$ Predictive.

Because RCM is so heavily weighted in utilization of predictive maintenance technologies, its program advantages and disadvantages mirror those of predictive maintenance. In addition to these advantages, RCM will allow a facility to more closely match resources to needs while improving reliability and decreasing cost.

\section{Advantages}

- Can be the most efficient maintenance program.

- Lower costs by eliminating unnecessary maintenance or overhauls.

- Minimize frequency of overhauls.

- Reduced probability of sudden equipment failures.

- Able to focus maintenance activities on critical components.

- Increased component reliability.

- Incorporates root cause analysis.

\section{Disadvantages}

- Can have significant startup cost, training and equipment cost.

- Savings potential not readily seen by management.

\subsection{Benefits of TPM [3]}

\subsubsection{Direct Benefits of TPM}

- Increase productivity and OPE (Overall Plant Efficiency) by 1.5 or 2 times.

- Rectify customer complaints.

- $\quad$ Reduce the manufacturing cost by $30 \%$.

- Satisfy the customers needs by $100 \%$ (Delivering the right quantity at the right time, in the required quality)

- Reduce accidents.

- Follow pollution control measures 


\subsubsection{Indirect Benefits of TPM}

- Higher confidence level among the employees.

- Keep the work place clean, neat and attractive.

- Favorable change in the attitude of the operators.

- Achieve goals by working as team.

- Horizontal deployment of a new concept in all areas of the organization.

- Share knowledge and experience.

- The workers get a feeling of owning the machine.

\subsection{Need for Research}

\subsubsection{Current Poor Motor Maintenance Practices}

In 2005, approximately $\$ 1.2$ Trillion was invested in maintenance programs with $\$ 500$ to $\$ 700$ Billion of that amount due to improper maintenance [6]. An additional $\$ 2.5$ Trillion in business opportunity was lost as a direct impact of poor maintenance practices, or $20 \%$ of the 2005 total USA Gross Domestic Product (GDP) [6]. A majority of the systems affected are plant motor systems.

In 2005, NetExpressUSA, Inc. published a study from a survey that said "only $20 \%$ of respondents track $100 \%$ of maintenance and repair work" [7]. A computerized maintenance management system cannot support enhanced maintenance productivity without complete and accurate information. $100 \%$ of maintenance activity must be tracked to greatest return.

Most of the current management programs focus only on keeping the motor running or getting it to run as soon as possible when it fails. But, the need of the hour is to have efficient maintenance management programs that not only ensures the motor keeps running but also makes sure it operates at optimal performance levels.

\subsubsection{Potential Energy Savings}

Efficient motor management has a tremendous potential for energy savings. A motor that is well managed will not draw more energy than what is originally required. Saving energy directly results in saving money. Ever increasing utility costs reduce profits, decrease capital and maintenance budgets, increase product costs and reduce 
competitiveness [8]. A common misconception within industry has been to equate an energy reduction or conservation program with the concept of turning off equipment and shutting down processes. Instead, the program of energy management challenges to produce the products or services with the absolute minimum energy consumption [8].

In addition to reduced energy costs and potentially increased profits, industries that take advantage of energy efficiency opportunities often gain additional benefits such as more productive state of the art technology that increases a facility's competitive edge and improves global competitiveness etc.

\subsubsection{Research Objectives}

Ideally, TPM must be done company-wide for all equipment to be able to get the greatest benefits. However, for this research work, TPM for one particular equipment i.e., electrical motor is chosen. As will be seen in the introduction part of chapter 2, in North America, electric motor systems consume over $20 \%$ of all energy [9]. This breaks down into $57 \%$ of all electrical energy generated in the United States and over $70 \%$ of industrial electrical energy use. In many process industries including heavy food processing such as corn milling, petro-chemical industries, forest products and others, the motor electrical energy use can exceed 90\% [9]. A US Department of Energy survey performed in 1998 showed a motor population of 1.2 billion electric motors in use within the United States of which over $96 \%$ are less than 5 horsepower, 5 to 25 horsepower make up about $2.5 \%$, and greater than 25 horsepower make up $1.5 \%$ while also using over $60 \%$ of the electrical energy [10]. Electric motors, and the technologies they drive, are a part of all of the products and technologies we use today.

Therefore, although TPM can be done for any and all equipment, because of the above mentioned facts, electrical motors were selected to build the TPM model.

The main objectives of this research may be summarized as follows:

1. To design and develop Total Productive Maintenance model for electric motors in manufacturing facilities.

2. To design and develop a computer based system to represent the model.

3. To verify the model's operations. 


\subsection{Chapter Summary}

This chapter reviews the importance of maintaining the equipments in a manufacturing facility. The chapter lists various energy consuming equipments used in the manufacturing environment. The concepts of Total Productive Maintenance, Reactive Maintenance, Predictive Maintenance, Preventive Maintenance and Reliability-Centered Maintenance are explained. The need for the research and the research objectives are described and finally a fictional case study is discussed to convey the importance of Total Productive Maintenance to the reader. 


\subsection{Literature Review}

\subsection{Introduction}

In North America, electric motor systems consume over $20 \%$ of all energy. This breaks down into $57 \%$ of all electrical energy generated in the United States and over $70 \%$ of industrial electrical energy use [9]. In many process industries including heavy food processing such as corn milling, petro-chemical industries, forest products and others, the motor electrical energy use can exceed 90\% [9]. A US Department of Energy survey performed in 1998 showed a motor population of 1.2 billion electric motors in use within the United States of which over 96\% are under 5 horsepower, 5 to 25 horsepower make up about 2.5\%, and greater than 25 horsepower make up 1.5\% while also using over $60 \%$ of the electrical energy[10]. Electric motors, and the technologies they drive, are a part of all of the products and technologies we use today.

Mechanical faults in electric motors comprise of approximately $53 \%$ of failure while winding and rotor faults make up the remaining $47 \%$ of faults, according to EPRI and EASA post-mortem studies [9]. Of the $47 \%$ of motor rotor and winding faults, depending on the study, $5-10 \%$ is related to electric motor rotors [9]. The remainder is electrical winding faults which normally start as a short between conductors.

Prior to 1980, the primary methods for evaluating the condition of electric motor condition consisted primarily of: Resistance, including milli-Ohm testing; Insulation resistance to ground testing; Hi-Potential testing; Surge comparison testing; Vibration analysis; and, Voltage and current testing [9]. Ultrasonics and infrared technologies were added to the motor system testing arsenal. Each method has its strengths and weaknesses and specific levels of training required and intrusiveness for testing.

In the 1980's, a number of companies introduced a variety of new technologies that viewed the electric motor windings [9]. Although each technology provided a different basic set of test results that varied in degrees of accuracy they were combined under the heading of motor circuit analyzers (MCA). In the 1980's and 1990's, motor current signature analysis (MCSA) instruments were introduced to the market. By the end of the 1990's, the combined technologies fell under the umbrella of the term Motor Diagnostics [9]. 


\subsection{Maintenance Practices in Industries}

One area of increasing focus is the maintaining of industries. In the past, the maintenance department was viewed as a "necessary evil." They were the high priced wrench turners who sat in the shop and waited for equipment to fail. In more recent history industries are finding ways to prevent the failures before they occur. Tools such as vibration analysis, infrared imaging, acoustic testing, and preventive maintenance help us maximize profits by minimizing downtime [11].

The purpose of a successful electric motor system maintenance and management program is to improve equipment readiness and uptime while reducing capital overhead. The program consists of particular maintenance and management tools designed to aid the maintenance engineer in equipment systems and their care. To actually realize the potential increases in profits, it must be taken a step further through maintenance planning and scheduling. In addition to identifying potential failures, industries must also focus their resources to correct them before the failure occurs [12]. With decreasing work forces and increasing responsibilities of those left at the facility, the efficiency of the resources easily becomes a second priority. This becomes a slippery slope as less work is completed, more failures occur and the time is spent repairing failures, not on preventing the failure from happening. The only way to break this cycle is to approach maintenance planning and scheduling as a new profit center. To do this we must develop a new, disciplined approach to identifying, prioritizing and completing maintenance work. The industries must understand that an effective maintenance planning and scheduling program will produce a more efficient work force and decrease overall maintenance downtime. This equates to higher profit margins for the company and in turn increases the facility's ability to survive.

\subsection{Total Productive Maintenance of Equipments in Industries}

TPM is an equipment-focused improvement effort; we work on creating the ideal equipment state. Any gap between our current state and the ideal state must be closed. These gaps are created in part by: deficiencies in our equipment maintenance plan; people's lack of knowledge as to how to perform their work correctly; and weaknesses in 
machine, process, and product designs [13]. In order to change equipment performance, operators, technicians, and engineers must change their own mindsets and work habits. They must learn to tackle improvement issues together as a team rather than separately. They must adopt new mindsets with each TPM step. These changes in people's thinking and behavior improve equipment productivity.

The first goal of TPM is to prevent equipment failure [17]. Every machine should be kept running as well every day as it has on its very best day. This is primarily achieved by developing a sound maintenance regimen and continually restoring machine deterioration to keep the performance of the machine consistent from one day to the next. Once this is achieved, other productivity losses can be eliminated to make the machine run better than it ever has before.

\subsubsection{TPM Effort at Agilent}

A TPM team at Agilent [11] recently attacked productivity losses on a very complex cluster tool used to deposit a layer of oxide on IC wafers. The operators, equipment techs, process techs, and engineers on this team used the TPM methods described in this book to improve this machine's productivity. In less than nine months, the machine's capacity was increased by over 50 percent without a single machine design change [11].

\subsubsection{Equipment Aging Paradigm}

Most people share a common belief that a new machine is "the best that it will ever be" and that it will continually deteriorate into a worse state as it is used in production. At some point it will become so deteriorated that it will need to be replaced with a new machine. TPM implementation creates an opposite attitude about equipment aging - that a new machine is "the worst that it will ever be."[14] The more we operate and maintain a piece of equipment, the more we learn about it. We use this knowledge to continually improve our maintenance plan and the productivity of the machine. We would only choose to replace a machine should its technology become obsolete, not because it has deteriorated into a poorly performing machine. The last day of a machine's use on the factory floor should be its best performing day ever.

However, none of the machines has probably seen its best possible day. The equipment contains productivity losses that are hidden from the view. If they were to be 
discovered the hidden productivity losses and eliminate them, the equipment could run better than it ever has before. These continual losses are called chronic losses and are most often thought of as the design limit of the machine. However, in most cases, chronic losses have a variety of real causes, which TPM activities can eliminate. The true design limit of the machine probably has a much lower level of loss than most people believe. Even design losses can often be reduced with simple design improvements to the machine.

Chronic loss is the "normal" operating state of the machine. Chronic losses are generally not repaired, as they are not even considered losses; they're just seen as the way the machines are. Some chronic losses for example, a certain regular minor stoppage, might simply be reset and the machine operation continued, with nothing ever found wrong with the machine or repaired.

Sporadic loss is a sudden departure of the machine from its "normal" operating state. Equipment that experiences sporadic machine failure is typically returned to production service by troubleshooting and repair work. Many sporadic losses are caused by one of the two types of machine deterioration [18]:

- Natural deterioration: The deterioration rate expected by the part's designer when used as specified. A component that deteriorates naturally achieves a natural or inherent life expectancy.

- Accelerated (or forced) deterioration: The deterioration rate of a part that is much higher than was expected by the part's designer. Accelerated deterioration is usually caused by the part's being used in an environment where it's specified conditions-of-use are not met. A part experiencing accelerated deterioration will have an unnaturally short lifetime.

\subsection{Total Productive Maintenance for Electrical Motors}

It has become common practice in corporate re-engineering to reduce short term costs by reducing maintenance and focusing away from maintenance management. As a result, energy costs and equipment downtime have increased, and company/corporate morale have decreased in all industries. Through proper and basic reactive, preventive, predictive, proactive and corrective maintenance practices, companies can achieve cost reduction in the long term. 
It is apparent that continued research and development into motor system maintenance improvements is required in order to further increase system efficiency, reliability and uptime. These areas include the following [19]:

- Circuit testing reliability

- Motor life estimation through risk assessment

- Motor system component life estimation

- The effects of various starting and operating methods on motor system components and motor system reliability

The answers to the above areas will allow for more reliable proactive assessment on the condition of motor systems. This will enable the maintenance manager to better plan downtime while providing information to properly apply proactive maintenance to the system.

The results of the study [10], performed at a pulp and paper manufacturer, showed a decrease from $26 \%$ combined planned and unplanned downtime to just fewer than $6 \%$ with no increase in maintenance costs. The 'savings' from the application of each stage of the motor management program were re-applied to the maintenance program, expanding it and capital improvements to the system. Progress from the inception of the program at a facility with no planned maintenance program to a completely functional reliability centered maintenance program was under three years.

A number of opportunities were evaluated and concluded by the project:

Motor management programs which combine preventive and predictive maintenance programs will provide profitable return on investments. Partnerships amongst each company's motor stakeholders including all departments of the company, suppliers and repair centers will have a positive impact. Use of a combination of instrument technologies will support the strengths of each allowing for a more complete view of the system being tested.

A variety of business cost factors are impacted by equipment reliability, including production and energy. The primary factor that stands out throughout the project is the view of 'first cost' and immediate solutions. Little consideration was found for long-term evaluation and solutions. Motor system maintenance and management practices are often not a primary consideration in the operation of a plant. 
The Thesis for the study [20] was to develop an overall system for energy, waste stream, and reliability improvement to a complete industrial system. As part of this approach, industrial process simulation utilizing process simulation software was included to determine the impact of implementing findings within the system. It was the position of the study that energy conservation could be achieved with the benefit of improved industrial competitiveness through a basic paradigm shift. The following were established as interactive with each other:

- Energy efficient equipment such as motors, lighting, pumps, etc.

- Waste stream improvements including reduction of rework

- Reliability and maintenance requirements of keeping the equipment in operation

- Product quality

- Process optimization by reducing process problems and bottlenecks

- Inventory control of product and maintenance equipment / spares

The overall objective was to present a system for industrial system energy auditing that improves not only energy use and waste stream, but also industrial competitiveness. The study [20] reviewed Reliability Centered Maintenance (RCM) and previous studies related to testing and maintenance. It was determined that an RCM program is absolutely essential in today's industrial and manufacturing sites. The requirement is for the process to continue unhampered throughout the production run. This is also known as production uptime, with the opposite being production downtime or the amount of time production is off line to due unexpected equipment failure. During the study [21], the general impression given by the reviewed industrial sites is that equipment maintenance is viewed and given a lower priority as it is perceived as an expense and not a savings, or income, for manufacturing. Based upon the findings of the project [21], it was determined that maintenance had direct responsibility for equipment uptime but lacked the training in being able to present the financial impact of maintenance to upper management.

The study report outlines a series of methods to calculate the energy and production impacts of reduced reliability in such cases as poor bearings, winding problems, compressed air, misalignment, pump seal issues, etc. These costs were found to project well into the \$Millions of USD in medium to large facilities. Return on investment, using 
the simple payback method, for the implementation of a properly implemented RCM program that reviewed the impact of all areas, was generally found to be less than one year and, in the cases of the sites studied, in a few months.

In general, the requirements found for test equipment to be used in projects like this, and the supporting software, were, in this order [16]:

1) Ease of use and interpretation;

2) Graphical representation; and,

3) Information presented.

The causes for the faults were found to be in this order:

1) Contamination;

2) Improper maintenance practices; and,

3) Improper application.

It was determined that the best ways to avoid the high rate of unexpected failure that was occurring was through a properly scheduled and maintained reliability and maintenance program. Motor improvements can be achieved through simple efficiency upgrades as well as through the identification of electrically and mechanically faulty motors.

In the pre-implementation of the study [22] in 1998 and 1999, the University of Illinois at Chicago Energy Resources Center was requested to review the following:

- Evaluate the economic benefits of acceptable installation methods and testing methods including Motor Circuit Analysis

- Evaluation of electric motor maintenance and management programs based upon industry successes and failures

- Evaluation and selection of field electric motor system efficiency testing and measurement equipment and software.

- Develop a strategy that incorporates tools and systems for performing electric motor efficiency and load analysis, assessing market requirements, market to industrial and commercial users, and training of service providers and motor system users. 
Upon completion of the initial stage, equipment and software was reviewed based upon the following criteria:

Considerations for Market Transformation [22]:

- Ease of use

- Marketability

- Initial cost

- Invasiveness of the program

- Equipment selection considerations:

- Initial cost

- Training requirements

- Ergonomics

- Accuracy

- Least intrusive

Instrument manufacturer [22]:

- Make the instrument non-invasive and convenient

- Make it simple/easy to use and hand-held

- Make it provide reasonable, accurate results

- Make the equipment cost effective

- Motor management programs which combine preventive and predictive maintenance will provide profitable return on investments

- Use of a combination of instrument technologies will support the strengths of each allowing for a more comprehensive view of the system being tested.

- All aspects of the business environment are impacted by equipment reliability, including production and energy.

- Equipment selection for ease of use and ease of interpretation was required. Hand-held equipment is preferred.

- Contrary to common thoughts, motors can often be de-energized even in 24/7 operations. The only time this was found to be an issue was in any study that allowed this comment to prevent it. In the studies that moved forward, almost without exception, almost all of the motors could be de-energized. 


\subsection{Conclusions}

There is a lot of conceptual knowledge about total productive maintenance and there is no built in software tool to incorporate the concepts. There is no attempt to transform the qualitative information available to quantitative values. Although the literature talks extensively about the importance of good maintenance practices and the relevance of sound maintenance practices in current time to improve productivity, reduce costs and enhance quality; it cannot become a reality unless there are tools that can give information pertaining to condition of the motor, what has to be done and how often they have to be done. There is an absolute need for the development of such a TPM tool. 


\subsection{Design of Total Productive Maintenance (TPM) Model for Electrical Motors}

\subsection{Concept of TPM for Motors}

As discussed in the first chapter, Total Productive Maintenance is a combination of reactive maintenance, preventive or periodic maintenance and predictive maintenance. To have an effective maintenance model, it is essential to include all the three maintenance practices to the right extent.

The flowchart representing the TPM model for electrical motors is given in Figure 3.1. The user is required to input the general information that includes the information of the user and plant, basic motor information including name used for motor identification, motor size in HP etc, into the model. These two must be input irrespective of the size of the motor. Now, the user is required gather information and find out what equipment are available in the facility to carry out the various predictive tests included in the TPM model. Once the available instruments are identified, they need to be checked in the check list. Depending on the instruments available, corresponding tests can be carried out. The model includes insulation temperature testing, bearing temperature testing, vibration test, voltage unbalance test, current unbalance test, locked rotor current test, short to ground test and open/short in windings test. The model calculates the efficiency of the motor, find the effective service factor value and \% load. The model also provides information on frequency of starts and stops (how many times the motor can be started in an hour and the time that has to be given in between two starts) and bearing lubrication, in terms of the amount of lubricant to be used and frequency of lubrication.

Based on the values provided by the user to the model in the form of input, the model interacts with the database at the back end and processes the input data using the inbuilt formulas. The output thus obtained is displayed to the user in the form of a comprehensive report. The report generated will have a list of periodic recommendations

irrespective of any tests conducted or not. Based on the test values input, corresponding predictive test results will be provided giving information on the condition of motor, indicating where the possible defects could be and also giving appropriate recommendations to prevent premature failure of the part. The report will also give maintenance cost information and has facility for the user to keep track of motor history. 


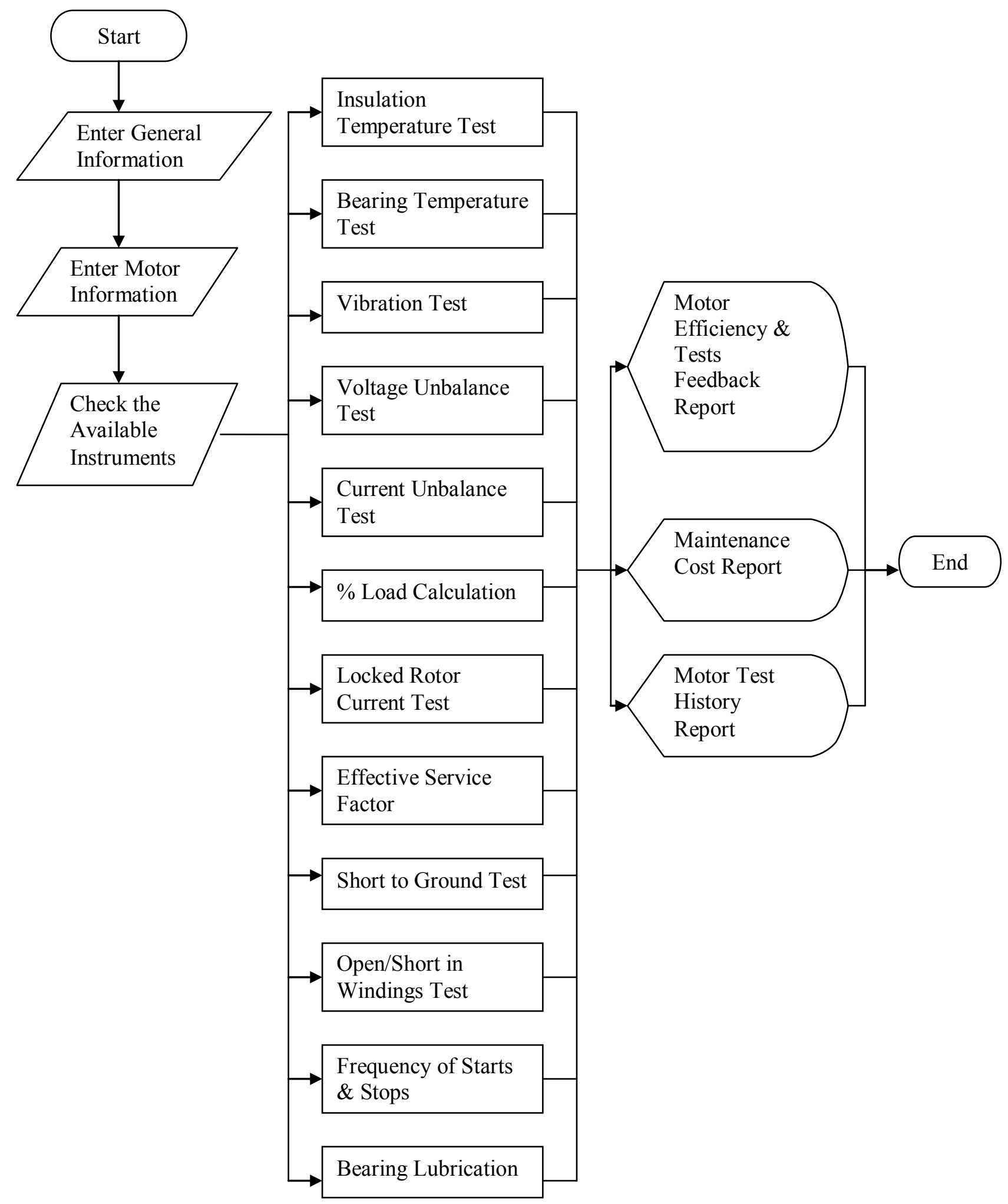

Figure 3.1 : Flowchart showing the sequence of steps in the TPM model for motors. 


\subsection{Reactive Maintenance for Motors}

Reactive maintenance is the effort put in by the maintenance department in replacing the motor that is broken or getting the motor back in action by repairing it. Irrespective of how well the motor is maintained by the practice of different maintenance practices, every motor will eventually breakdown at some point. Then, it becomes very important to get the motor back in action as soon as possible by having a sound repair policy in place or by quickly replacing the failed motor with another motor that is equally good or better than the previous one. Other maintenance practices when followed no doubt, increase the life of the motor considerably. They also help in giving indications to the user about the possible problems in the motor and their time of failure. This will help the maintenance department in being prepared with actions to be taken when the motor actually fails.

\subsection{Periodic Maintenance for Motors}

Periodic maintenance includes actions performed on a time- or machine-runbased schedule that detect, preclude, or mitigate degradation of a component or system with the aim of sustaining or extending its useful life through controlling degradation to an acceptable level. From the study of literature on motor maintenance, a list of about 9 recommendations was selected. These recommendations when carried out regularly would help to improve the performance of the motor, reduce the degradation of parts and significantly improve the life of the motor. The model will have a section in the report generated having list of periodic maintenance practices [23] giving the user information on what has to be done and how often they have to be carried out.

List of periodic maintenance practices:

1) Clean the external surface of the motor once every two weeks

2) Clean the internal parts of the motor once every two months

3) Replace the lubricant regularly. The amount of lubricant to be used and the information on the frequency of lubrication will be provided by the section in the model on bearing lubrication. 
4) Monitor the condition of the lubricant once every two months

5) Check for mounting or base rigidity once in two months

6) Check for coupling alignment once in two months

7) Check for shaft alignment once in two months

8) Check for belt and pulley tension, wear, positioning, slip etc once every two months

9) Check for audible noise once every two weeks

\subsection{Predictive Maintenance for Motors}

Predictive maintenance can be defined as measurements that detect the onset of a degradation mechanism, thereby allowing causal stressors to be eliminated or controlled prior to any significant deterioration in the component physical state. Results indicate current and future functional capability. Basically, predictive maintenance differs from preventive maintenance by basing maintenance need on the actual condition of the machine rather than on some preset schedule.

With the view of not complicating the model, top three causes of failures were found from the extensive study of literature [24] on motor failures. The top three motor failures were found to be due to:

- Insulation failure

- Bearing failure

- Rotor bar and stator windings failure

\subsection{Predictive Motor Tests}

From the study of literature [30] on predictive motor testing, a set of test practices were listed and information was gathered pertaining to inputs required, formulae used for processing the inputs, data required to be used in the processing of information and output value obtained. Based on the output obtained from each of the tests, an elaborate study was done in order to determine what the output indicates in terms of the condition of the motor part. Once, the condition is determined, the user will be given a set of recommendations to be followed in order to prevent the part from failing prematurely and stop the degradation of the part completely or to whatever extent possible. 


\subsubsection{Insulation temperature test}

Instrument required: Electronic Thermometer

Data used [24]: Standard ambient temperature for all insulation classes: $104^{\circ} \mathrm{F}$

Insulating Class A: Limiting observable temperature $154^{\circ} \mathrm{F}$

Insulating Class B: Limiting observable temperature $174^{\circ} \mathrm{F}$

Insulating Class F: Limiting observable temperature $194^{\circ} \mathrm{F}$

Insulating Class $\mathrm{H}$ : Limiting observable temperature $214{ }^{\circ} \mathrm{F}$

The user is asked to measure the temperature at the insulation in ${ }^{\circ} \mathrm{F}$ using a electronic thermometer and input into the model. From literature [24] it is found there are four different classes of insulation A, B, F \& H. Each class has a limiting observable temperature beyond which, the insulation will deteriorate and will fail earlier than expected. The above limiting observable temperatures are for ambient temperature of 104 ${ }^{\circ} \mathrm{F}$. The user must input the current ambient temperature and the programming in the model according changes the limiting observable temperatures. The user measured temperature of the insulation is compared with the limiting observable temperature and appropriate message is displayed in the report.

If the measured insulation temperature is less than the limited observable temperature then the report will show the message "The measured insulation temperature is less than the suggested limited observable temperature. So, there seems to be no problem with the insulation."

If the measured insulation temperature is greater than limited observable temperature then, "the measured insulation temperature is greater than the suggested limited observable temperature. So, there seems to be some problem with insulation."

Recommended Actions [23]:

1) Poor cooling is a common cause of insulation over temperature failure. Inadequate cooling is caused by plugged cooling ducts or accumulated dust on windings. Keeping the motor clean promotes heat dissipation and prolongs insulation life.

2) Remove any kind of contamination. Some types of contamination cause insulation damage through chemical reaction. Oil contamination is a common cause of insulation deterioration. It can allow leakage current to increase and encourages the accumulation of 
dust brought in by cooling air. Abrasive dust brought in with cooling air can erode insulation to the point of failure.

3) Check for voltage conditions. Under voltage causes insulation temperature stress, because a motor operating at lower than nameplate voltage runs hotter than if supplied at proper voltage.

The flow chart in Figure 3.2 shows the sequence of steps followed in insulation temperature testing.

\subsubsection{Bearing temperature test}

Instrument used: Electronic Thermometer

This predictive test expects the user to measure the temperature at the bearing location and at the middle of the motor using an electronic thermometer and input the readings in ${ }^{\circ} \mathrm{F}$. The temperature at the bearing and the temperature at the middle of the motor are compared with each other and the difference between them is calculated.

If bearing temperature is greater than temperature at the middle of the motor and difference is greater than or equal to 10 then, there is a greater increase in temperature at the bearing location than at the middle of the motor. This difference in the temperature indicates that there could be a bearing problem.

Recommended Actions [25]:

1) A very common cause of rising in bearing temperature is inadequate lubrication. So, verify that there is adequate lubrication. Check the section on bearing lubrication.

2) Check the alignment of the bearing. Misalignment can cause an increase in temperature.

3) Make sure there is symmetric loading on the bearings.

4) Schedule a bearing change soon.

If bearing temperature is greater than temperature at the middle of the motor and difference is greater than or equal to 10 then, there is a greater increase in temperature at the middle of the motor than at the bearing location. This suggests that the existing problem is associated with something external to the motor.

Recommended Actions [25]:

1) Check for an increase in loading. Check the section 3.5.6 on \% Load Calculations 
2) Check for obstruction of cooling air flow. Remove all obstructions and make room for air movement thereby enabling proper heat dissipation.

3) Check for under voltage. Make sure the motor is running at the nameplate voltage or a little higher voltage reading.

4) Check for the development of an voltage unbalance condition. Check the section on Voltage Unbalance Test.

The flow chart in Figure 3.2 shows the sequence of steps followed in bearing temperature testing.

\subsubsection{Vibration test}

Vibration analysis is a method that can be used by the maintenance personnel to determine mechanical faults in rotating equipment. The equipment (for example, motors) can be monitored while it is operating and can detect signs of failures, thereby reducing the risk of catastrophic failures. Energy losses can occur due to bearing failure, inadequate lubrication (greasing), belt tension, misalignment and unbalances in the equipment [26]. These losses surface out as vibration, heat and noise. The equipment used to perform vibration analysis is "Miniature Vibration Meter", and measures vibration velocity in an equipment in inches per second. It can be used to check vibrations in motors, pumps, compressors, and fans. To perform vibration analysis, the meter stylus should be gently pressed on the motor casing.

Data used for vibration reading analysis. The motors are categorized into three classes [26].

Class 1: $5 \mathrm{hp}$ to $150 \mathrm{hp}$ motors

Class 11: $200 \mathrm{hp}$ to $500 \mathrm{hp}$ motors

Class 111: $>600 \mathrm{hp}$ motors 


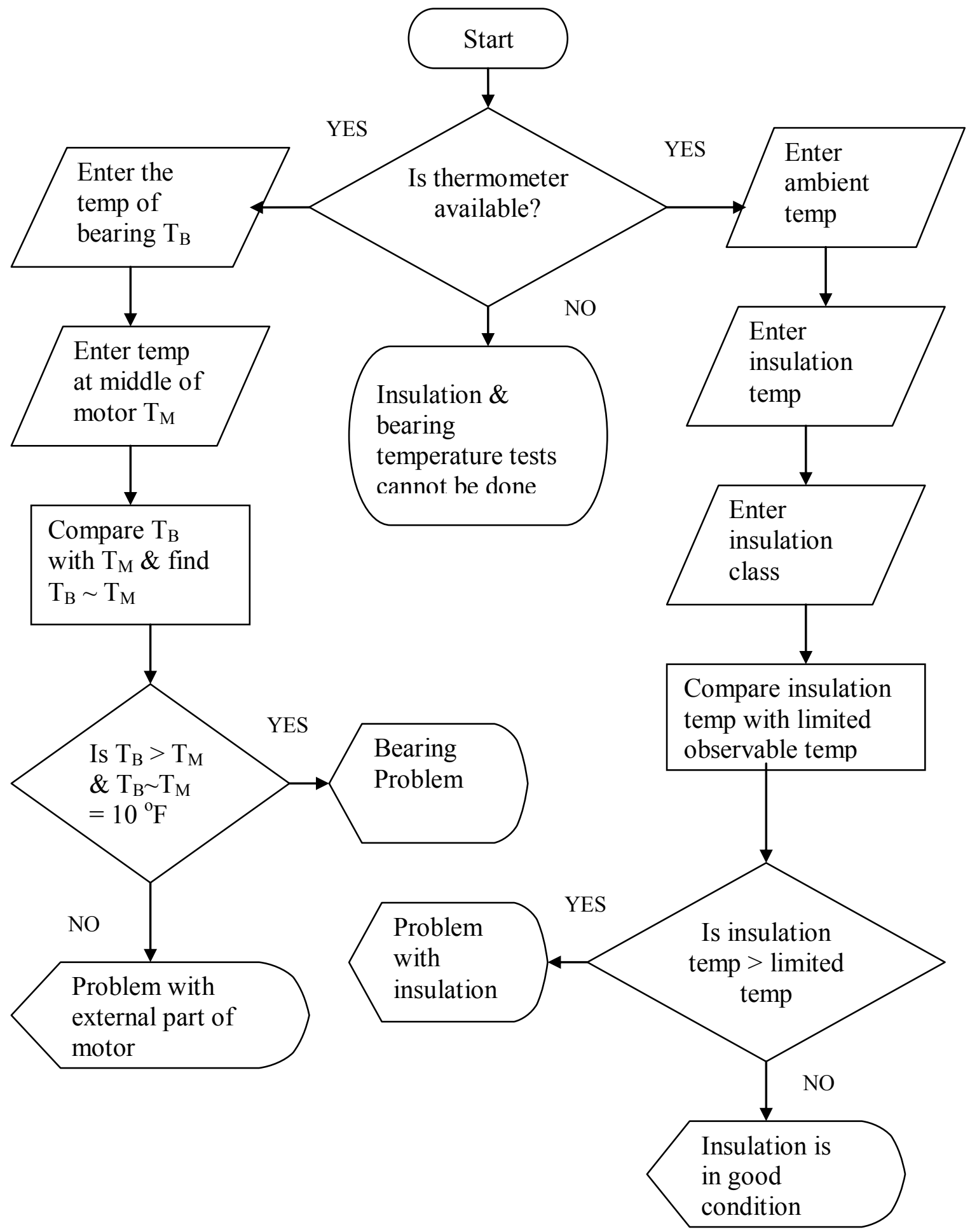

Figure 3.2: Flowchart showing the sequence of steps in insulation and bearing temperature testing 


\begin{tabular}{|c|c|c|c|}
\hline $\begin{array}{c}\text { Vibration Meter } \\
\text { Reading (Inches / Sec) }\end{array}$ & Class I & Class II & Class III \\
\hline 0.01 & & & \\
\hline 0.02 & & \multirow{2}{*}{\multicolumn{2}{|c|}{ Good }} \\
\hline 0.03 & & & \\
\hline \multicolumn{4}{|l|}{0.04} \\
\hline \multicolumn{4}{|l|}{$\mathbf{0 . 0 7}$} \\
\hline 0.11 & & \multicolumn{2}{|c|}{ Satisfactory } \\
\hline \multicolumn{4}{|l|}{0.18} \\
\hline 0.28 & & Unsatisfactory & \\
\hline \multicolumn{4}{|l|}{0.44} \\
\hline \multicolumn{4}{|l|}{0.70} \\
\hline 0.71 & & \multicolumn{2}{|c|}{ Unacceptable } \\
\hline 1.10 & & & \\
\hline
\end{tabular}

Figure 3.3: Vibration readings for different classes [29]

The user is asked to input three readings of vibration measured at three different locations on the surface of the motor. The average of the three readings is found and based on this the condition of the motor is found to be good, satisfactory, unsatisfactory or unacceptable. If the condition of the motor based on the average vibration reading is found to be good or satisfactory then the motor seems to be running ok. If it is found to be unsatisfactory or unacceptable, then the following actions are recommended [26]:

1) High vibration amplitudes (Vibration in inches per second) can be due to locked drive coupling. These high amplitudes can damage the motor bearings. The drive coupling should be checked and the motor should be serviced periodically.

2) High vibrations can be due to problems in motor sheave and drive belts. The motor sheave wears out with time, and can become eccentric. In this scenario, the sheave should be replaced. The belts should be checked for proper tension and alignment. If not, then the belt tension should be adjusted.

3) Improper lubrication in the bearings can cause excessive vibrations in the motor. Greasing the motor bearings will reduce the friction in the bearings and vibration amplitudes.

4) The motor bearing housing (fasteners) gets loose with time. It needs to be tightened to reduce vibrations in the equipment.

5) Journal or bearing housing wear results in bearing wear. The housing should be inspected to reduce the wear in the bearings. 


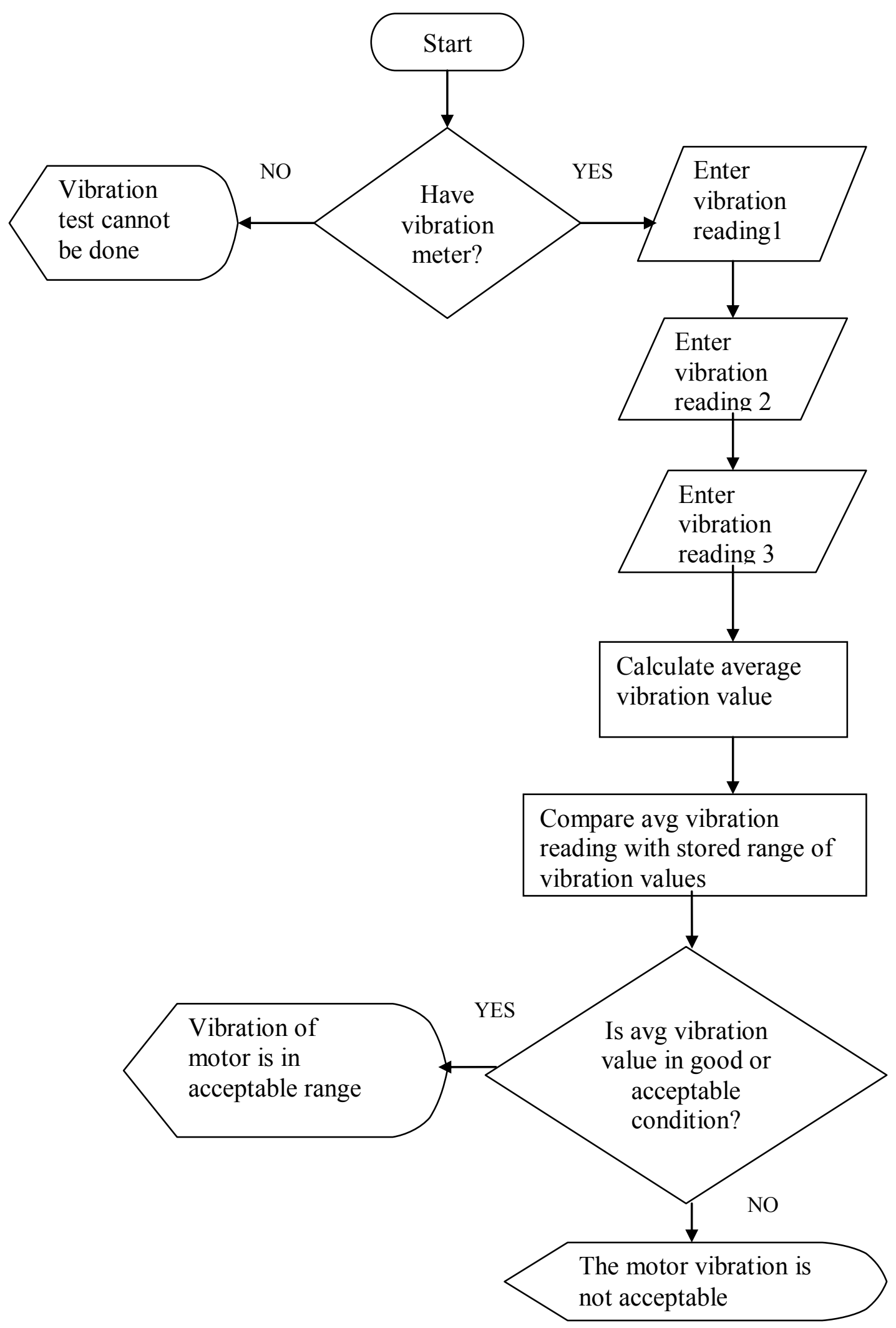

Figure 3.4: Flowchart showing the sequence of steps in vibration testing 


\subsubsection{Voltage unbalance test}

Instrument used: Voltmeter

The user is expected to measure the voltage at each phase of the motor using a voltmeter and input the readings in volts into the model. The values thus input are used to calculate the percentage of voltage unbalance using the formula [27] given below:

$$
\% \text { Unbalance }=\frac{(100 * \text { maximum deviation from average voltage })}{\text { Average Voltage }}
$$

Voltage unbalance is problematic for several reasons.

1) Wastes energy

2) Leads to high current unbalance, which in turn leads to high losses

3) A modest phase unbalance of $2 \%$ can increase losses by $25 \%$

4) A prolonged operation under unbalanced voltage can damage or destroy a motor

From literature [27] it is found that every $1 \%$ increase in voltage unbalance will reduce the insulation life by double the number of times. Greater the voltage unbalance, greater will be the heat generation. For the voltage unbalance between $<$ $5 \%$, following actions are recommended [27]:

1) Regularly monitor the voltages in all the three phases of the motor

2) Check for proper adjustment of the motors

3) Check for the size of the cables, if the cables are undersized it could lead to an unbalance in voltage

4) Look into the power factor

If the $\%$ voltage unbalance is $>5$, it is an unacceptable condition. This would greatly affect the performance of the motor and will cause very quick failure of insulation. The motor has to be immediately stopped and thoroughly looked into the cause for increase in voltage unbalance. The flow chart in Figure 3.5 gives flow of activities in voltage unbalance test. 


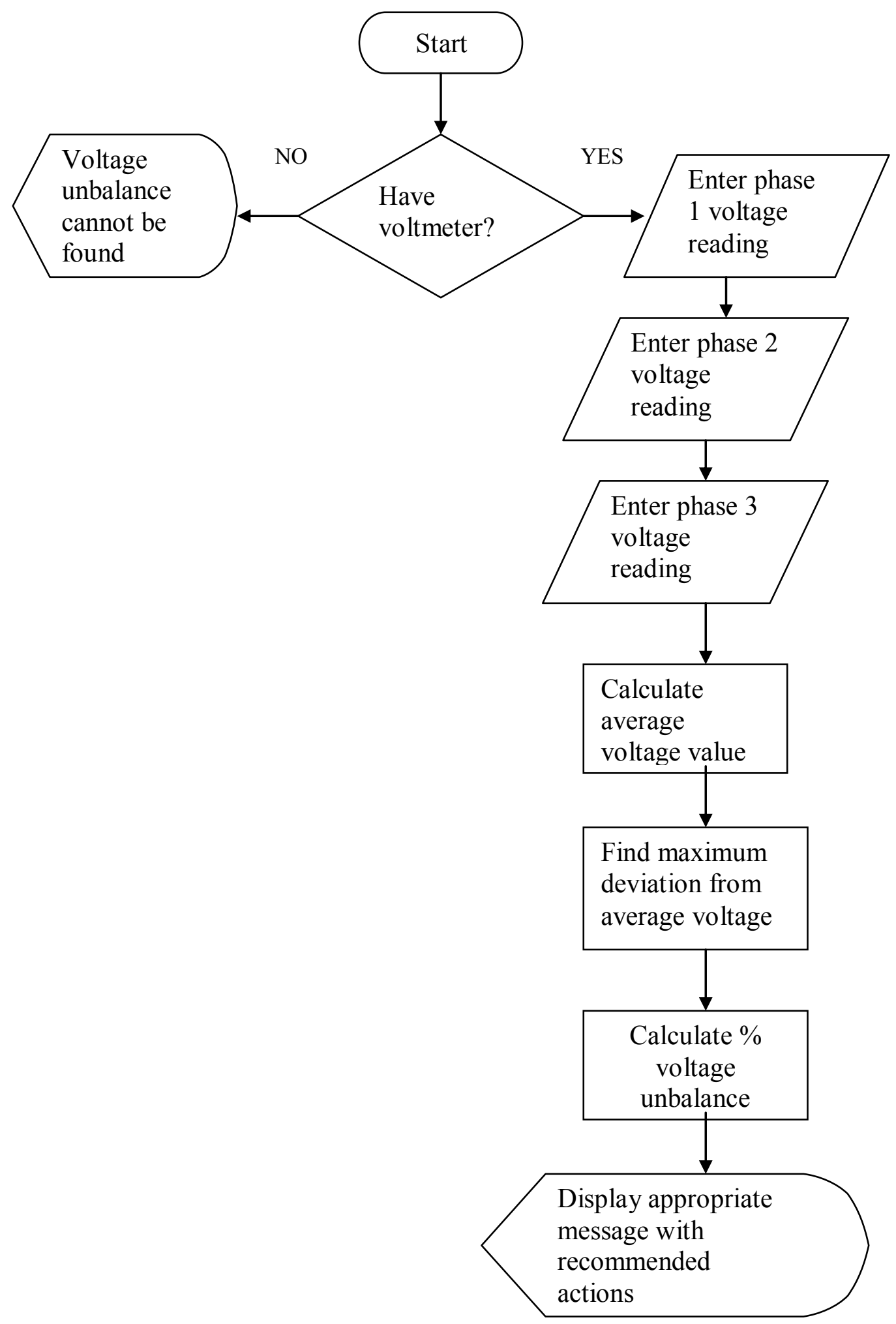

Figure 3.5: Flowchart showing the sequence of steps in voltage unbalance test. 


\subsubsection{Current unbalance test}

Instrument used: Ammeter

Current unbalance test is very similar to voltage unbalance test. Current unbalance causes overheating and considerably reduces life of insulation. A formula [28] similar to that of voltage unbalance is used to calculate the \% current unbalance. The user is expected to measure the current in three phases of the motor and input them into the model.

$$
\% \text { Unbalance }=\frac{(100 * \text { maximum deviation from average current })}{\text { Average Current }}
$$

The actions recommended [28] to reduce the percentage current unbalance are:

1) Check if the motor is drawing more than its rated current.

2) A common rule of thumb is that voltage unbalance can be the cause of up to 8 times larger current unbalances. So, see if there is an voltage unbalance and take necessary actions. See the section on voltage unbalance

3) If the motor was operating under no load or very light load condition, then there's nothing to worry. The current unbalance will vanish as the motor reaches the required load.

The flow chart in Figure 3.6 gives the flow of activities in current unbalance test.

\subsubsection{Percentage Load calculation}

Instrument used: Voltmeter \& Ammeter

Accurately evaluating electric motor load can be useful when troubleshooting conditions. In machines over $50 \%$ loaded this can be performed with a relatively good degree of accuracy with a voltmeter and ammeter, if more advanced instruments are not available. If using an ammeter or voltmeter with $\min / \mathrm{max}$ capabilities, peak loading can be obtained, in variable loads, by taking max readings across a full cycle of operation. Otherwise, the results are a snapshot of the point in time and cycle of operation.

Take voltage and current for each phase of the motor (Vab; Vac; Vbc; Aab; Abc; Aac). Calculate the average of each: 


$$
\begin{gathered}
V_{a v e}=\frac{V_{a b}+V_{a c}+V_{b c}}{3} \\
A_{a v e}=\frac{A_{a b}+A_{a c}+A_{b c}}{3}
\end{gathered}
$$

Using the nameplate voltage (Vn) and current (An), the true load can be estimated as [29]:

$$
\% \text { Load }=\left(\frac{V_{\text {ave }}}{V_{n}}\right) \times\left(\frac{V_{\text {ave }}}{A_{n}}\right) \times 100 \%
$$

So, to calculate \%load of the motor, the user must have both an ammeter and a voltmeter. When a motor is overloaded, its performance gets affected; the motor will be running under stress and will fail prematurely. Overheating is a good indication of the motor being overloaded. It can be due to something as simple as belts that may be too tight, inadequate wiring, or voltage that's too low. Possible corrective actions include: readjusting belt tension, increasing the motor size, and corrective adjustments to the power situation. The flow chart in figure 3.7 shows the sequence of steps in calculating \% load of the motor. Also, electrical logging is another practical possibility to determine the percentage load.

\subsubsection{Locked rotor current test}

Locked rotor current is that current drawn from the line with the starting device or compensator in the full running position, with the rotor locked and with normal voltage on the motor terminal [30]. Based on the comparison made between calculated locked rotor current value and standard locked rotor current value obtained from literature, we can predict the condition of rotor bar and stator windings of the motor.

To calculate the locked rotor current, the user must give the model $\mathrm{kVA} / \mathrm{hp}$ code, minimum voltage of the three phases in volts, size of the motor in hp. The formula [31] used to calculate locked rotor current (LRC) is,

$$
\text { LRCcalc }=\frac{1000 \times h p \times k V A / h p}{\sqrt{3} \times \text { Volts }}
$$




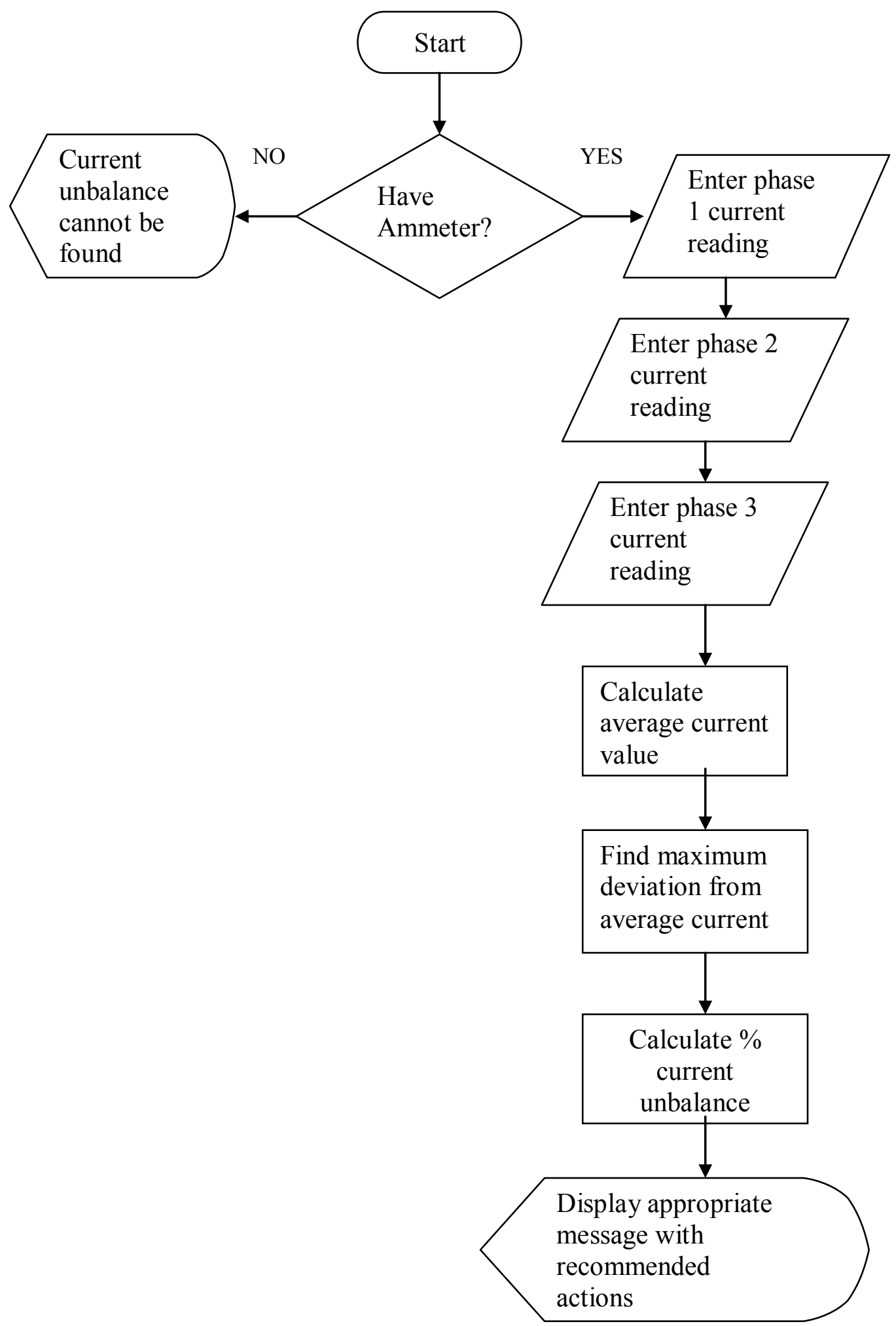

Figure 3 6: Flowchart showing the sequence of steps in current unbalance test. 


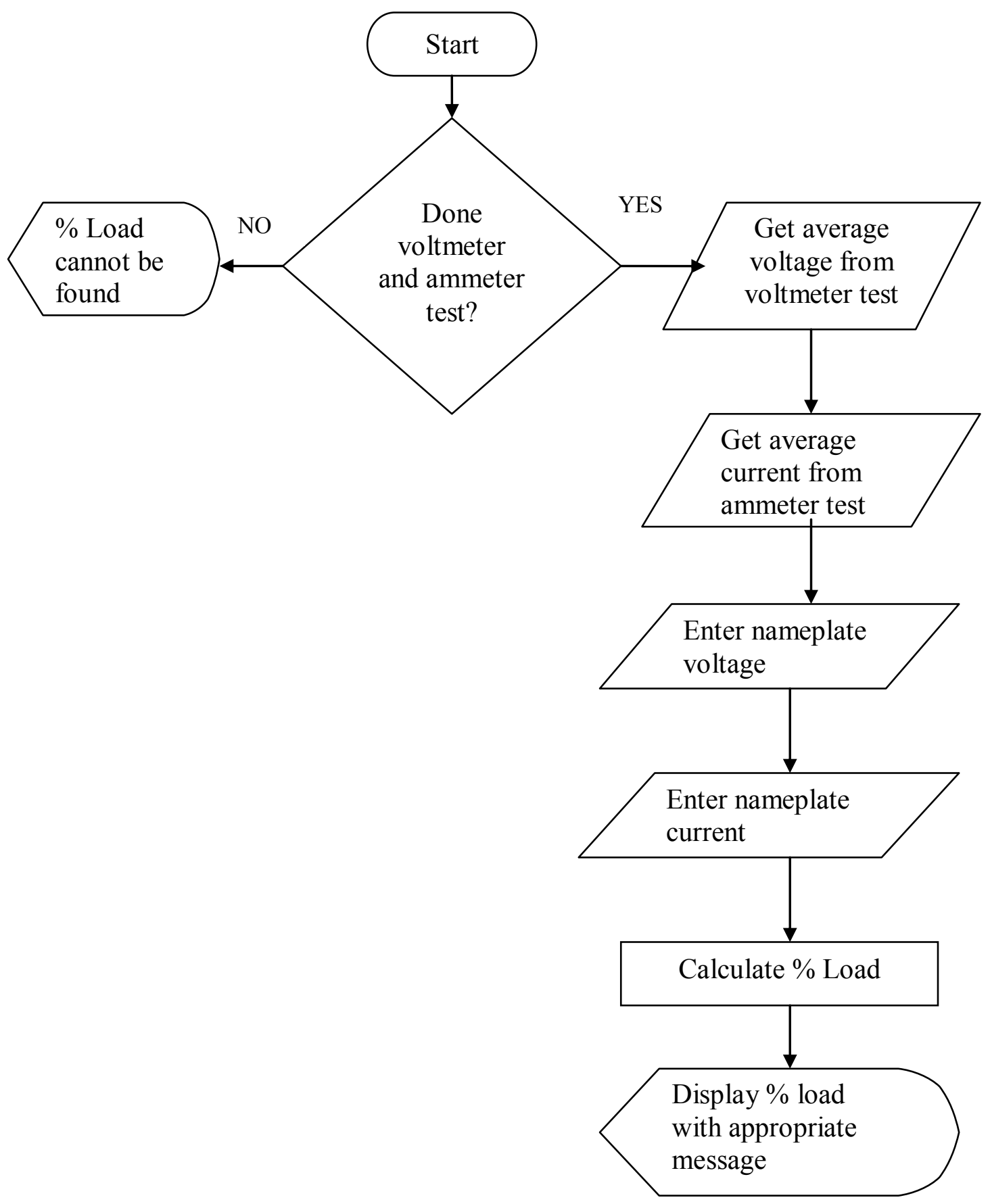

Figure 3.7: showing the sequence of steps in current unbalance test. 
For the $\mathrm{kVA} / \mathrm{hp}$ code input by the user, corresponding numerical value for that will be used in the formula. Table 3.1 gives the list of kVA/hp codes [31] with their values.

\begin{tabular}{|c|c|}
\hline kVA/hp Code & Value \\
\hline A & 3.15 \\
\hline B & 3.55 \\
\hline C & 4.00 \\
\hline$D$ & 4.50 \\
\hline E & 5.00 \\
\hline F & 5.60 \\
\hline G & 6.30 \\
\hline$H$ & 7.10 \\
\hline J & 8.00 \\
\hline K & 9.00 \\
\hline L & 10.00 \\
\hline M & 11.20 \\
\hline N & 12.50 \\
\hline P & 14.00 \\
\hline$R$ & 16.00 \\
\hline$S$ & 18.00 \\
\hline T & 20.00 \\
\hline U & 22.40 \\
\hline
\end{tabular}

Table 3.1: : $\mathrm{kVA} / \mathrm{hp}$ codes and values

Again from literature [32], the standard LRC values were found and are listed in Table 3.2. For obtaining the standard value of LRC the user must input information on the phase and the voltage of the motor.

\begin{tabular}{|c|c|c|c|c|c|c|}
\hline $\begin{array}{c}\text { Motor } \\
\text { Size } \\
\text { in hp }\end{array}$ & \multicolumn{7}{|c|}{$\begin{array}{c}\text { LRC in Amperes } \\
\text { 1 phase } \\
230 \mathrm{~V}\end{array}$} & $\begin{array}{c}3 \text { phase } \\
208 \mathrm{~V}\end{array}$ & $\begin{array}{c}3 \text { phase } \\
220 \mathrm{~V}\end{array}$ & $\begin{array}{c}3 \text { phase } \\
440 \mathrm{~V}\end{array}$ & $\begin{array}{c}3 \text { phase } \\
2300 \mathrm{~V}\end{array}$ & $\begin{array}{c}3 \text { phase } \\
4000 \mathrm{~V}\end{array}$ \\
\hline 5 & $\mathrm{~N} \mathrm{~A}$ & 95 & 90 & 45 & $\mathrm{~N} \mathrm{~A}$ & $\mathrm{~N} \mathrm{~A}$ \\
\hline 7.5 & 50 & 127 & 120 & 60 & 11 & $\mathrm{~N} \mathrm{~A}$ \\
\hline 10 & 100 & 158 & 150 & 75 & 14 & $\mathrm{~N} \mathrm{~A}$ \\
\hline 15 & 200 & 232 & 220 & 110 & 21 & $\mathrm{~N} \mathrm{~A}$ \\
\hline 20 & 300 & 307 & 290 & 145 & 28 & $\mathrm{~N} \mathrm{~A}$ \\
\hline 25 & 400 & 385 & 365 & 183 & 35 & 20 \\
\hline 30 & 500 & 460 & 435 & 218 & 42 & 24 \\
\hline 40 & 700 & 612 & 580 & 290 & 55 & 32 \\
\hline 50 & 900 & 766 & 725 & 363 & 69 & 40 \\
\hline 60 & 1100 & 919 & 870 & 435.5 & 82.9 & 48 \\
\hline 75 & 1400 & 1148.5 & 1087.5 & 544.25 & 103.75 & 60 \\
\hline 100 & 1900 & 1531 & 1450 & 725.5 & 138.5 & 80 \\
\hline 125 & 2400 & 1913.5 & 1812.5 & 906.75 & 173.25 & 100 \\
\hline 150 & 2900 & 2296 & 2175 & 1088 & 208 & 120 \\
\hline
\end{tabular}




\begin{tabular}{|c|c|c|c|c|c|c|}
\hline $\begin{array}{c}\text { Motor } \\
\begin{array}{c}\text { Size } \\
\text { in hp }\end{array}\end{array}$ & $\begin{array}{c}\text { 1 phase } \\
230 \mathrm{~V}\end{array}$ & $\begin{array}{c}\text { 3 phase } \\
208 \mathrm{~V}\end{array}$ & $\begin{array}{c}\text { 3 phase } \\
220 \mathrm{~V}\end{array}$ & $\begin{array}{c}\text { 3 phase } \\
440 \mathrm{~V}\end{array}$ & $\begin{array}{c}\text { 3 phase } \\
2300 \mathrm{~V}\end{array}$ & $\begin{array}{c}\text { 3 phase } \\
4000 \mathrm{~V}\end{array}$ \\
\hline 200 & 3900 & 3061 & 2900 & 1450.5 & 277.5 & 160 \\
\hline 250 & 4900 & 3826 & 3625 & 1813 & 347 & 200 \\
\hline 300 & 5900 & 4591 & 4350 & 2175.5 & 416.5 & 240 \\
\hline 350 & 6900 & 5356 & 5075 & 2538 & 486 & 280 \\
\hline 400 & 7900 & 6121 & 5800 & 2900.5 & 555.5 & 320 \\
\hline 450 & 8900 & 6886 & 6525 & 3263 & 625 & 360 \\
\hline 500 & 9900 & 7651 & 7250 & 3625.5 & 694.5 & 400 \\
\hline 600 & 11900 & 9181 & 8700 & 4350.5 & 833.5 & 480 \\
\hline 700 & 13900 & 10711 & 10150 & 5075.5 & 972.5 & 560 \\
\hline 800 & 15900 & 12241 & 11600 & 5800.5 & 1111.5 & 640 \\
\hline 1000 & 19900 & 15301 & 14500 & 7250.5 & 1389.5 & 800 \\
\hline
\end{tabular}

Table 3.2: Standard Locked Rotor current Values

If the calculated locked rotor current is greater than the suggested standard locked rotor current. This indicates the possibility of rotor bar and stator winding faults.

The recommended actions are [33]:

1) Common causes of rotor bar damage are high thermal and mechanical stresses. Pulsating mechanical loads such as reciprocating compressor or coal crushers can subject the rotor cage to high mechanical stresses. So, regulate the load applied on the rotor cage keeping it well within limits and thereby reducing stresses.

2) Stator winding are subject to insulation breakdown caused by:

- Mechanical vibration - check the section on vibration testing

- Insulation temperature - check the section on insulation temperature testing

- Damage during installation

\subsubsection{Effective service factor (ESF) calculation}

Irrespective of the nameplate service factor, an effective service factor of greater than 1 indicates that the motor is under stress. The service factor test identifies how close the motor is operating to its nameplate service factor. It predicts heat based deterioration and provides a accurate thermal assessment of the motor. Two elements affecting the ESF number are real operating voltage condition and steady state load conditions [34]. The ESF number represents the thermal stress caused by these two conditions on the motor. Power conditions may also place unnecessary stress on the motor. 


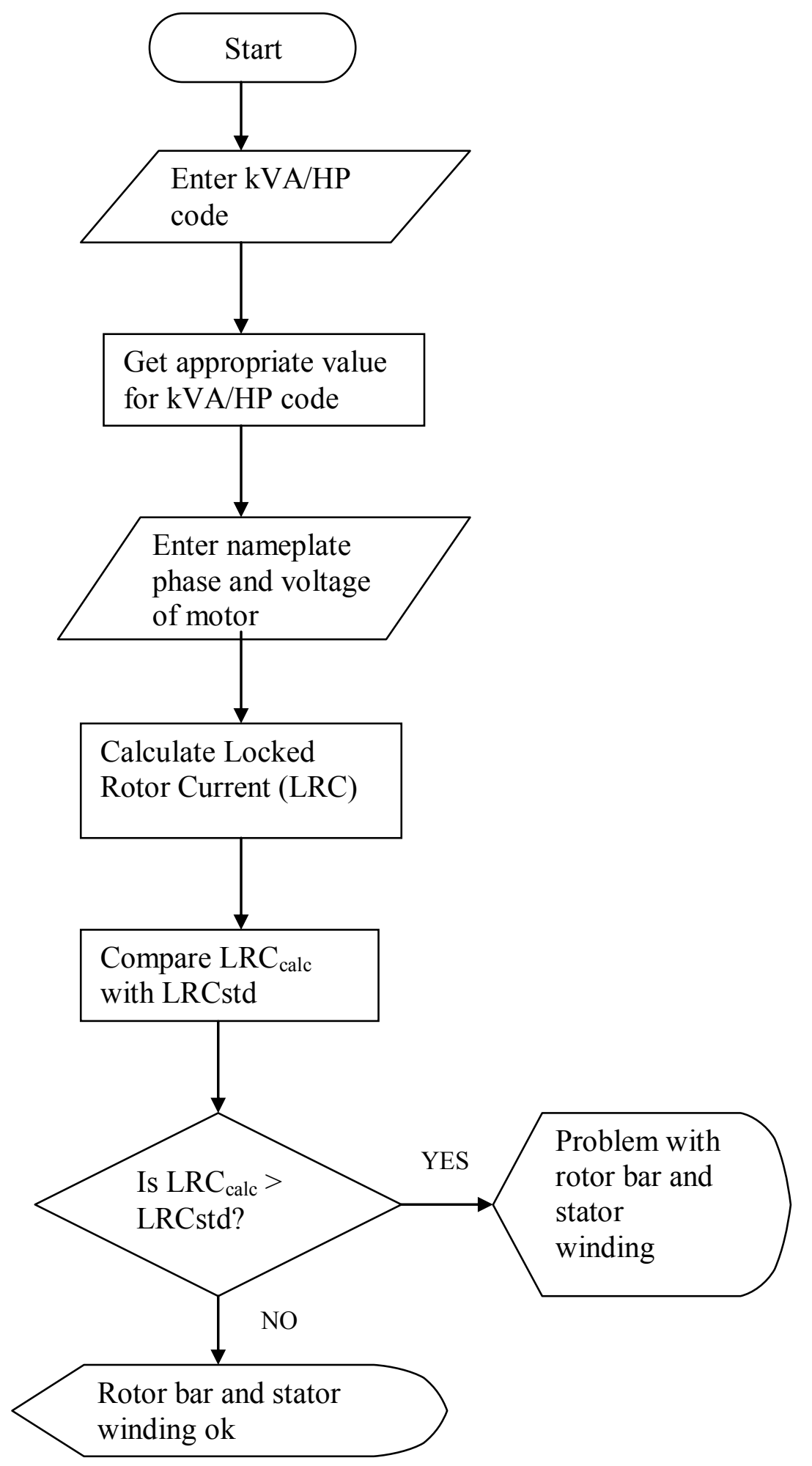

Figure 3.8: Flowchart showing the sequence of steps in LRC test. 
ESF is obtained by dividing the estimated percentage load by the NEMA derating factor [34].

$$
E S F=\frac{\% \text { Load }}{\text { NEMA derating factor }}
$$

NEMA derating factor is obtained as a corresponding value of $\%$ voltage unbalance. For a voltage unbalance of greater than $5 \%$, there is no NEMA derating factor available. Hence, as it was seen before voltage unbalance of greater than $5 \%$ is unacceptable. Table 3.3 gives the \% voltage unbalance and their corresponding NEMA derating factors [34].

\begin{tabular}{|c|c|}
\hline $\begin{array}{c}\text { \% Voltage } \\
\text { Unbalance }\end{array}$ & $\begin{array}{c}\text { Derating } \\
\text { Factor }\end{array}$ \\
\hline 0.5 & 1.000 \\
\hline 1.0 & 1.000 \\
\hline 1.5 & 0.975 \\
\hline 2.0 & 0.950 \\
\hline 2.5 & 0.925 \\
\hline 3.0 & 0.900 \\
\hline 3.5 & 0.850 \\
\hline 4.0 & 0.825 \\
\hline 4.5 & 0.800 \\
\hline 5.0 & 0.750 \\
\hline
\end{tabular}

Table 3.3: Derating factors for $\%$ voltage unbalances

If the ESF is less than 1, then the motor's operating condition is good. But, if it is greater than 1, then the motor is running under stress. The recommended actions are

1) Decrease load

2) Look into voltage unbalance.

Flow chart in Figure 3.8 shows the steps followed in calculating the ESF. 


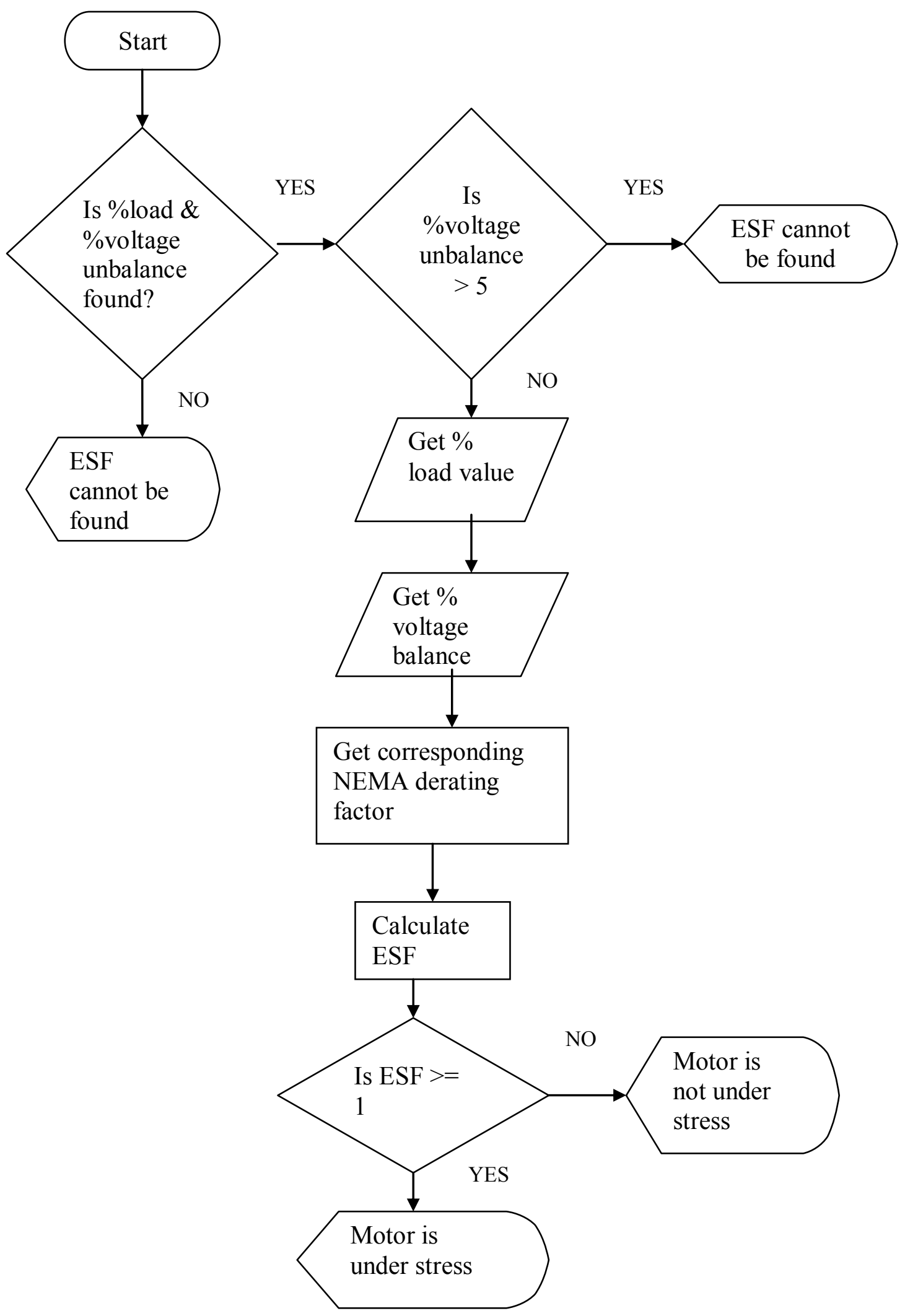

Figure 3.9: showing the sequence of steps in ESF test. 


\subsubsection{Short to ground test}

Instrument used: Ohm meter

This test predicts the occurrence of short in any of the three phases of the motor. The user is required to turn off all power sources to the machine and disconnect the 3 phase motor lines from the drive before testing [35]. Once this is done, using the ohmmeter the user can find the resistance in each of the phases. The reading will be infinity, zero or some numerical value. If the reading happens to be infinity, then it indicates that there is no short in that particular cable. If it is zero or any other numerical value, then there could be some problem with the cable or in other words, there could be short in the cable [35]. The flow chart in Figure 3.9 shows the sequential steps.

\subsubsection{Open/short in windings test}

Instrument used: Ohmmeter

This test is similar to the test described in previous section. This helps in predicting the open or short in windings of the motor. First, disconnect all the power from the machine. Put the ohmmeter between phase1-phase2, phase2-phase3 and phase1-phase 3 . The expected range is usually between 0.3 to $2.0 \mathrm{ohms}$ [35]. Most are about 0.8 ohms. If it is zero then it can be concluded that there is a short between the phases. If it is infinite or well above $2000 \mathrm{ohms}$, then there is an open between the phases [35]. The flow chart in Figure 3.10 shows the steps involved in the test. 


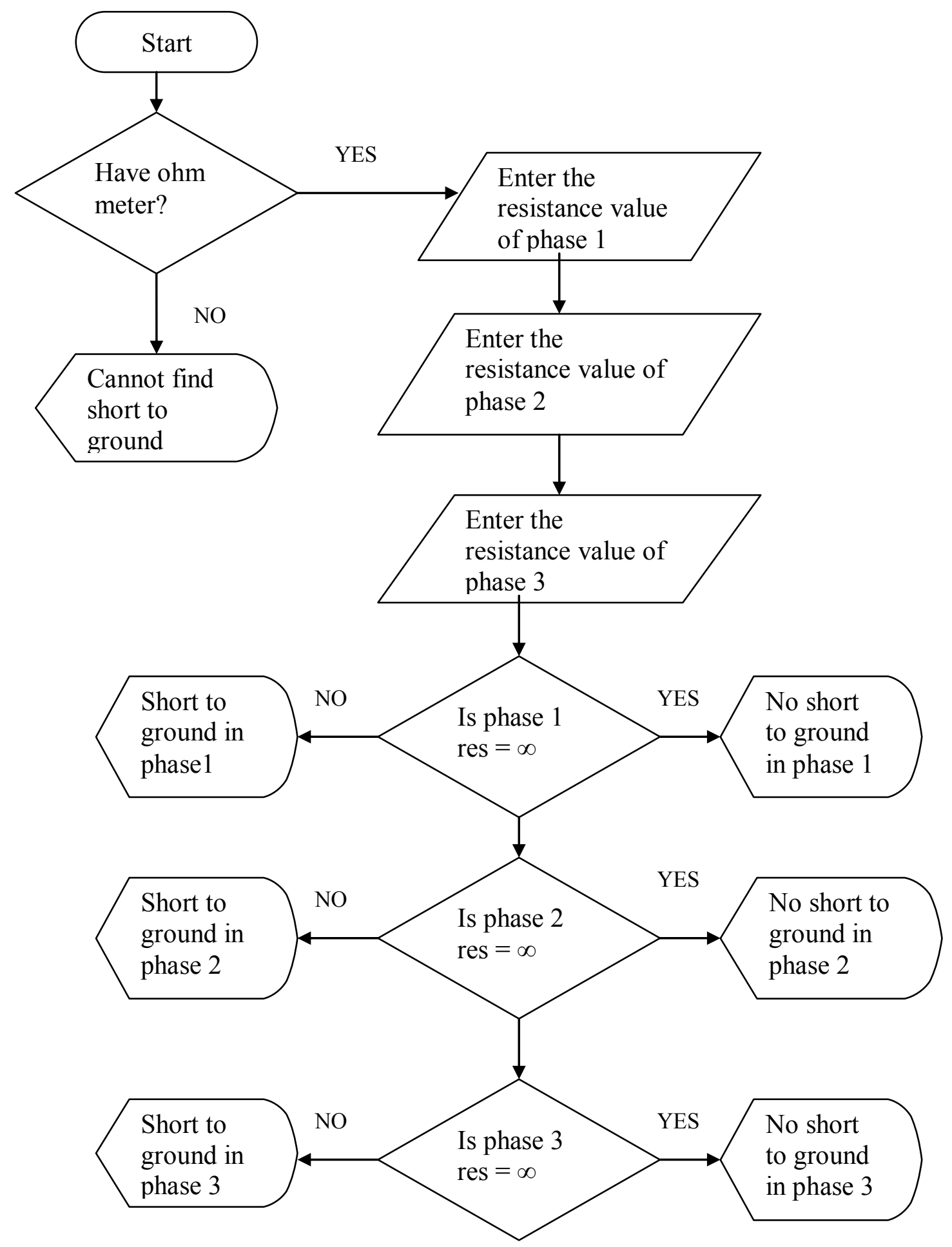

Figure 3.10: Flowchart showing the sequence of steps in short to ground test. 


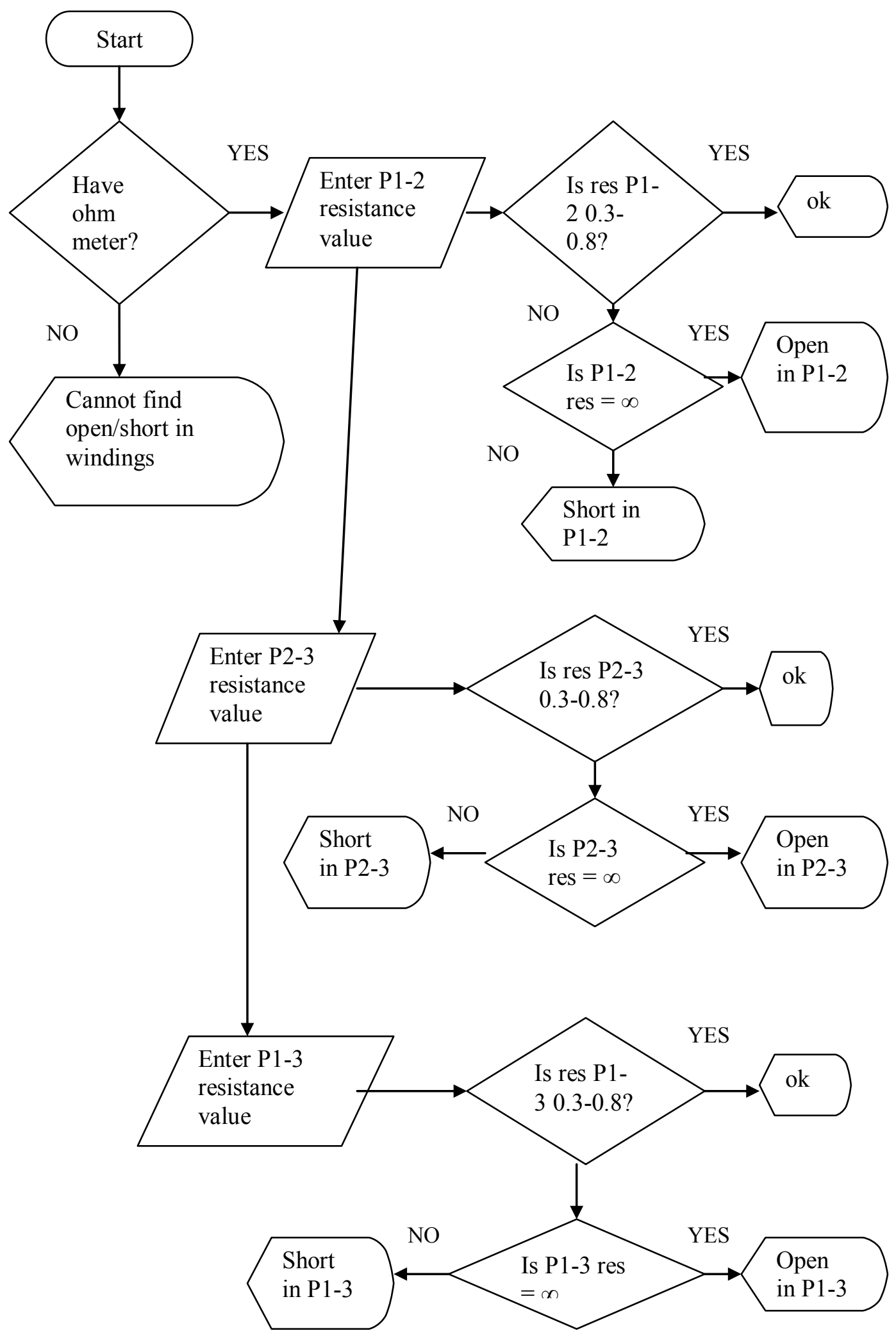

Figure 3.11: Flowchart showing the sequence of steps in open/short in windings test. 


\subsubsection{Polarization index test}

Instrument used: Polarization Index (PI) Tester

The PI test is performed in order to quantitatively measure the ability of an insulator to polarize. When an insulator polarizes, the electric dipoles distributed throughout the insulator align themselves with an applied electric field [36]. As the molecules polarize, a "polarization current", also called absorption current, is developed that adds to the insulation leakage current. This additional polarization current decreases over time and drops to zero when the insulation is completely polarized.

The PI result becomes confusing when attempting to attribute variations in the PI value to the polarizability of the insulator or other affects such as humidity or moisture, surface leakage or instrument error. The result is even more confusing when attempting to reconcile a PI of 1 when one is expecting some other PI. The PI test is typically performed at 500,1000, 2500 or 5000 volts, depending on the operating voltage of the motors being tested and takes 10 minutes to complete. The PI value is calculated by dividing the insulation resistance at 10 minutes by the resistance at 1 minute as shown below [36]:

$P I=\frac{I R(10 \mathrm{~min})}{I R(1 \mathrm{~min})}$

In general, insulators that are in good condition will show a "high" polarization index while insulators that are damaged will not. As recommended in IEEE 43-2000, if the one-minute insulation resistance is greater than 5000Mohms, the PI measurement may not be meaningful.

To address the situation where the PI may not be meaningful, the Dielectric Absorption (DA) is widely used instead. The DA is the IR value at 3 minutes divided by the IR value at 30 seconds. The motivation for even doing the DA test is to reduce the test time to 3 minutes instead of 10 minutes for the PI test when the PI test may not be worthwhile. To date there are no accepted values for the DA. However, some usefulness can be obtained by trending the DA value over time. 
The Dielectric Absorption (DA) Test is essentially a short-duration PI test and is usually intended for smaller motors. Larger motors whose insulation does not easily polarize are also good candidates for the DA Test. Other than the shorter test time, all other principles are the same as the PI test, explained in the next section.

While the PI test is recommended only for motors 200 horsepower or greater, the DA test is useful for motors in approximately the 50 to 200 horsepower range. The DA value is the ratio of the ground wall insulation resistance (IR) at 3 minutes to the IR value at 30 seconds. The flowchart in Figure 3.11 shows the sequence of steps followed in PI and DA test.

If the PI or DA index is greater than equal to 2 , then the insulation is in good condition. Otherwise, a value of less than 2 is a low polarization index value and indicates that the insulation is brittle and must be either upgraded or replaced with better quality insulation.

\subsection{Efficiency of the Motor}

Instruments used: Wattmeter \& Tachometer

To calculate the efficiency of the motor, the user needs to measure the power in $\mathrm{kW}$ using a Wattmeter and speed in rpm using a tachometer. Also, the rated speeds of the motor at no load and full load need to be obtained from the nameplate and input into the model. Using all these values the model calculates the efficiency of the motor using the formula [23]:

$$
\text { Efficiency }=\frac{\text { \&ctual hpoutput } x 0.746 \mathrm{~kW} / \mathrm{hp}}{\text { Measured powerin } \mathrm{kW}}
$$

Actual hp output $=\%$ of full load $\mathrm{x}$ size of motor

$$
\% \text { Full Load }=\frac{\text { Rated speed at noload-Measured speed }}{\text { Rated speed at noload }- \text { Rated speed at full load }}
$$

A motor that is maintained well and is operating under good conditions will have a high efficiency. If the efficiency is low, then it is recommended that the user takes initiative as soon as possible to find the cause for the poor performance of the motor 
resulting in low efficiency. Flow chart in Figure 3.12 shows the method followed in calculating the efficiency of the motor.

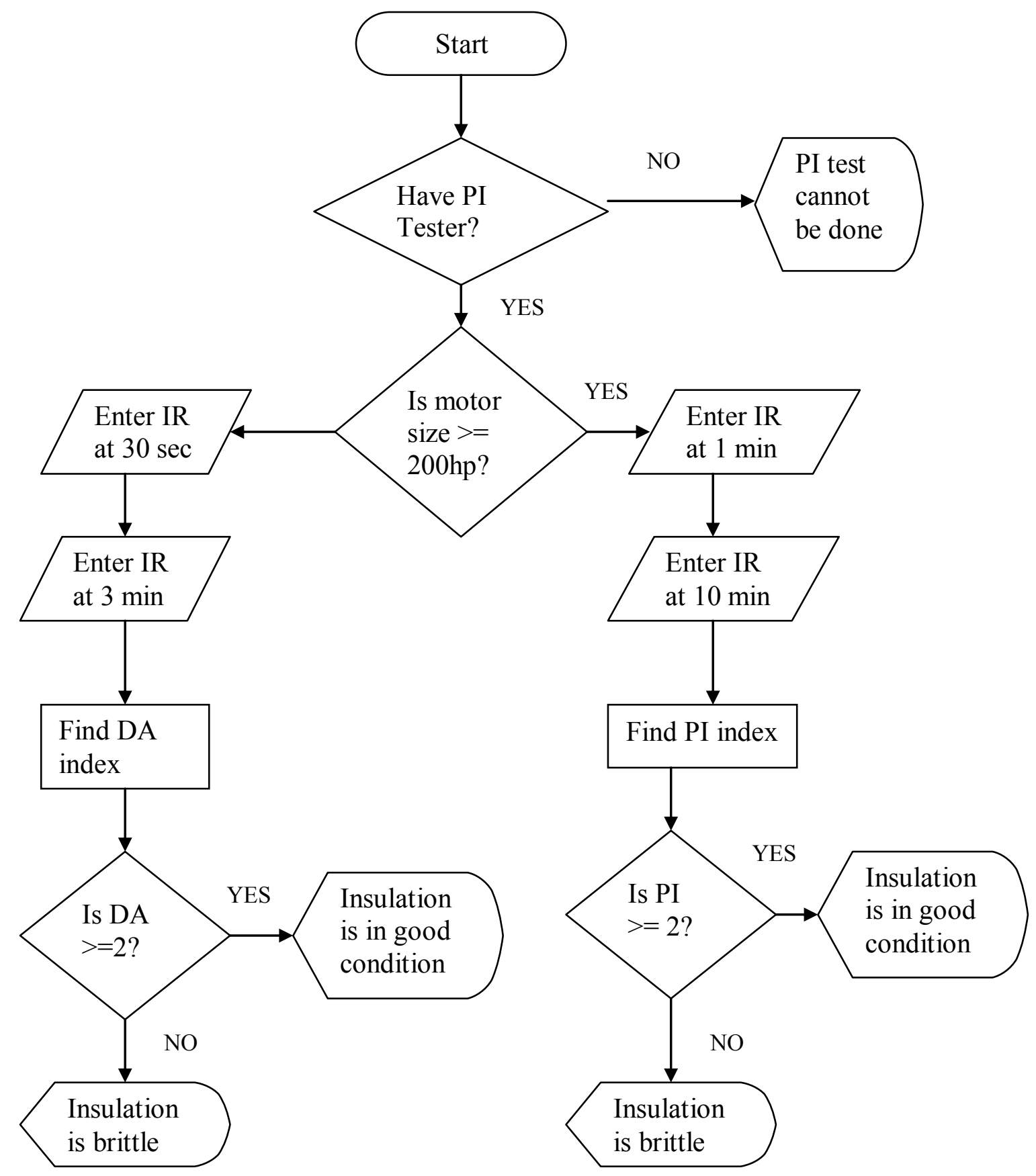

Figure 3.12: Flowchart showing the sequence of steps in polarization index test. 


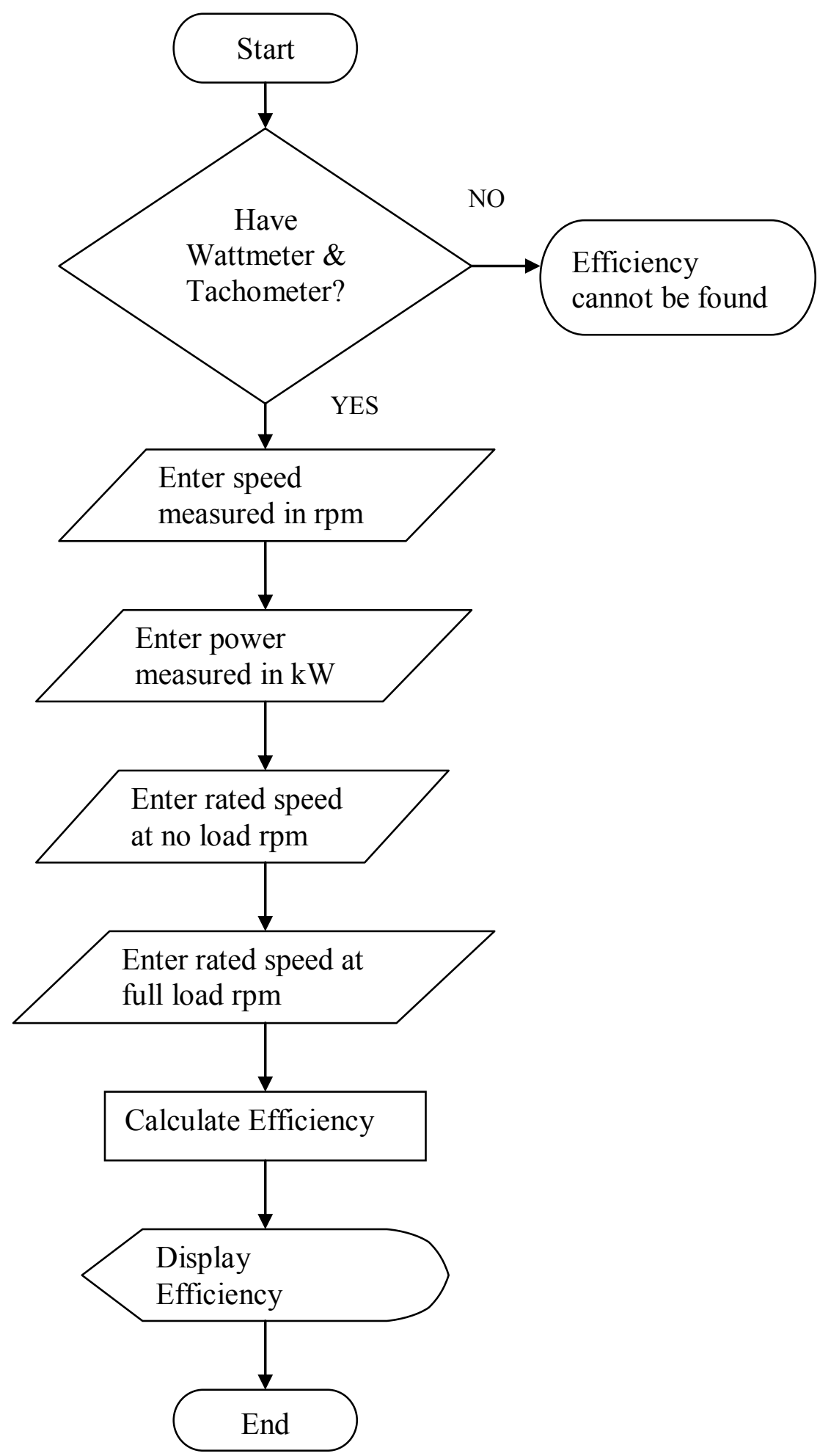

Figure 3.13: Flowchart showing the sequence of steps in efficiency calculation. 


\subsection{Frequency of starts and stops}

From the study of literature [34], it is seen that the maintenance personnel are usually not aware about the frequency of starts and stops for the motor. Limiting the frequency of start up, the most stressful portion of the motor operation, is highly important. Many well documented cases of recurring motor failure were approached by increasing the size of the motor. This shortened the time between failures, however; the root cause of failure was the frequency of starts and stops. The key is to closely monitor the number of starts, hourly for small or medium motors, and daily for large sized motors. The model has a section devoted to this, which would give the user information on the frequency of starts and stops having input the size of the motor and number of poles in the motor. The report will have information on maximum number of starts per hour (A) and minimum rest or off time in seconds between starts (C). Flow chart in Figure 3.13 shows the details of frequency of starts and stops. Table 3.4 has the information on frequency of starts and stops for all the sizes of the motor differing in number of poles [34].

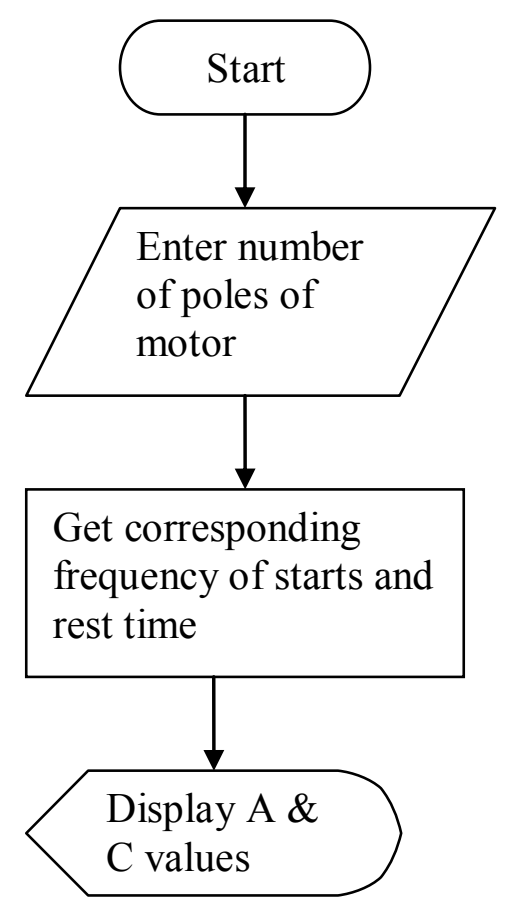

Figure 3.14: Flowchart showing the details of frequency of starts and stops. 


\begin{tabular}{|c|c|c|c|c|c|c|}
\hline \multirow{2}{*}{$\begin{array}{c}\text { Motor Size } \\
\text { HP }\end{array}$} & \multicolumn{2}{|c|}{2 - Pole } & \multicolumn{2}{c|}{4 - Pole } & \multicolumn{2}{c|}{6 - Pole } \\
\cline { 2 - 7 } & A & C & A & C & A & C \\
\hline 5 & 8 & 83 & 16 & 42 & 18 & 37 \\
\hline 7.5 & 7 & 87 & 14 & 44 & 16 & 39 \\
\hline 10 & 6 & 92 & 13 & 46 & 14 & 41 \\
\hline 15 & 5 & 100 & 11 & 46 & 12 & 44 \\
\hline 20 & 5 & 100 & 10 & 55 & 11 & 48 \\
\hline 25 & 5 & 100 & 10 & 55 & 11 & 48 \\
\hline 30 & 4 & 115 & 8 & 65 & 9 & 56 \\
\hline 40 & 4 & 115 & 8 & 65 & 9 & 56 \\
\hline 50 & 3 & 145 & 7 & 72 & 8 & 64 \\
\hline 60 & 3 & 165 & 7 & 81 & 8 & 70 \\
\hline 75 & 3 & 180 & 6 & 90 & 7 & 79 \\
\hline 100 & 3 & 220 & 5 & 110 & 6 & 97 \\
\hline 200 & 2 & 600 & 4 & 300 & 5 & 268 \\
\hline 250 & 1 & 1000 & 4 & 500 & 4 & 440 \\
\hline 300 & 1 & 1000 & 4 & 500 & 4 & 440 \\
\hline 350 & 1 & 1000 & 4 & 550 & 4 & 440 \\
\hline 400 & 1 & 1200 & 4 & 580 & 4 & 465 \\
\hline 450 & 1 & 1260 & 4 & 640 & 4 & 465 \\
\hline 500 & 1 & 1320 & 4 & 640 & 4 & 465 \\
\hline 600 & 1 & 1320 & 4 & 675 & 4 & 480 \\
\hline 700 & 1 & 1400 & 4 & 675 & 4 & 480 \\
\hline 800 & 1 & 1400 & 4 & 690 & 4 & 510 \\
\hline 1000 & 1 & 1440 & 4 & 700 & 4 & 510 \\
\hline
\end{tabular}

Table 3.4: Information for frequency of starts and stops

\subsection{Bearing lubrication}

One of the most important components of electrical motor maintenance program is the lubrication of bearings [37]. Yet, this vital aspect of preventive maintenance remains one of the least understood functions of maintenance. There is constant debate concerning whether a bearing should be 'flushed,' a limited amount of grease added, how often or if the motor should be operating or tagged-out. Many motor manufactures outline the preferred, and safest, method for lubricating electric motor bearings. There are specific physical properties for this process in the motor bearing housing and in order to protect motor windings from contamination.

The model has a section on bearing lubrication that gives information on how much of lubricant must be used and how often the bearing must be lubricated. To get the amount of lubricant, the user needs to enter the bearing number obtained from the nameplate and select the lubricant that is used specifying whether it is oil or grease. If the lubricant used is grease, then the amount is displayed in cubic inches and if it is 
oil, then the amount of oil to be used is given in number of teaspoons. Figure 3.14 gives the information on amount of lubrication. Table 3.5 gives the list of all bearing numbers and their corresponding amount of lubricant to be used. To obtain the frequency of lubrication, the user is expected to input the rated motor speed in rpm, Motor frame obtained from the nameplate and hours of operation for the motor. Figure 3.15 gives the information on frequency of lubrication. Table 3.6 classifies the motor speeds into three classes, lists appropriate motor frames falling under each class and has corresponding information on frequency of lubrication [37].

\begin{tabular}{|c|c|c|}
\hline $\begin{array}{c}\text { Bearing } \\
\text { Number }\end{array}$ & $\begin{array}{c}\text { Amount in } \\
\text { cubic inches } \\
\text { (Grease) }\end{array}$ & $\begin{array}{c}\text { Amount in } \\
\text { Teaspoons } \\
\text { (Oil) }\end{array}$ \\
\hline 203 & 0.15 & 0.5 \\
\hline 205 & 0.27 & 0.9 \\
\hline 206 & 0.34 & 1.1 \\
\hline 207 & 0.43 & 1.4 \\
\hline 208 & 0.52 & 1.7 \\
\hline 209 & 0.61 & 2 \\
\hline 210 & 0.72 & 2.4 \\
\hline 212 & 0.95 & 3.1 \\
\hline 213 & 1.07 & 3.6 \\
\hline 216 & 1.49 & 4.9 \\
\hline 219 & 2.8 & 7.2 \\
\hline 222 & 3 & 10 \\
\hline 307 & 0.53 & 1.8 \\
\hline 308 & 0.66 & 2.2 \\
\hline 309 & 0.81 & 2.7 \\
\hline 310 & 0.97 & 3.2 \\
\hline 311 & 1.14 & 3.8 \\
\hline 312 & 1.33 & 4.4 \\
\hline
\end{tabular}

Table 3.5: Amount of lubrication

\begin{tabular}{|c|c|c|c|}
\hline Motor RPM & Motor Frame & 8 hrs/day & $>8$ hrs/day \\
\hline 3600 & 284T - 286T & 6 months & 2 months \\
\hline & 324T - 587U & 4 months & 2 months \\
\hline 1800 & $284 T-326 \mathrm{~T}$ & 4 years & 18 months \\
\hline & $364 \mathrm{~T}-365 \mathrm{~T}$ & 1 year & 4 months \\
\hline & $404 \mathrm{~T}-449 \mathrm{~T}$ & 9 months & 3 months \\
\hline & $505 \mathrm{U}-587 \mathrm{U}$ & 6 months & 2 months \\
\hline 1200 \& below & 284T - 326T & 4 years & 18 months \\
\hline & $364 \mathrm{~T}-449 \mathrm{~T}$ & 1 year & 4 months \\
\hline & $505 \mathrm{U}-587 \mathrm{U}$ & 9 months & 3 months \\
\hline
\end{tabular}

Table 3.6: Frequency of lubrication 


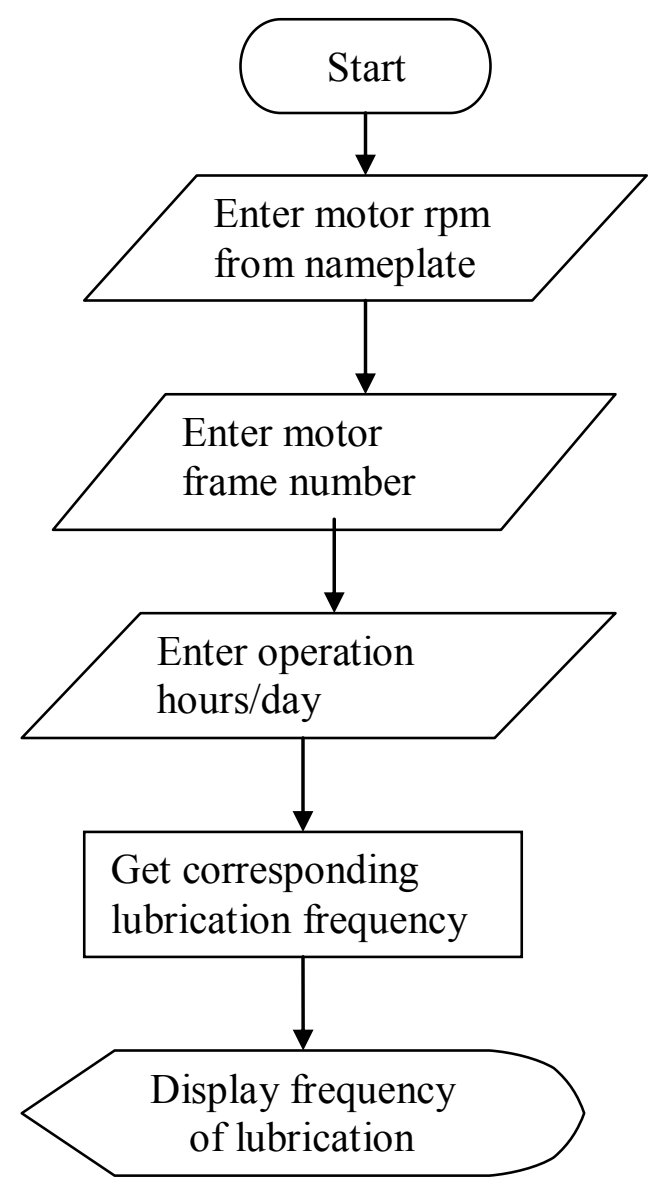

Figure 3.15: Flowchart showing information on amount of lubrication.

\subsection{Motor Maintenance Cost}

The report has a section devoted to giving information on the cost incurred for the maintenance of the motor. The report has two tables, one giving the periodic maintenance cost information and the other having the predictive maintenance cost information. The cost shown for the maintenance may not be very accurate but, it definitely gives an approximate value that indicates on an average how much money may have to be spent on motor maintenance. 


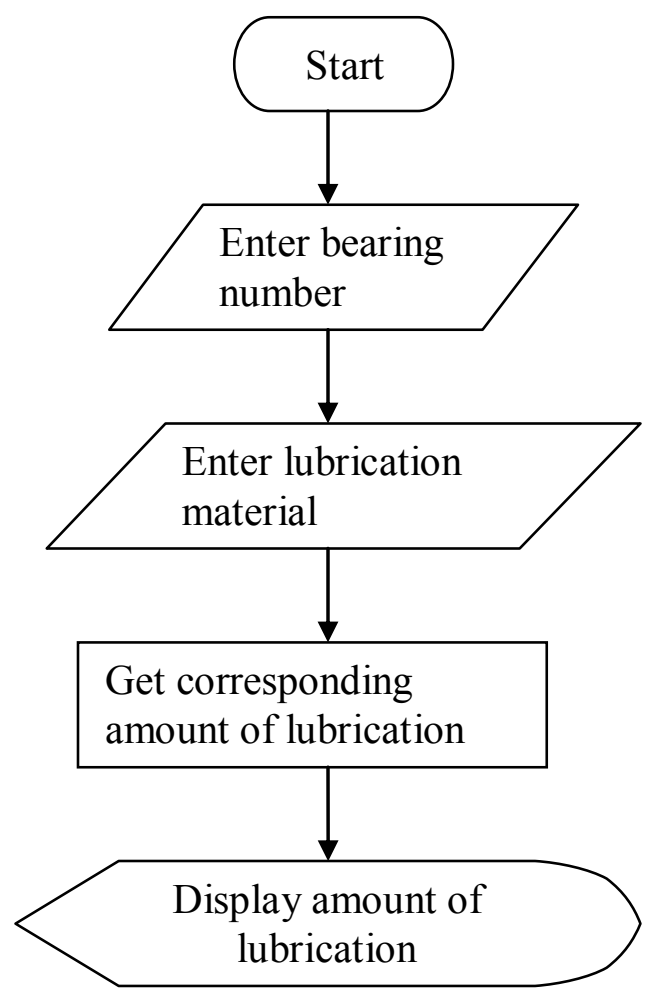

Figure 3.16: Flowchart showing information on frequency of lubrication.

\subsubsection{Periodic Maintenance Cost}

As discussed in the beginning of this chapter, from literature, we have a list of 9 recommendations as periodic motor maintenance activities. Also, there is information on how often each activity must be carried out and how much time an activity takes every single time. The user provides the labor cost in $\$ / \mathrm{hr}$ in the plant information section of general information. Using all these, the annual cost incurred for each maintenance action is calculated and displayed. The sum of individual annual costs gives the total periodic motor maintenance annual cost. As an example, the annual periodic maintenance cost for one recommendation is calculated and shown below, Recommended action: Clean the external surface of motor.

The external surface of the motor must be cleaned every two weeks. So, this means the activity will be done 26 times a year. Every time the external surface of motor is cleaned, it takes about 15 minutes. Therefore, in a year, it takes about 390 minutes or 6.5 hours. The number of hours multiplied by the labor cost $(\$ / \mathrm{hr})$ will give the annual periodic maintenance cost for this one activity. 
Similarly, the annual costs are calculated for other 8 recommended actions and the sum is found to give the annual periodic maintenance cost. Table 3.7 has the cost details for periodic maintenance recommendations.

\begin{tabular}{|l|l|l|}
\hline \multicolumn{1}{|c|}{ Maintenance Activity } & \multicolumn{1}{c|}{ Frequency } & \multicolumn{1}{c|}{ Cost (\$) } \\
\hline Clean the external surface of the motor & every 2 weeks & $6.5^{*} \mathrm{LC}$ \\
\hline Clean the internal parts of the motor & every 2 months & $12^{*} \mathrm{LC}$ \\
\hline Replace the lubricant & depends & $\mathrm{A}{ }^{*} \mathrm{LC}$ \\
\hline Monitor lubricant condition & every 2 months & $1.5^{*} \mathrm{LC}$ \\
\hline Check for mounting / base rigidity & every 2 months & $1.5^{*} \mathrm{LC}$ \\
\hline Check for coupling alignment & every 2 months & $1.5^{*} \mathrm{LC}$ \\
\hline Check for shaft alignment & every 2 months & $1.5^{*} \mathrm{LC}$ \\
\hline $\begin{array}{l}\text { Check for belt and pulley tension, wear, positioning, slip } \\
\text { etc }\end{array}$ & every 2 months & $1.5^{*} \mathrm{LC}$ \\
\hline Check for audible noise & every 2 weeks & $4.33^{*} \mathrm{LC}$ \\
\hline & & \\
\hline Total Annual Periodic Maintenance Cost & & Sum \\
\hline
\end{tabular}

Table 3.7: Periodic maintenance cost calculations

The recommendation asks the user to replace the lubricant. For this activity, the frequency varies depending on the rated speed of the motor, motor frame and operation hours of the motor. The value is obtained from the frequency of lubrication section of the model and used in calculating the annual costs following the example shown above.

\subsubsection{Predictive Maintenance Cost}

For each of the predictive tests listed and described in the previous sections of this chapter, the capital cost and labor cost are tabulated. The capital cost is the cost incurred in buying the equipment required to carry out the test. Labor cost is calculated for each test very similar to that described in the periodic maintenance cost calculation. The cost for each predictive motor maintenance test will be the sum of capital and labor cost. Unlike the periodic maintenance cost calculations, annual maintenance cost cannot be found for predictive motor tests. This is because the predictive tests listed for the motor are not based on time, but on the condition of the motor. Table 3.8 has the cost details for all the predictive motor tests listed. 


\begin{tabular}{|c|c|c|c|c|}
\hline Test & $\begin{array}{c}\text { Time } \\
\text { Required } \\
\text { (min) }\end{array}$ & $\begin{array}{c}\text { Capital } \\
\text { Cost } \\
\text { (CC) }\end{array}$ & $\begin{array}{l}\text { Labor Cost } \\
\text { (LC) }\end{array}$ & $\begin{array}{l}\text { Total } \\
\text { cost }\end{array}$ \\
\hline Insulation temperature testing & $15 \mathrm{~min}$ & $\$ 200$ & $0.25 *$ LC $(\$ / h r)$ & $\mathrm{CC}+\mathrm{LC}$ \\
\hline Bearing temperature testing & $10 \mathrm{~min}$ & $\$ 200$ & $0.17^{*} \mathrm{LC}(\$ / \mathrm{hr})$ & $\mathrm{CC}+\mathrm{LC}$ \\
\hline Vibration test & $10 \mathrm{~min}$ & $\$ 1,000$ & $0.17{ }^{*} \mathrm{LC}(\$ / \mathrm{hr})$ & $\mathrm{CC}+\mathrm{LC}$ \\
\hline Voltage test & $15 \mathrm{~min}$ & $\$ 500$ & $0.25 *$ LC $(\$ / \mathrm{hr})$ & $\mathrm{CC}+\mathrm{LC}$ \\
\hline Ammeter test & $15 \mathrm{~min}$ & $\$ 500$ & $0.25{ }^{*} \mathrm{LC}(\$ / \mathrm{hr})$ & $\mathrm{CC}+\mathrm{LC}$ \\
\hline \% Load calculation & $30 \mathrm{~min}$ & $\$ 1,000$ & $0.50 *$ LC $(\$ / \mathrm{hr})$ & $\mathrm{CC}+\mathrm{LC}$ \\
\hline Locked Rotor Current & $10 \mathrm{~min}$ & $\$ 0$ & $0.17^{*} \mathrm{LC}(\$ / \mathrm{hr})$ & $\mathrm{CC}+\mathrm{LC}$ \\
\hline Test for short to ground & $15 \mathrm{~min}$ & $\$ 2,000$ & $0.25 *$ LC $(\$ / \mathrm{hr})$ & $\mathrm{CC}+\mathrm{LC}$ \\
\hline Test for open/short in windings & $15 \mathrm{~min}$ & $\$ 2,000$ & $0.25 *$ LC (\$/hr) & $\mathrm{CC}+\mathrm{LC}$ \\
\hline PI Test & $20 \mathrm{~min}$ & $\$ 2,500$ & $0.33^{*} \mathrm{LC}(\$ / \mathrm{hr})$ & $C C+L C$ \\
\hline
\end{tabular}

Table 3.8: Predictive maintenance cost calculations

\subsection{History of Motor Testing}

The TPM model designed for motors generates a report that includes information on all previous test values for a particular motor. Every time a test value is entered into the model for a particular test, the value is stored in the database. So, when the tests are repeated on the same motor and test values entered, the report has a section wherein the current value and all the previous values will be listed in tabular format row after row. Using this, the user will be able to know the trend of the test values. If the test values remain constant, then it may be concluded that there is neither deterioration nor improvement in the performance of the motor. If there is a gradual increase, the motor efficiency may be going up because of various reasons including the regular maintenance done on the motor as one of them. If there seems to be gradual decrease, then the motor is gradually deteriorating and the maintenance personnel must do some regular upkeep and take initiatives to improve the condition of the motor. If there is a sudden rise or drop in the value, then it indicates that there is something seriously wrong with the motor and immediate action must be taken to find out what could be the possible reason for this sudden change in the value.

\subsection{Conclusion}

The user inputs the user information, plant information and basic motor information. Once the available instruments are checked, corresponding test sections get activated and the required information for each test is collected from the user. The data is used to calculate meaningful parameters that indicate the condition of the 
motor using formulas. Some of the data that is obtained will be compared with the standard values got from literature and meaningful statements are derived out of it and appropriate recommendations are given. The report will also provide maintenance cost information and facilitate tracking of the motor test history. 


\subsection{Model Development}

\subsection{Introduction to Microsoft Access ${ }^{\circledR}$}

The TPM model for electrical motors is developed in Microsoft Access. Access is a database software provided by Microsoft. Microsoft Access is a powerful program to create and manage databases. It has many built in features to assist in constructing and viewing information. Access is much more involved and is a more genuine database application than other programs. The TPM model to be complete, not only needs a database, but also a user interface that is easy to use and navigate between sections. Although Access can be used as a powerful tool to build and manage databases, the user interface cannot be developed. So, VB script is the base language for Microsoft Access to be able to develop the several user interfaces incorporated in the model [38]. Access enables the creation of tables, forms and reports. A table is a collection of data about a specific topic. For the TPM model one large single table is created that has all the field value. Using a single table for all field values means that the data is stored only once, which makes the database more efficient, and reduces data-entry errors. A form is a graphical representation of a table. One can add, update, and delete records in the table by using a form. Although a form can be named different from a table, they both still manipulate the same information and the same exact data. Hence, if a record is changed in a form, it will be changed in the table also. A form is very good to use when there are numerous fields in a table. This way one can see all the fields in one screen, whereas if it was in the table view (datasheet) one would have to keep scrolling to get the field desired. A report is an effective way to present the data in a printed format. Since the size and appearance of everything on the report can be controlled, the information can be displayed in the way one wants to see it.

\subsection{Why Access $®$ ?}

Access comes bundled in Microsoft Office tools, so no separate installation of the software is required. Access is noted for its friendly user interface and ease of use. It is great for working on small to medium size applications [38]. Also it can be used to build 
both database and user interface. One does not have to build database and user interfaces as separate entities and then link them up, they can be built using the same software. All required calculations using formulas, comparisons between data, various other logical and mathematical analyses can be done using VB Scripting that is incorporated within Access. Because of all these advantages, it is decided to build the model using Microsoft Access.

\subsection{Design of the Model}

In the design phase of the total predictive maintenance model, initially all the data required for all the tests were gathered and a master table was built with all these as separate columns, also called as field values. For each field value, a decision was made whether to use a text box or a combo box. Combo boxes were used for the ones whose values would be provided in drop down menu. For the rest text boxes were used. Along with the master table, few smaller tables were created where required. For each field value the type was decided as either character or a number, again for number, integer, double, etc were specified and required size was determined.

After designing the tables for the model, user interfaces were designed. The user interfaces built in Access are called as forms. The model has one main form separated by tabs for different tests. The general information tab has text boxes and combo boxes to get inputs from the user. There is also a search combo button to search for any record and update/modify the record. The model is designed to have grouping of controls to physically create a border for controls of common information. In the instruments tab, check boxes are used to select the available instruments. Object linking functionality is used to display the price and other information related to the test instruments. Command buttons are used to get efficiency, frequency of starts and stops, bearing lubrication information etc. The model is designed to include record navigational buttons to move between records like first record, previous record, next record and last record. Also have command buttons for entering new record, deleting existing record, save and update record and exit button. These buttons are not inside the Tabs but in the form container. So these buttons can be used from any of the Tabs. Utmost importance is given to easy navigation; the user can navigate using the 
background form or the menu bar to any report or forms. The model is designed in such a way as to follow a systematic data flow. There is no redundancy in data capture.

The querying feature of Access is also used in building the model. The model is designed to use MS Access report designer for all the reports. Have used many formatting options to make the reports look professional. While designing the maintenance cost estimation report, different line tools are used to obtain the report in tabular format.

\subsection{Inputs}

The inputs section includes all the interfaces built for the user to be able to provide the necessary information. The user is required to provide the general information including user and plant information, basic motor information, check the available instruments and provide the applicable predictive motor test input values obtained either by measuring using the instruments or from the details on the nameplate.

\subsubsection{Main Content Form}

When the user opens the Access file by double clicking on it, the main content form is displayed. The opening form has three tabs on it. The first button will take the user to a form that has sections related to general information, motor information, predictive tests information, efficiency and effective service factor calculations, frequency of starts and stops of motor and bearing lubrication. The "Reports" button will take the user to another form from where all the generated reports can be accessed. The "Exit" button will close the program completely. Figure 4.1 shows the main content form.

\subsubsection{Plant, Motor and Tests Information}

Clicking on the "Plants, Motor \& Tests Entry" button on the main content sheet will take the user to a form that has several tabs on the top of the screen. Each tab opens up a different form having text boxes enabling the user to input the appropriate 
data. When the cursor is placed on the label or within the text box, a message will be displayed to tell the user what kind of data has to be provided and how the data must be obtained. The user can use either the keyboard arrow keys with enter button, or the mouse to navigate through the various sections. Not all data in all sections is mandatory. It is a customized model that enables the user to input as much information as available.

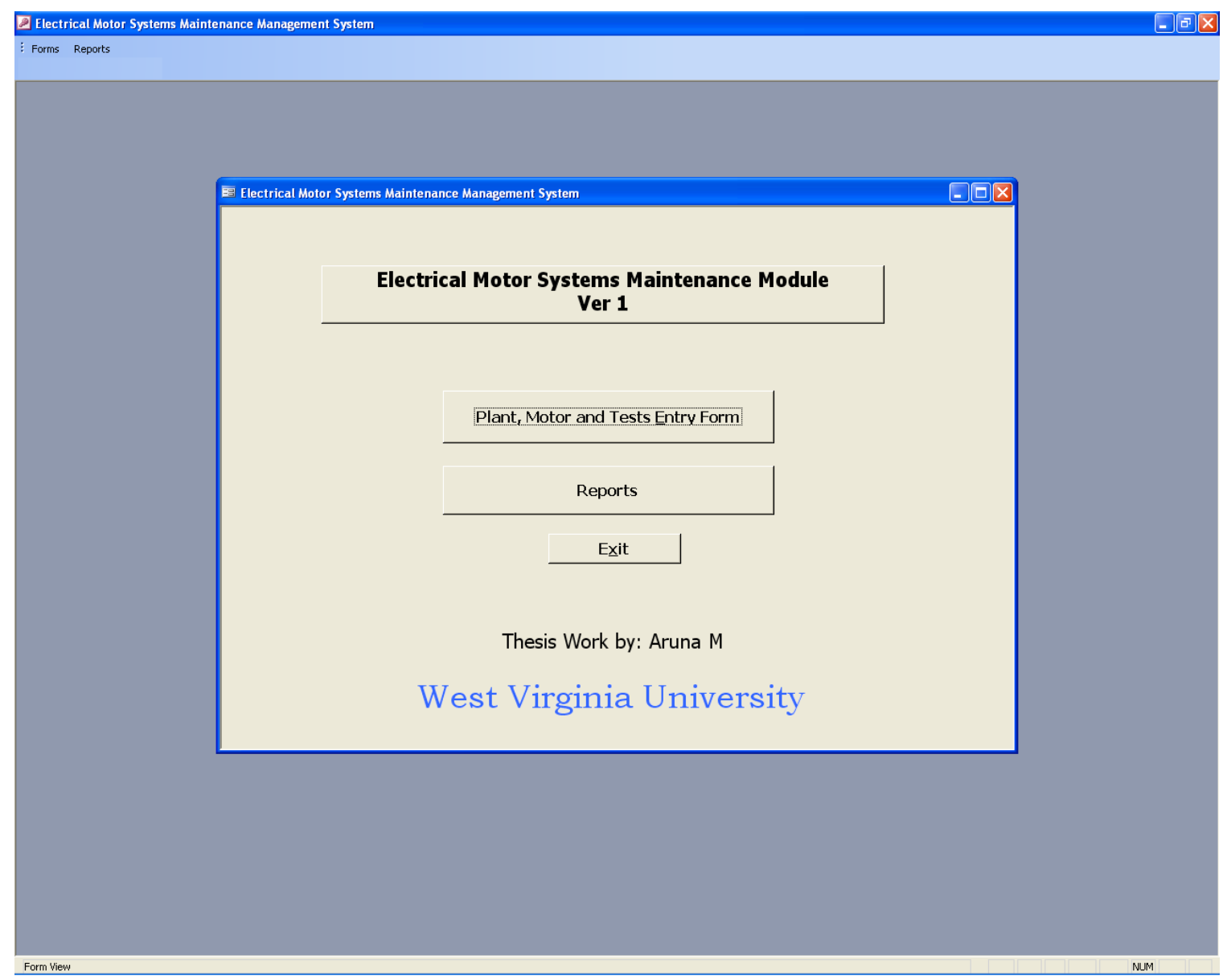

Figure 4.1: Main content form

\subsubsection{General Information}

General information form is divided into two sections. First section is for the user information and the second one for plant information. Under user information, user name and designation must be provided. And under plant information section, plant name, plant type (can be selected from the list of options available from the drop down menu, if none of them apply then 'other' may be chosen), product produced and plant profile (chosen from the drop down menu) must be input. Figure 4.2 shows the 
general information form. The general information form must be completed before moving to the other sections.

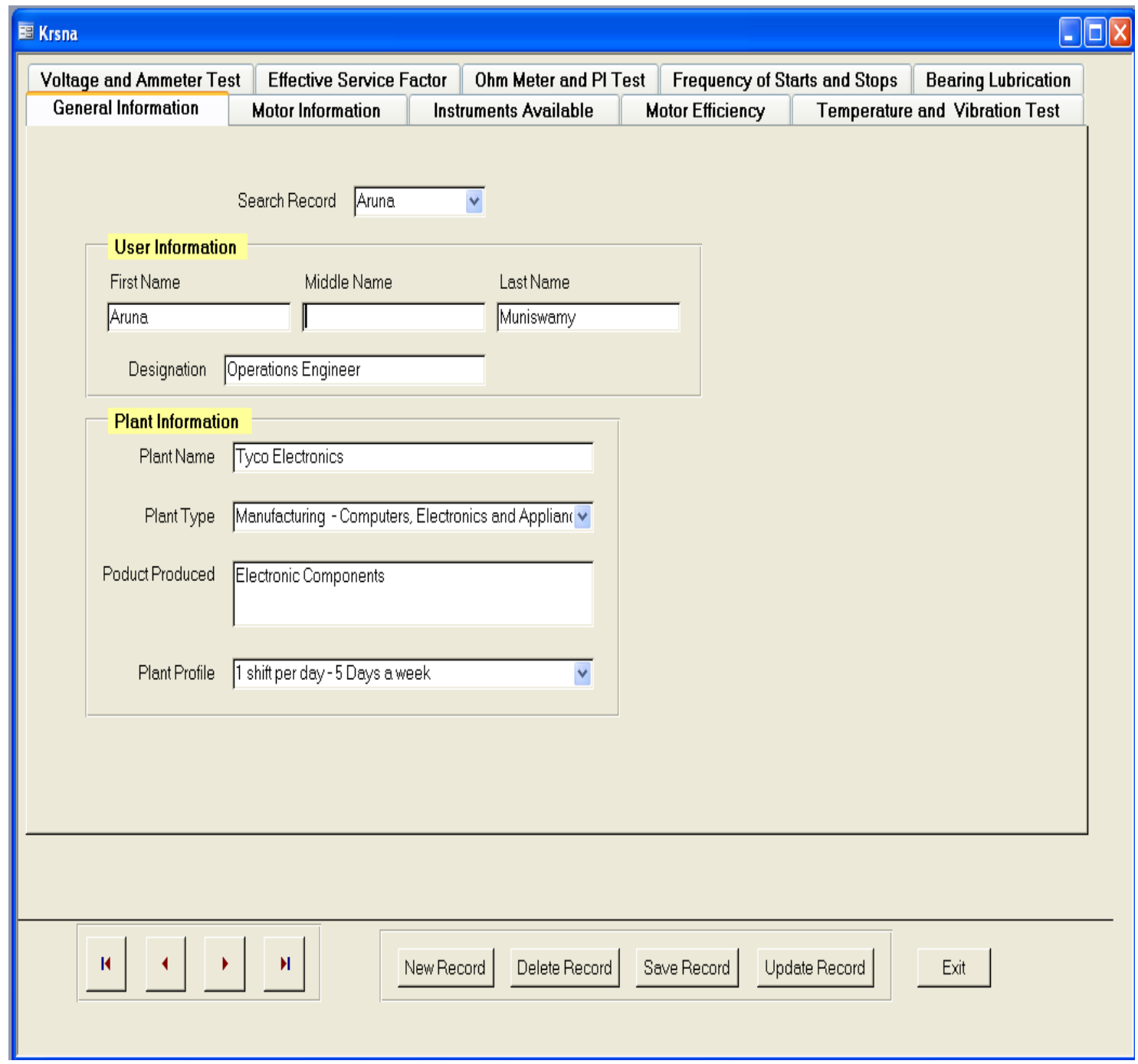

Figure 4.2: General Information Form

\subsubsection{Basic Motor Information}

This form requires the user to input some basic information about the motor. A unique name for the motor which can be used for its identification must be provided to the model. This is the name that will be used in searching for a particular motor. After the data is entered for a particular motor the first time, if additional information must be entered for the same motor subsequently, the motor name must be retained the same. The model will save the data under the same motor name, but based on the 
time and date of the data entry, it will keep them as separate records and track the motor history. The name of the motor can have text or/and numbers. Motor size must be entered in horse power (hp). The age of the motor must be entered in months. The design life of the motor must be obtained from the nameplate and entered in years. The labor cost incurred for the maintenance of motor must be entered in $\$ / \mathrm{hr}$. This cost information will be used in the periodic and predictive maintenance cost calculations.

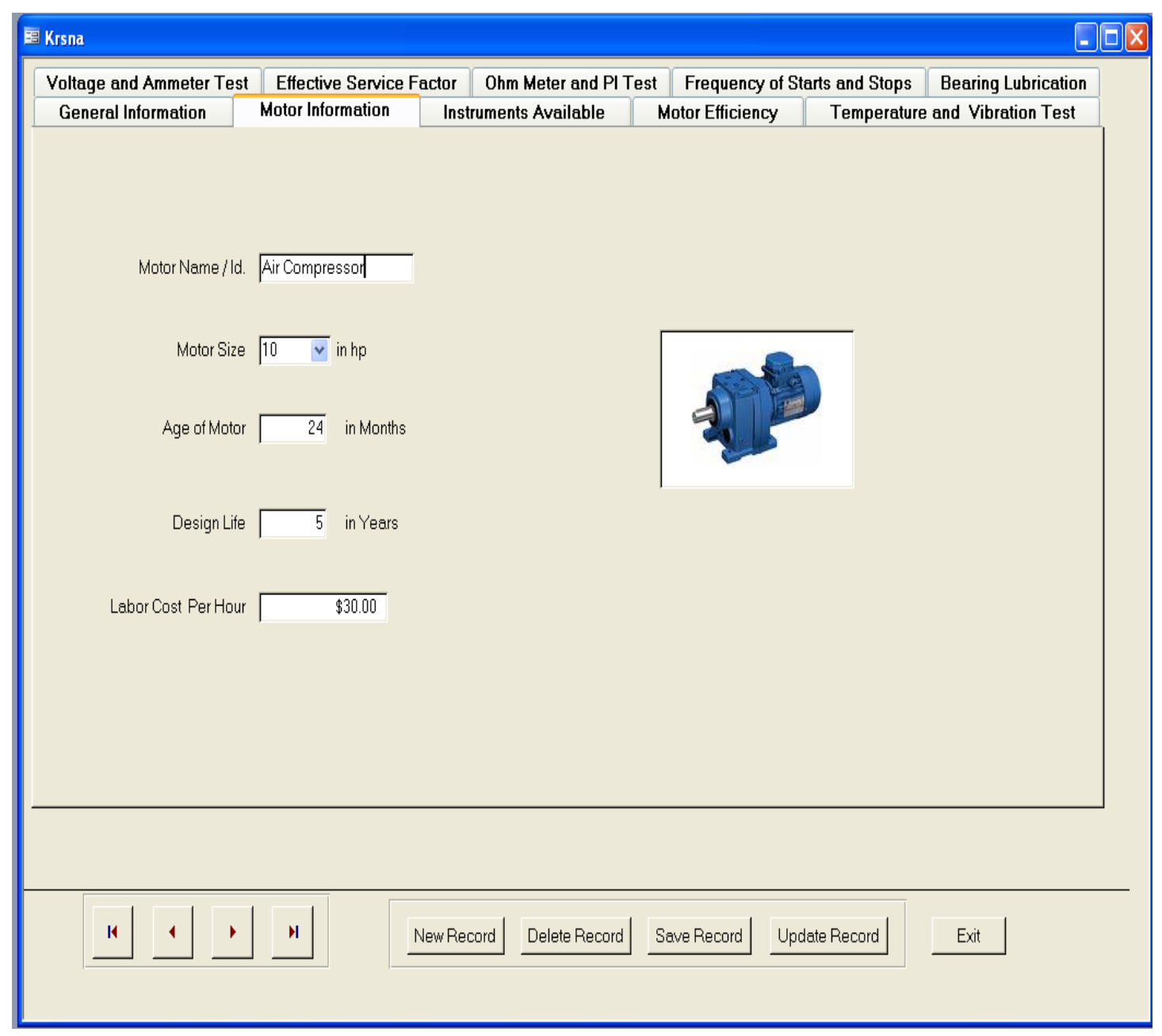

Figure 4.3: Basic Motor Information

\subsubsection{Available Instruments}

This section lists all the instruments required to conduct the motor maintenance testing. A table is provided alongside that provides information on price of the instrument, type of the test (destructive/non-destructive), experience required to carry out the test and type of personnel required to conduct the test. The price of the 
instruments listed is based on the current market price. The user can anytime click on the table and the table will let the user update the instrument price details. If the facility has access to all instruments listed, "Select All Instruments" button may be checked. Otherwise, the user may select only those instruments that are available. Based on the instruments selected, only those tests that can be conducted with available instruments will be enabled. All other sections will be disabled.

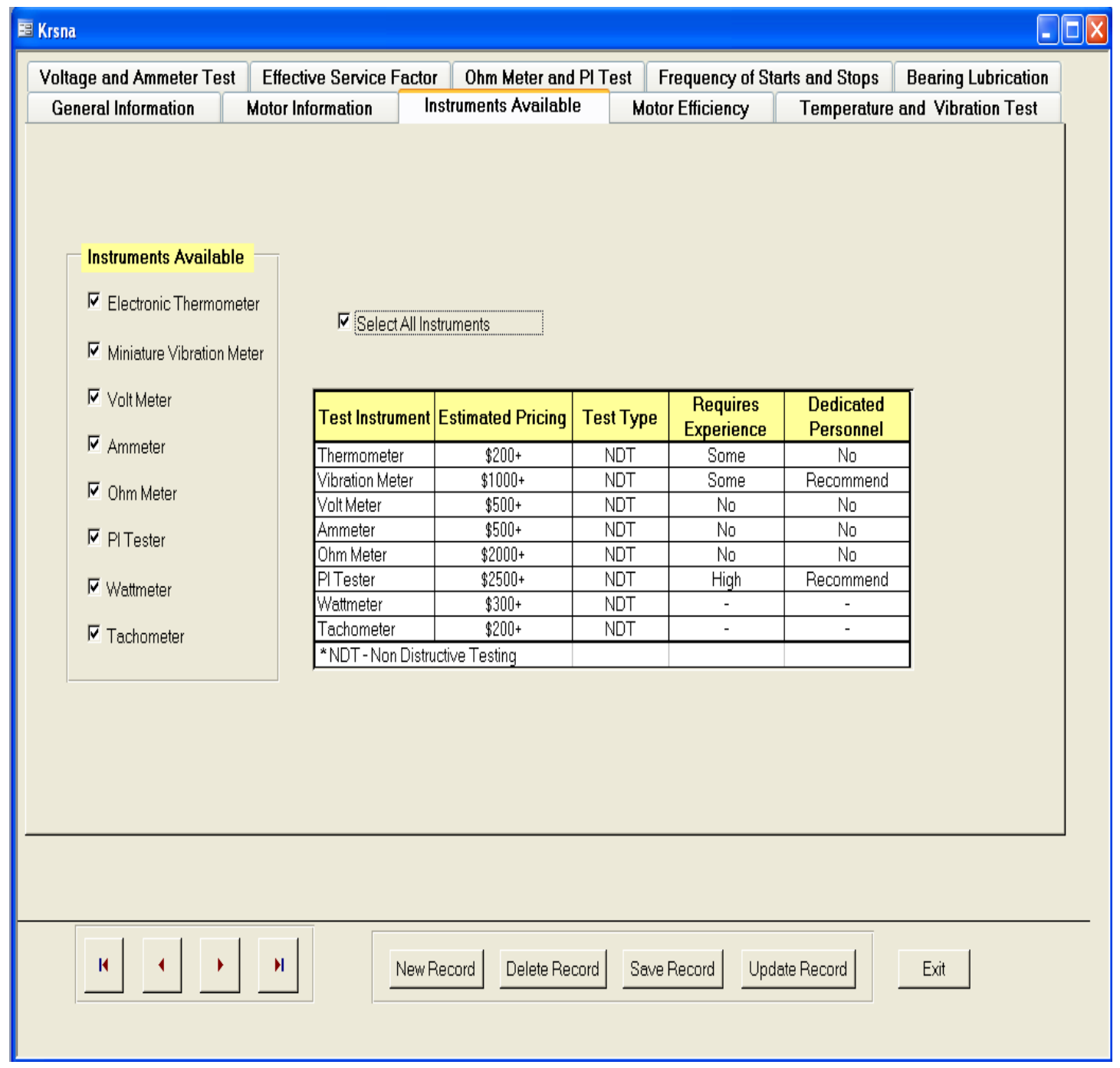

Figure 4.4: Instrument Checklist Form

\subsubsection{Motor Efficiency}

The user is required to enter the rated speed at no load and full load in rpm from the nameplate, speed in rpm and power in $\mathrm{kW}$ measured using a tachometer and wattmeter. With these, the efficiency of the motor calculated by the model can be 
viewed clicking on the "Click here to find efficiency" button. The efficiency will also be included in the detailed report that will be generated after all the data is enterd and the record is saved.

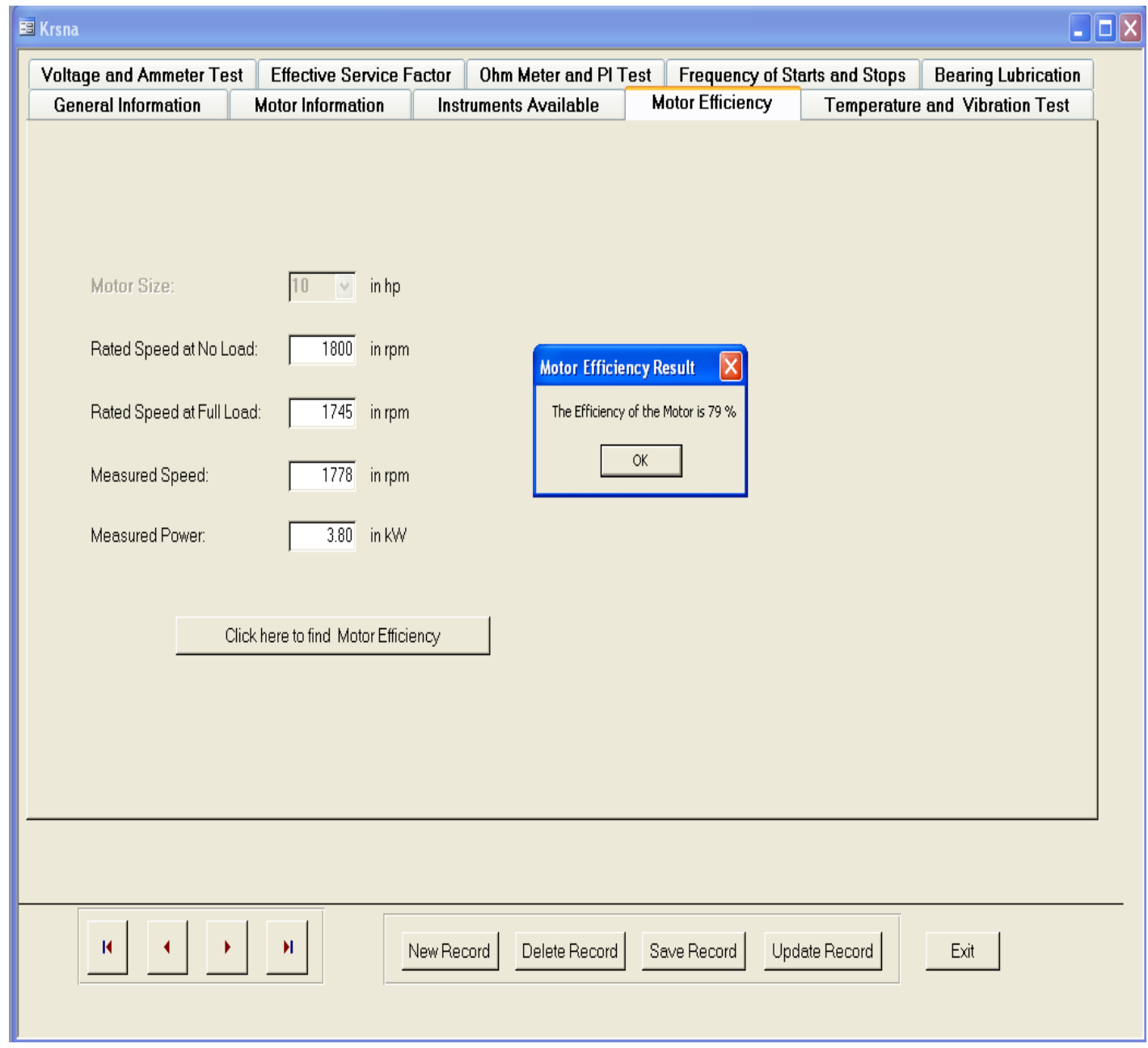

Figure 4.5: Motor Efficiency Form

\subsubsection{Temperature Tests}

Temperature test has two sections. One is for insulation temperature testing and the other for bearing temperature testing. Ambient temperature and insulation temperature must be entered in ${ }^{\circ} \mathrm{F}$ along with selecting the insulation class from the dropdown menu. For bearing temperature testing, temperature at the middle of the motor and temperature at the bearing location must be measured using an electronic thermometer and entered in ${ }^{\circ} \mathrm{F}$. Figure 4.6 shows the temperature tests form. 


\subsubsection{Vibration Test}

There are three text boxes provided to enter the three vibration readings measured at three different locations on the surface of the motor in inches per second using a vibration meter. Figure 4.6 shows the vibration test form.

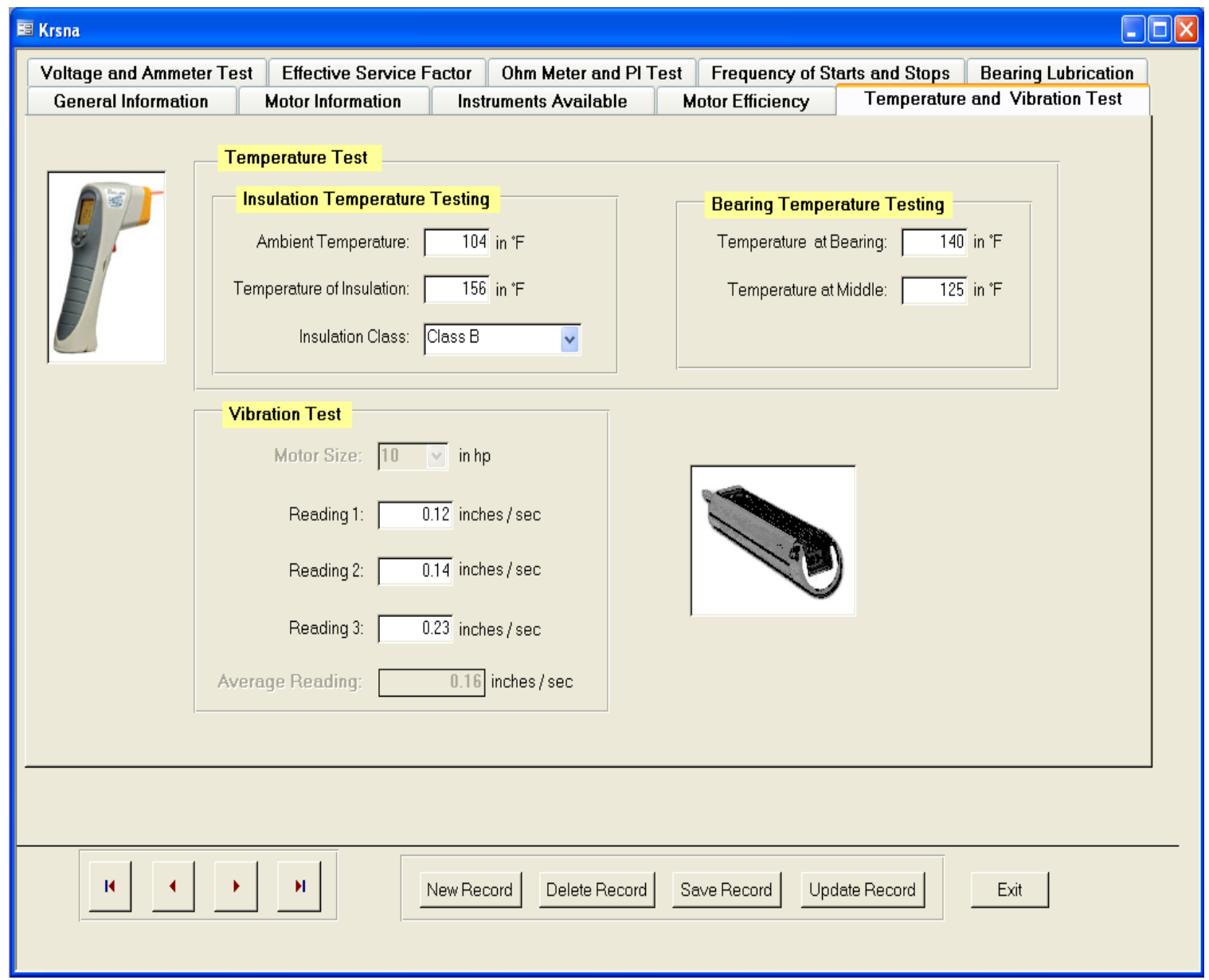

Figure 4.6: Temperature and Vibration Test Form

\subsubsection{Voltage Unbalance Test}

Voltage of the three phases of the motor is measured in volts using a voltmeter and entered in the three text boxes provided. Using this, the average voltage and the $\%$ voltage unbalance will be calculated and displayed. Figure 4.7 shows the voltage unbalance test form. 


\subsubsection{Current Unbalance Test}

Current at the three phases of the motor is measured in amps using an ammeter and entered in the three text boxes provided. Using this, the average current and the $\%$ current unbalance will be calculated and displayed. Figure 4.7 shows the current unbalance test form.

\subsubsection{9 \% Load Test}

The user must input the nameplate voltage and current, the model will take the average voltage and current readings from the $\%$ voltage unbalance test and $\%$ current unbalance test and display the calculated \% load.

\subsubsection{Locked Rotor Current Test}

The user must select the appropriate $\mathrm{kVA} / \mathrm{hp}$ code, motor phase and voltage from the built in drop down menu list. The locked rotor current that is calculated by the model using formula and interacting with the database will be displayed. 


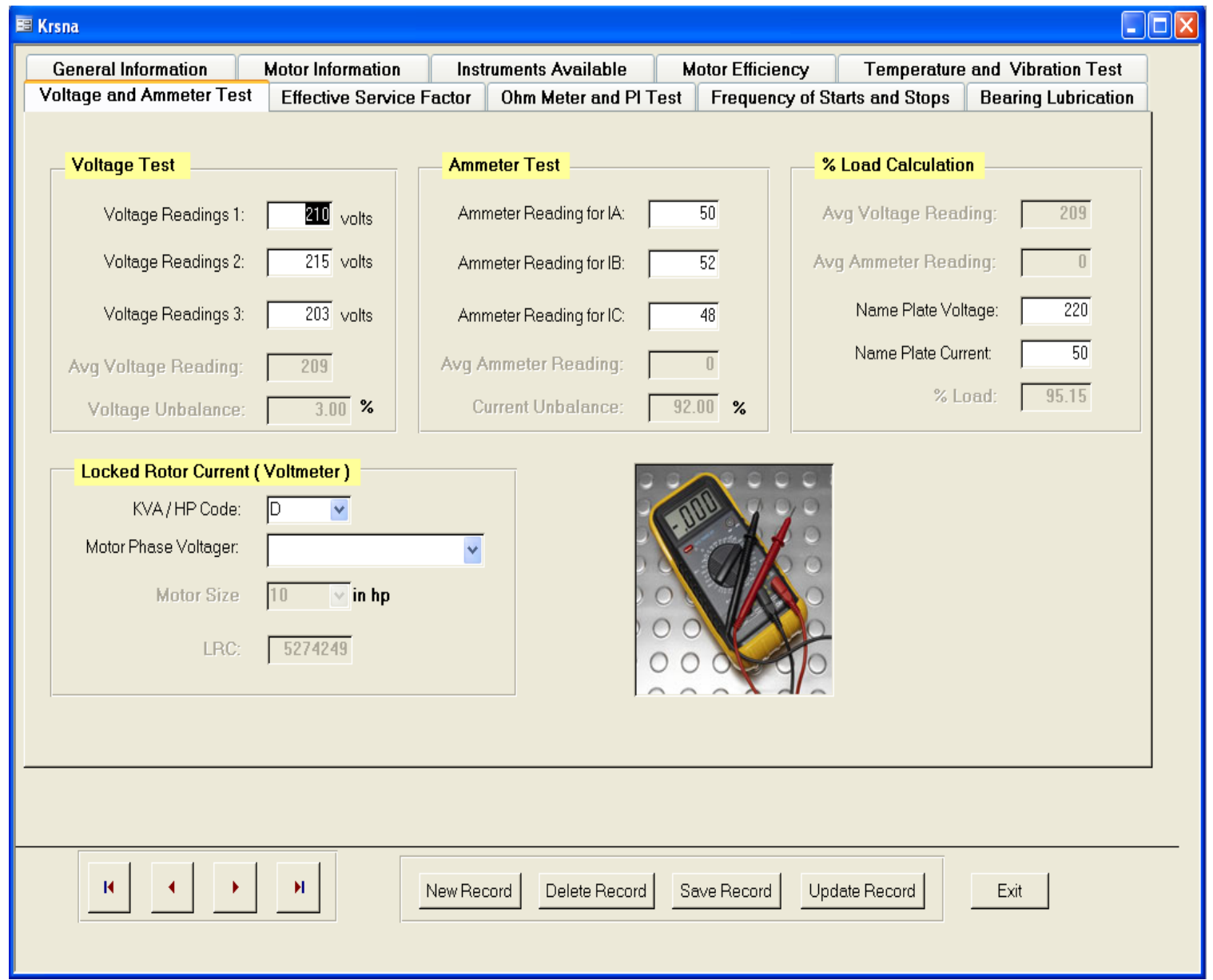

Figure 4.7: Voltage, Ammeter, \% Load and Locked Rotor Current Test Form

\subsubsection{Effective Service Factor Test}

There is no specific input data required for calculating the effective service factor. The percentage load and percentage voltage unbalance are taken from the previous tests and used to calculate the effective service factor. 


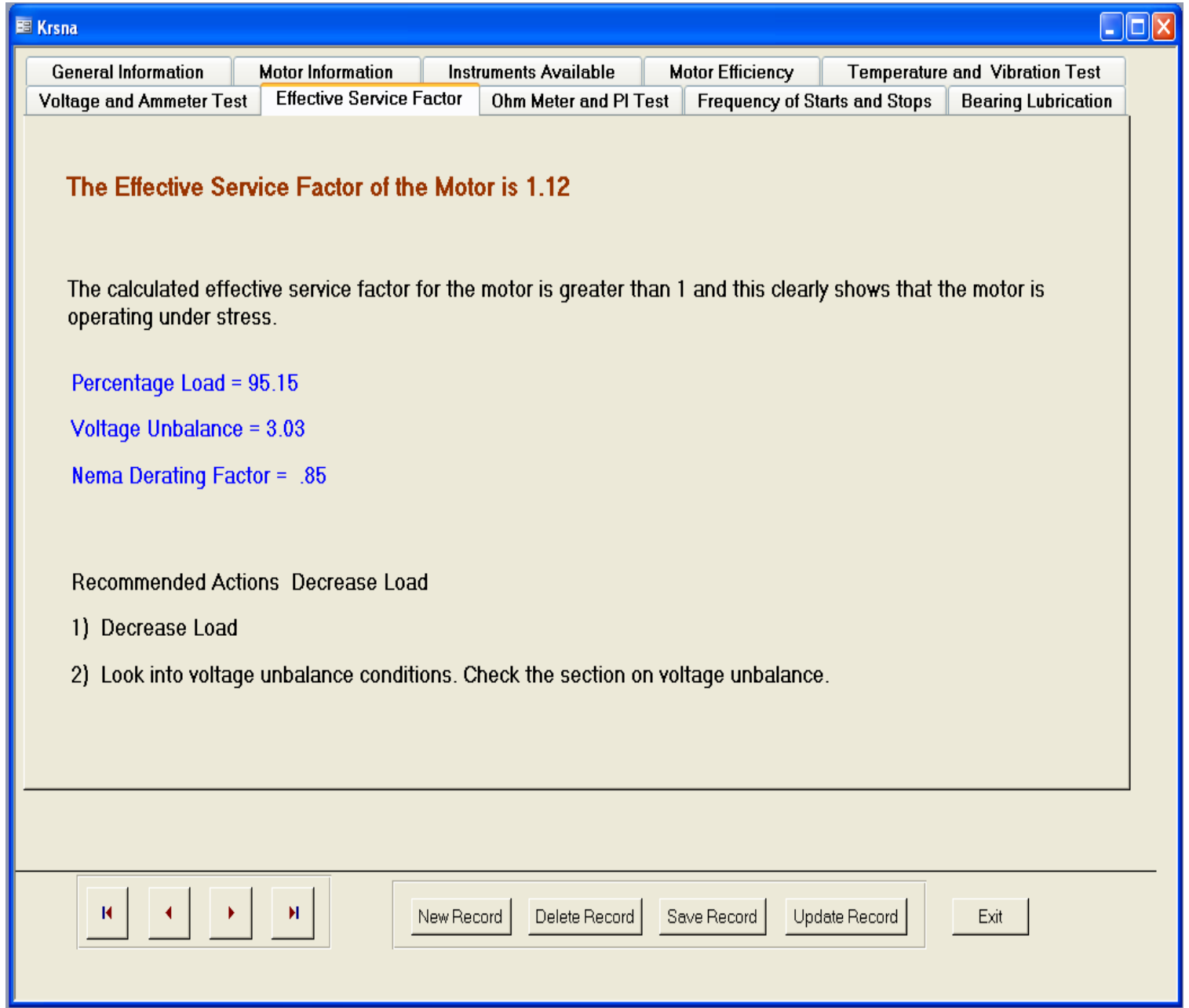

Figure 4.8: Effective Service Factor Form

\subsubsection{Ohm Meter Test}

Both short to ground test and open/short in windings test are included under this category. The user must measure the resistance in ohms using the ohm meter at each of the three phases and enter them in the spaces provided. Based on the values obtained, the model will compare and analyze the data with the standard data and give appropriate messages with recommendations in the report.

\subsubsection{PI Test}

Based on the size of the motor, input in the basic motor information, either the polarization index test or the dielectric absorption test will be enabled. For motor size that is greater than $200 \mathrm{HP}$, enter IR reading measured at the insulation using a PI 
tester at 1 minute and 10 minutes. For a motor size that is less than or equal to 200 $\mathrm{HP}$, enter IR reading measured at the insulation using a PI tester at 30 seconds and 3 minutes.

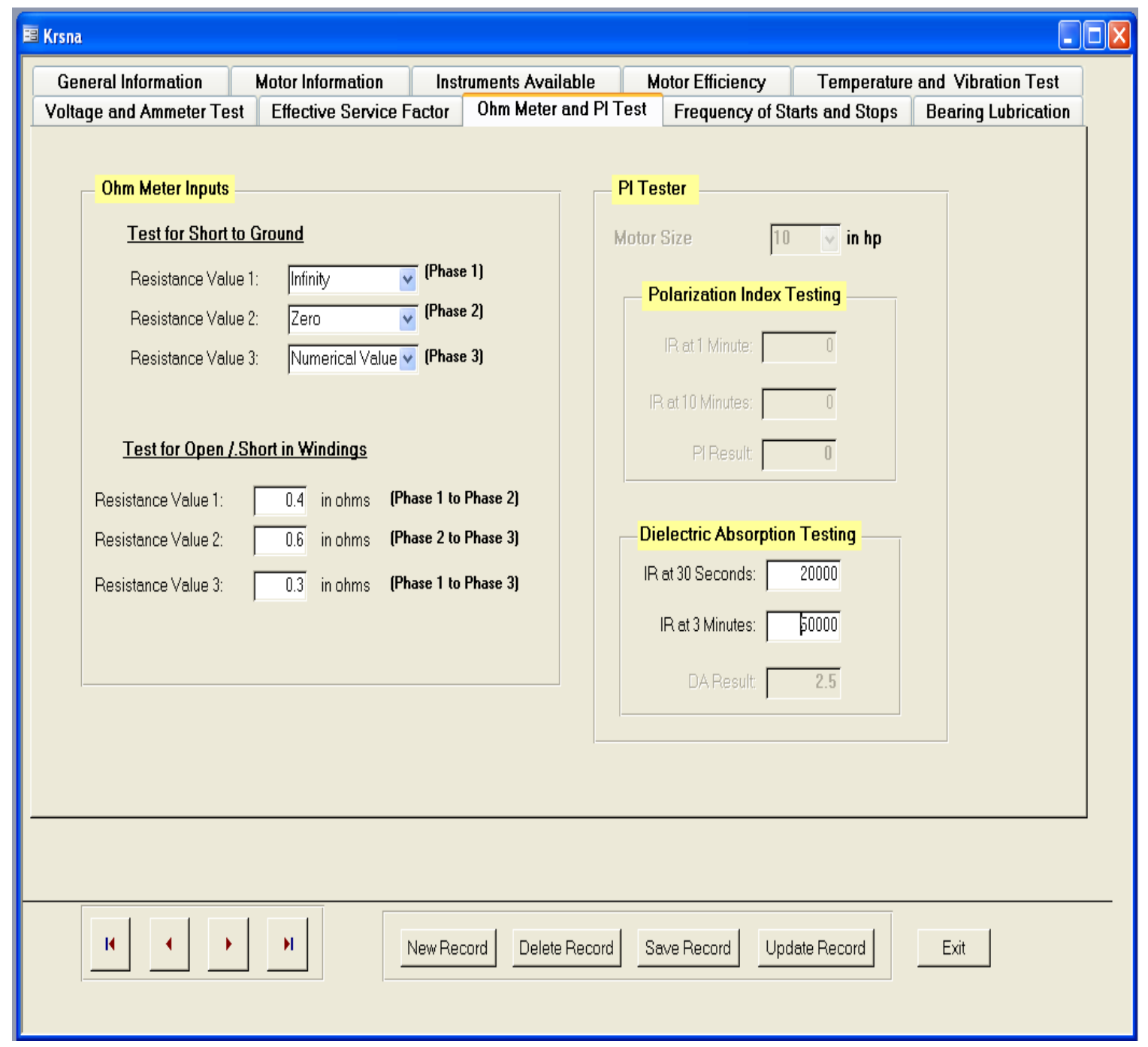

Figure 4.9: Ohm meter test and polarization index test form

\subsubsection{Frequency of Starts \& Stops}

To know the limited number of starts allowed and the rest time to be given between two starts for a motor, the user must find the number of poles in a motor and input it selecting from the list in drop down menu. After selecting the number of poles, the button below "Click here to find the frequency of starts and stops" can be hit for the result to be displayed. The result will also be displayed in the printable report. 


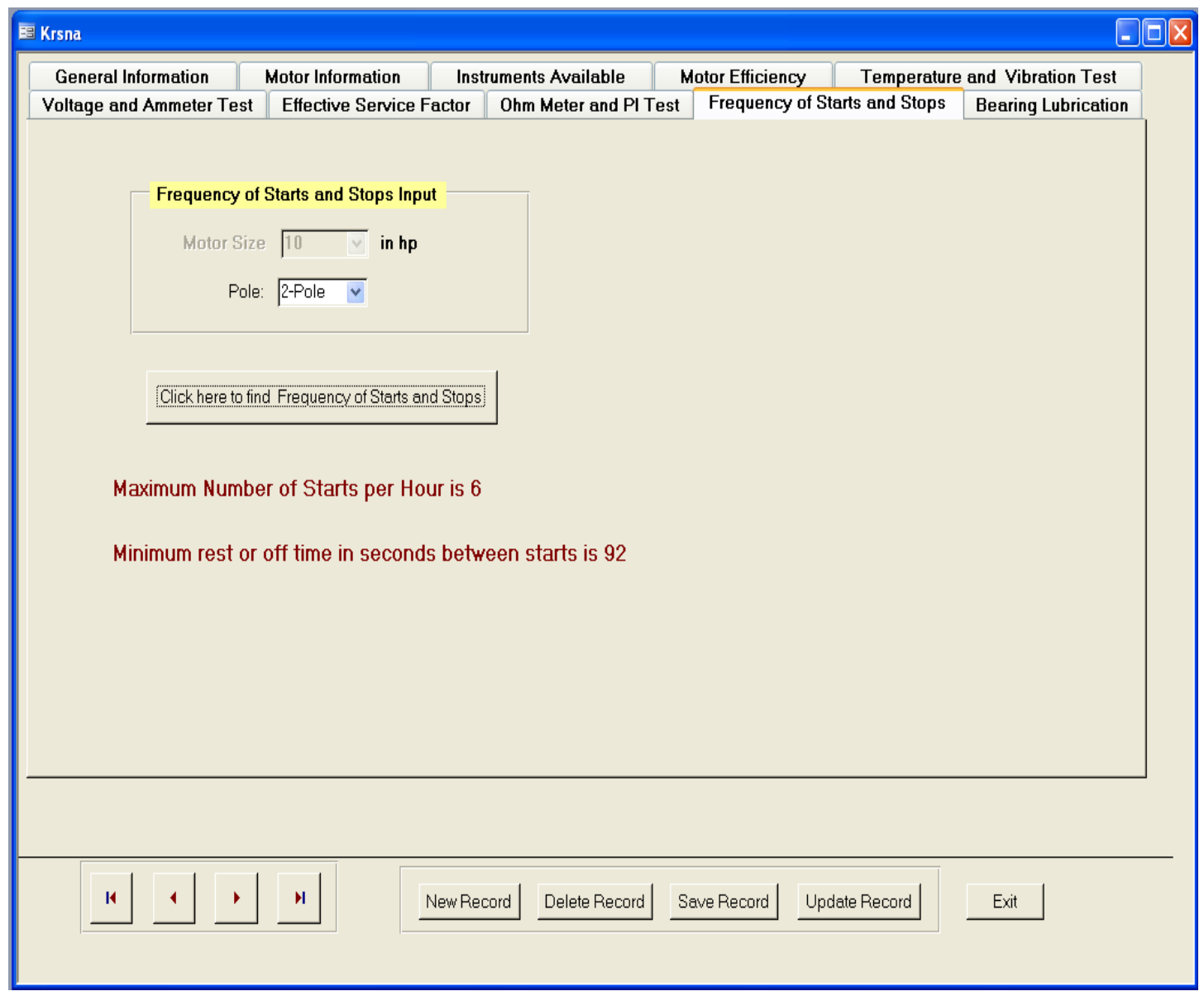

Figure 4.10: Frequency of Starts \& Stops Form

\subsubsection{Bearing Lubrication}

This form has two sections, one for giving the quantity of bearing lubricant and the other for frequency of bearing lubrication. For the model to give the amount of bearing lubricant, one has to select the right bearing number from the built in drop down menu list. This can be found on the nameplate. The user must also specify the material used for lubricating the bearing. It could be either oil or grease. If the material selected is grease, then the amount is displayed in cubic inches and if it is oil, then the quantity is given in number of teaspoons.

To get the information on how often the bearing has to be lubricated, the user must enter the rated speed of the motor in RPM, motor frame number from the nameplate and select how many hours the motor runs in a day. Depending on the rated speed of the motor, the list of motor frames will accordingly change and the user may pick the one that is appropriate. 


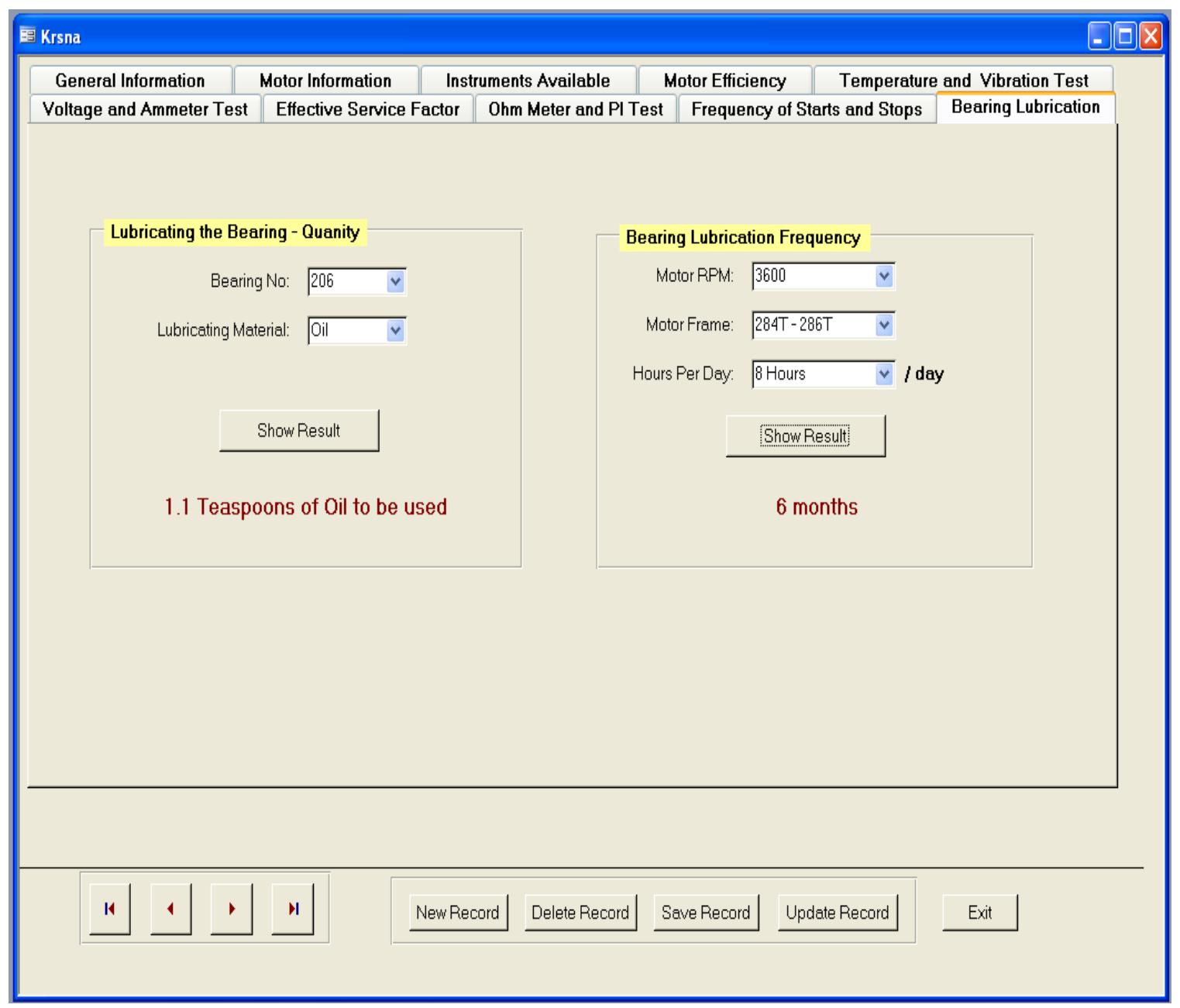

Figure 4.11: Bearing Lubrication Form

\subsection{Data Processing}

Program was developed in VB Script to process the data. The program facilitates the calculation of parameters using formulas and making logical comparisons between the data input by the user and the standard data saved in the database. The program makes the generation of appropriate results for every test practical. The program is the link between user interface at the front end and the database at the back end. The program also enables various other features of the model like, adding a new record, deleting a record, modifying or updating a record and saving a record. 
It is in the programming part of the model building where the conditions are specified as to the enabling and disabling of selective sections of the model based on the instruments selected. The program developed is included in Appendix I.

The database has one major table with about 108 columns. There are few smaller tables with their respective column field values. Tables listed in Appendix II shows the tables' columns used in the database of the model.

\subsection{Output}

To view the output of the model, the user must click on the Reports button on the main content sheet. This will take one to the reports form that has several buttons. Upon clicking once, the first button gives a brief general information, set of periodic recommendations, motor efficiency and the results for all the predictive tests for which the values were available. The Maintenance cost report will display the periodic annual maintenance cost information and the predictive maintenance cost in tabular format.

The section under motor test history has several buttons, one for each predictive motor test. When clicked on any of these, they will give all the previous test data pertaining to that test till date. Figure 4.12 shows the main report form. A sample report will be included in the next chapter for an example used for validation of test results.

\subsection{Conclusion}

This chapter includes a brief description about Microsoft Access. It explains the reason for preferring to build the model using Access over other software. The chapter covers the inputs to the model, processing of the data, program developed to develop the model and outputs obtained from the model. The tables used in the database as an integral part of model building is also a part of this chapter. 


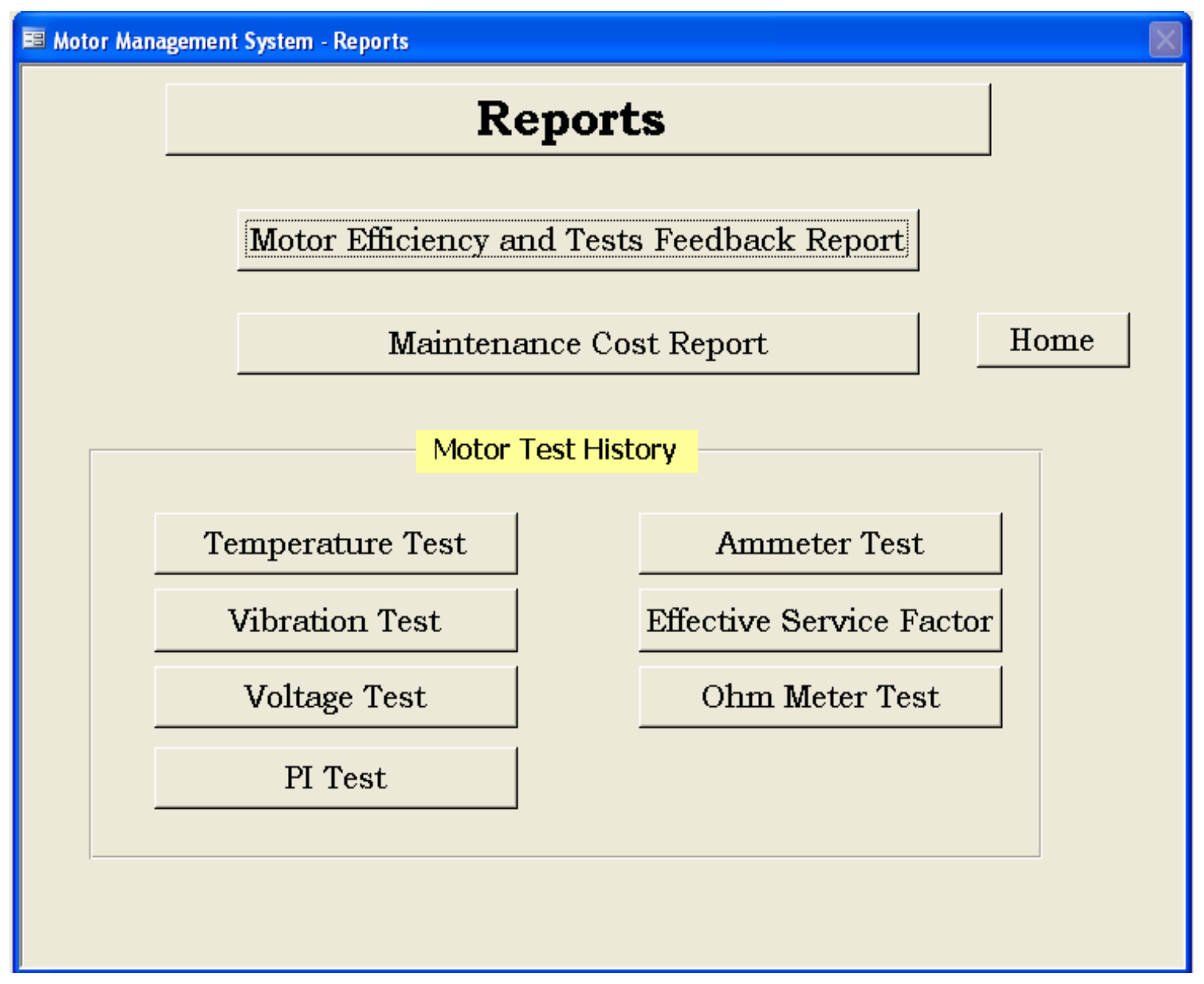

Figure 4.12: Main Report Form 


\subsection{System Implementation}

\subsection{Validation Example}

An example of a motor of size $10 \mathrm{hp}$ is considered for validating the results of the tests. All the calculations, comparisons and conclusions are done manually. The same values are input into the TPM model developed and the report generated by the model is printed. The manual results are compared with the results from the model. If both of them match, then it may be concluded that the model is efficient in producing right results.

1) Motor Information

Motor ID: Air Compressor

Motor Size: $10 \mathrm{hp}$

Age of motor: 24 months

Labor Cost: $\$ 30 / \mathrm{hr}$

2) Motor Efficiency

Rated speed at no load: $1800 \mathrm{rpm}$

Rated speed at full load: $1745 \mathrm{rpm}$

Measured speed: $1778 \mathrm{rpm}$

Measured power: $3.8 \mathrm{Kw}$

$$
\begin{gathered}
\% \text { Full Load }=\frac{\text { (Rated speed at noload }- \text { Measuredspeed })}{\text { (Rated speed at noload }- \text { Rated speed at full load }} \\
\% \text { Full load }=\frac{(800-1778}{(800-1745}- \\
\% \text { Fullload }=0.4
\end{gathered}
$$

Actual hp output $=\%$ of full load $\mathrm{x}$ size of motor

$$
\begin{aligned}
& =0.4 \times 10 \\
& =4 \mathrm{hp}
\end{aligned}
$$


Efficiency $=($ actual hp output $\times 0.746 \mathrm{~kW} / \mathrm{hp})$

Measured power in $\mathrm{kW}$

$=(4 \mathrm{hp} \times 0.746 \mathrm{~kW} / \mathrm{hp})$

$3.8 \mathrm{~kW}$

$=78.53 \%$

Efficiency $\sim 79 \%$

3) Insulation temperature testing

Ambient temperature: $104{ }^{\circ} \mathrm{F}$

Insulation temperature: $156{ }^{\circ} \mathrm{F}$

Insulation class: $\mathrm{B}$

For insulation class B and an ambient temperature of $104^{\circ} \mathrm{F}$, the limited observable temperature is $154{ }^{\circ} \mathrm{F}$. Since the measured insulation temperature is $156^{\circ} \mathrm{F}$ and this is slightly greater than limited observable temperature. The insulation may be somewhat overheated, if left unattended, it may get worse. Along with this message the recommended actions will be displayed.

4) Bearing temperature testing

Temperature at bearing location $\mathrm{T}_{\mathrm{B}}: 140{ }^{\circ} \mathrm{F}$

Temperature at the middle of motor $\mathrm{T}_{\mathrm{M}}: 125^{\circ} \mathrm{F}$

It is clear that $\mathrm{T}_{\mathrm{B}}$ is greater than $\mathrm{T}_{\mathrm{M}}$ and the difference is more than $10{ }^{\circ} \mathrm{F}$. Therefore the bearing location is hotter than the middle of the motor, there seems to be a problem with the bearing, the recommended actions must be followed.

5) Vibration test

Vibration Reading 1 (R1): 0.12

Vibration Reading 2 (R2): 0.14

Vibration Reading 3 (R3): 0.23

Average Vibration Reading $=(\mathrm{R} 1+\mathrm{R} 2+\mathrm{R} 3)$ 
This reading when compared to the standard range of values saved in database, the motor is in unacceptable condition and the recommended actions need to be practiced.

6) Voltage Unbalance Test

Voltage of Phase 1: 210 volts

Voltage of Phase 2: 215 volts

Voltage of Phase 3: 203 volts

Average Voltage $=209.33$ volts

Maximum deviation from average voltage $=209.33-203=6.33$

$\%$ Unbalance $=100 * 6.33 / 209.33=3.02$

So, there is $3 \%$ voltage unbalance.

7) Current Unbalance Test

Current in Phase 1: $50 \mathrm{~A}$

Current in Phase 2: $52 \mathrm{~A}$

Current in Phase 3: 48 A

Average Current $=50 \mathrm{~A}$

Maximum deviation from average voltage $=52-50=2$

$\%$ Unbalance $=100 * 2 / 50=4$

So, there is $4 \%$ current unbalance.

8) Locked Rotor Current Test

$\mathrm{kVA} / \mathrm{hp}$ code: $\mathrm{D}$

Motor phase \& voltage: $3 \phi 220$ volts

For the selected $\mathrm{kVA} / \mathrm{hp}$ code, the value from the table saved in the database and to be considered for calculating locked rotor current is 4.5 . For a $3 \phi 220$ volts motor of size $10 \mathrm{hp}$, the standard locked rotor current permissible is 150 .

$$
\begin{aligned}
\text { LRCcalc } & =\frac{1000 \times h p \times k \text { VA } / h p}{\sqrt{3} \times \text { Volts }} \\
& =168 .
\end{aligned}
$$


The LRC calc is greater than LRC std and this indicates that there could be a problem with rotor bar or stator winding.

9) $\%$ Load Test

Nameplate voltage: $220 \mathrm{~V}$

Nameplate current: $50 \mathrm{~A}$

Average voltage from voltage test is $209.33 \mathrm{~V}$ and average current from current unbalance test is $50 \mathrm{~A}$.

$$
\begin{aligned}
\% \text { Load } & =\left(\frac{V_{\text {ave }}}{V_{n}}\right) \times\left(\frac{V_{\text {ave }}}{A_{n}}\right) \times 100 \% \\
& =0.9515 \times 1 \times 100 \\
& =95.15
\end{aligned}
$$

The motor is $\sim 95 \%$ loaded. If the load is kept within $90 \%$, the motor life will be prolonged and the motor will run smoothly.

\section{0) Short to Ground Test}

Resistance in phase 1: Infinite

Resistance in phase 2: Zero

Resistance in phase 3: Numerical Value

Analyzing the above data with the standard data listed in chapter 3, we can conclude that there seems to be no short in phase 1 and it is likely that there could be a short in phase 2 and phase 3 .

\section{1) Open/Short in Windings Test}

Resistance Phase1 - Phase2: 0.4

Resistance Phase2 - Phase3: 0.6

Resistance Phase 3 - Phase1: 0.3

All the resistance readings are within range and therefore there is no short or open in the windings, the windings are in good condition. And looking at LRC test and open/short in windings test, one can conclude the problem is with rotor bar and not with stator windings. 
12) Polarization Index Test

Since the motor size is less than $10 \mathrm{hp}$, it is appropriate that we do dielectric absorption test and not polarization test. So, the model will enable DA test section and disable PI test.

Dielectric Absorption Test

IR at 30 sec: 20,000

IR at 3 min: 50,000

DA index $=20,000 / 50,000$

$$
=0.4
$$

DA index is less than 2 and this is a low polarization index value, this indicates that the insulation is brittle.

13) Frequency of starts and stops

Number of poles: 4

For a $10 \mathrm{hp}$ motor having 4 poles, referring the data given in chapter 3 , it can be said that the maximum number of starts allowed per hour is 13 and minimum rest time that has to be given in between is 46 seconds.

14) Bearing Lubrication

- Lubricant Quantity

Bearing Number: 206

Lubricating Material: Grease

Referring data obtained from literature and tabulated in chapter 3 , the amount of lubricant to be used for a bearing numbered 206 is 0.34 cubic inches.

- Lubrication Frequency

Motor RPM: 1800

Motor Frame: 404T - 449T

Motor hours/day -8

For the above details, the bearing must be lubricated every 6 months.

15) Maintenance Cost Calculations 
Periodic Maintenance Cost

\begin{tabular}{|l|l|l|}
\hline \multicolumn{1}{|c|}{ Maintenance Activity } & Frequency & \multicolumn{1}{c|}{ Cost (\$) } \\
\hline Clean the external surface of the motor & every 2 weeks & $\begin{array}{l}(6.5 \mathrm{hrs} \text { * } \\
\$ 30 / \mathrm{hr}) 195\end{array}$ \\
\hline Clean the internal parts of the motor & every 2 months & 360 \\
\hline Replace the lubricant & every 6 months & 180 \\
\hline Monitor lubricant condition & every 2 months & 45 \\
\hline Check for mounting / base rigidity & every 2 months & 45 \\
\hline Check for coupling alignment & every 2 months & 45 \\
\hline Check for shaft alignment & every 2 months & 45 \\
\hline $\begin{array}{l}\text { Check for belt and pulley tension, wear, positioning, slip } \\
\text { etc }\end{array}$ & every 2 months & 45 \\
\hline Check for audible noise & every 2 weeks & 130 \\
\hline \multicolumn{2}{|l|}{} & 1090 \\
\hline Total Annual Periodic Maintenance Cost & & \\
\hline
\end{tabular}

So, the total annual periodic maintenance cost come to $\$ 1090$.

Predictive Maintenance Cost

\begin{tabular}{|l|l|l|l|l|}
\hline \multicolumn{1}{|c|}{ Test } & $\begin{array}{c}\text { Time } \\
\text { Required } \\
(\mathbf{m i n})\end{array}$ & $\begin{array}{c}\text { Capital } \\
\text { Cost } \\
(\mathbf{C C})\end{array}$ & \multicolumn{1}{|c|}{$\begin{array}{c}\text { Labor Cost } \\
(\text { LC) } \$\end{array}$} & \multicolumn{1}{|c|}{$\begin{array}{c}\text { Total } \\
\text { cost } \$\end{array}$} \\
\hline Insulation temperature testing & $15 \mathrm{~min}$ & $\$ 200$ & $\begin{array}{l}\left(0.25 \mathrm{hrs}{ }^{*}\right. \\
\$ 30 / \mathrm{hr}) 7.5\end{array}$ & 207.5 \\
\hline Bearing temperature testing & $10 \mathrm{~min}$ & $\$ 200$ & 5 & 205 \\
\hline Vibration test & $10 \mathrm{~min}$ & $\$ 1,000$ & 5 & 1005 \\
\hline Voltage test & $15 \mathrm{~min}$ & $\$ 500$ & 7.5 & 507.5 \\
\hline Ammeter test & $15 \mathrm{~min}$ & $\$ 500$ & 7.5 & 507.5 \\
\hline \% Load calculation & $30 \mathrm{~min}$ & $\$ 1,000$ & 15 & 1015 \\
\hline Locked Rotor Current & $10 \mathrm{~min}$ & $\$ 0$ & 5 & 5 \\
\hline Test for short to ground & $15 \mathrm{~min}$ & $\$ 2,000$ & 7.5 & 2007.5 \\
\hline Test for open/short in windings & $15 \mathrm{~min}$ & $\$ 2,000$ & 7.5 & 2007.5 \\
\hline PI Test & $20 \mathrm{~min}$ & $\$ 2,500$ & 9.9 & 2510 \\
\hline
\end{tabular}

The total cost for each predictive motor maintenance test is the sum of capital cost and labor cost.

\subsection{Reports from Model}

The same details as listed above and used for manual calculations are entered in the TPM model developed using Access. The report generated by the model is printed and attached herein. 


\subsection{Conclusion}

The calculated values for various parameters like, efficiency, percentage voltage unbalance, percentage current unbalance, percentage load etc shown in the report are matching with the hand calculated values, recorded in the first section of this chapter. The cost calculations shown in the report are same as the results tabulated by manual calculation. The recommended actions and messages displayed for every test in the report when compared with the detailed descriptions included in the third chapter, they are found to be appropriate. Therefore, it can be concluded that the total productive maintenance model developed for electrical motors is quite efficient. 


\subsection{Conclusions and Future Work}

\subsection{Conclusions}

The total productive maintenance model thus built in Microsoft Access ${ }^{\circledR}$ for electrical motor can be a useful tool to predict the possible problems or deterioration happening in insulation, bearing, rotor bar and stator windings of the motor. There were several difficulties faced in the design and development of the total productive maintenance model. The initial difficulty was in choosing the failures to be considered in the model and then to choose the appropriate tests that can predict the faults in the chosen failures. There was a need for an extensive study of literature in being able to gather all the formulae, standard data, and measures for comparison, recommended actions to correct the faults etc for each of the tests. In building the model, the primary concern was regarding using the same information in multiple tests without asking the user to input the same information more than once. For example, motor size in hp; this was solved by using this in general motor information and taking this every other test where it is needed. Considerable time was spent in pairing up the tests that were interdependent. For example, percentage load calculations require both voltage and current unbalance tests to be completed before percentage load can be found. To be able to have an efficient model, master tables were created having all required information in one single table. For example, see the main table column details in Appendix II. The other issue was to enable the user to be able to change the instrument costs for all the instruments in the list. This was achieved using the OLE feature. OLE stands for Object Linking \& Embedding. Using this feature the pictures of motor, vibration meter etc were embedded on to the model screen and the table for instrument cost information is linked to the excel file of the same. The output result was huge since we had several tests and other motor related information. Based on the individual test results, corresponding test output had to be printed. Access reporting is limited to 21 inches length in report. To overcome this problem, Auto field incrementer or decrementer feature is used. Menu bar is used to prepare a custom made menu bar to make the model look professional. 
So, although there were several issues and difficulties in designing and developing the total productive maintenance model for electrical motors, they were overcome with a lot of literature study related to the area. The model thus built is an efficient one in guiding the user in the area of motor maintenance.

\subsection{Future work}

Although the model thus developed is quite capable of efficiently gathering data form the user, process it and output meaningful results; this is just a first step in building such models in the area of total productive maintenance. There is a very good scope to do a lot more in this particular field. Some of them are:

1) This model includes tests that predict problems associated with insulation failure, bearing failure and rotor bar, stator windings failure. These were chosen because they are the top most failures leading to the breakdown of the motor. Many other failures exist and they can be included in the model.

2) This model includes recommendations pertaining to periodic and predictive maintenance practices; one can include other maintenance practices as well.

3) This is a TPM model developed exclusively for motors; there are many other energy consuming equipments as listed in the beginning of chapter 1 . The same idea can be extended to other equipments. And when all these are tied together, it will be a company wide TPM model including all the equipment maintenance practices under its umbrella.

4) This model does not include the criticality of equipment. Criticality aspects of the motor was deliberately left out with the view of not over complicating the model and keep the model within the limits of initial practical application. By incorporating this into the model, the model will be more flexible in handling issues of a particular motor depending on how critical or important it is in the line of production.

5) As of now, the model does keep track of the history of motor tests. But, it displays the results in tabular fashion in separate rows. This can be extended and the model may be improved to generate graphs, so that it becomes more visual and the data trend will be easy to track and interpret. 
6) The model no doubt gives the periodic and predictive maintenance cost. But it does not give results pertaining to optimum cost (considering productivity cost and maintenance cost). This can be tied in to the model.

7) The motor harmonic trending can be included in the model. Although the harmonics of the motor does not help in assessing the condition of the motor, it certainly gives a lot of information pertaining to the equipment driven by the motor. 


\subsection{References}

1. Solutions for Energy Security \& Facility Management Challenges: Proceedings (WEEC) $\left(25^{\text {th }}: 2002\right)$ By Joyce Wells, Assn of Energy engineers, World Energy engineering Congress 2002 A, Association of Energy Engineers. Published by Marcel Dekker, 2004 ISBN 0824709349, 9780824709341

2. Motor Diagnostics and Motor Health Study; Dr. Howard W. Penrose, Ph.D. BJM Corp and Terrence O'Hanlon, CMRP, Reliability Web; A Motor Diagnostic Study Co-Sponsored by Net Express USA.

3. Venkatesh, J. (2003), "An Introduction to Total Productive Maintenance", available at: http://plant-maintenance.com/article/tpm intro.shtml (accessed 25 April 2005).

4. Operations and Maintenance Best Practices - A Guide To Achieving Operational Efficiency; G P Sullivan, R Pugh, A P Melendez, W D Hunt December 2002

5. Handbook for Reliability-Centered Maintenance Requirements for Navel Aircraft, Weapons Systems Support Equipment, Department of Defense, USA, MIL-HDBK-2173 (AS), 1998

6. Considerations in Reliability-Centered Motor Management, Success by Design Reliability Services; Dr. Howard W. Penrose 2007 http://www.motordiagnostics.com/2007\%20Papers/Considerations $\% 20$ for $\% 2$ 0RCMM.pdf

7. Maintenance and Management Communication Study, Part1 Success by Design Reliability Services; Dr. Howard W. Penrose 2006 http://www.motordiagnostics.com/Projects/Communication1.pdf

8. Energy Management for Motor Driven Systems. The Energy Saving Network - Plug It In; Office of Industrial Technologies. By Gilbert A. McCoy \& John G. Douglass, Washington State University; Revision 2 - March 2000 
9. Motor Diagnostics and Motor Health Study; Dr. Howard W. Penrose, Ph.D. BJM Corp and Terrence O'Hanlon, CMRP, Reliability Web; A Motor Diagnostic Study Co-Sponsored by Net Express USA

10. US Department of Energy, United States Industrial Electric Motor Systems Market Opportunities Assessment, US Department of Energy Office of Industrial Technologies (US DOE - OIT) Motor Challenge Program, December 1998

11. Practical TPM: Successful Equipment Management at Agilent Technologies, James A. Leflar; 2001

12. Electrical Motor Diagnostics, Second Edition, Howard W. Penrose, ISBN: 978-0-9712450-7-5

13. Total Productive Maintenance - Terry Wireman, Second Edition; Chapter 1: The History and Impact of Total Productive Maintenance; Industrial Press

14. A Driving Lesson for Operation and Maintenance - An Article About Maintenance Planning and Scheduling Meeting; By Torbjorn Idhamane VP \& Partner, IDCON, Inc.,

15. Maintenance Planning \& Scheduling - The New Profit Center; By Chris Hykin, Advantage Team Leader, International Paper; IDCON, Inc.,

16. An Introduction to Predictive Maintenance; By R. Keith Mobley Technology and Engineering - Butterworth Heinemann; 2002

17. Complete Guide to Preventive and Predictive Maintenance; By Joel Levitt, Industrial Pr (2005) - ISBN 0831132531

18. Practical TPM: Successful Equipment Management at Agilent Technologies, James A. Leflar; 2001; Chapter 2: Improving Machine performance

19. “A Novel Approach to Electric Motor System Maintenance and Management for Industrial and Commercial Uptime and Energy Costs," KWU, 1997; Program Funded by Dreisilker Electric Motors, Inc. of Glen Ellyn, Illinois.

20. "In-Service Motor Testing," Washington State University, 1999; The research was performed for the Northwest Energy Efficiency Alliance between March 30, 1998 and May 31, 1999. 
21. "A Novel Approach to Industrial Assessments for Improved Energy, Waste Stream, Process and Reliability," KWU, 2000

22. 'Improved Motors for Utility Applications', EPRI EL-4286, Volume 1\& 2, 1763-1, Final Report, October 1982.

23. Energy - Efficient Motor Systems: A Handbook on Technology, Program, and Policy Opportunities; By Steven Nadel, R. Neal Elliot, Michael Shepard, Steve Greenberg, Gail Katz, and Anibal T. de Almeida, Second Edition 2002

24. Motor Application and Maintenance Handbook; By Robert W. Smeaton. Published by Mc Graw Hill, 1969

25. Handbook of Electric Machines; By S. A. Nasar. Published by Mc Graw Hill, 1987

26. Vibration Test, Standard Assessment recommendation for Industries As A Measure of Energy Reduction, Industrial Assessment Center, WVU; Funded By US Department of Energy.

27. Modern Plant Testing; Information on Voltage Levels and Voltage Unbalance Testing, Baker Instruments - an SFK Group Company; Bakerweb

28. Electric Motor Handbook; By E. H. Werninck. Published by Mc Graw Hill Book Company (UK) Limited, 1988

29. Energy Reduction Through Improved Maintenance Practices; By Kenneth E. Bannister, 1999; 128p ISBN 0-8311-3082-2

30. 'Maintenance Engineering Handbook', Higgins, Morrow, McGraw-Hill, ISBN 0-07-028755-4.

31. Motor Testing Tip - Using the Kva/HP Code, Voltmeter and Ammeter to Commission an Electric Motor, Article 07-0107, Reliabilityweb; Howard W. Penrose

32. J. G. Douglass, 'Efficacy of Methods for Estimating in-Service Motor Efficiency', Washington State University, Cooperative Extension Energy Program, June 1997.

33. E. Wiedenbrug, A. Ramme, E. Matheson, A. von Jouanne, A. Wallace, 'Modern on-line testing of Induction Motors for Predictive Maintenance and Monitoring', Pulp and Paper Conference June 2001. 
34. Practical Machinery Vibration Analysis and Predictive Maintenance; By Paresh Girdhar, Cornelius Scheffer - Technology \& Engineering - Elsevier (2004)

35. Servo Motor Testing Using Ohm Meter; Article from MachineTool Help.Com http://www.machinetoolhelp.com/Troubleshooting/ServoMotortesting.html

36. Principles of Off-line Testing, Dielectric Absorption Testing and Polarization Testing; Baker Instrumentation, an SFK Group of Company.

37. Electric Motor Bearing Greasing Basics, Article by Dr. Howard W. Penrose President, SUCCESS by DESIGN on Reliabilityweb.Com http://www.reliabilityweb.com/art06/motor_greasing.htm

38. Microsoft Office Access Bible; By Cary N. Prague, Michael R. Irwin and Jennifer Reardon. Published by Wiley in 2003

39. Database Design for Mere Mortals - A Hands-On Guide To Relational Database Design; By Michael J. Hernandez, Second Edition, Addison Wesley, 2003 


\subsection{Appendix I}

\section{VB Script code}

$1 \quad$ Private Sub cmd_Save_Click()

' This portion of code is used to save the record to the table with Test Calculations

On Error GoTo Err_cmd_Save_Click

Dim rst As New ADODB. Recordset

rst.Open "KRSNA", CurrentProject.Connection, adOpenDynamic, adLockOptimistic

With rst

.AddNew

' unique_id $=$.[ID]

'! [ID] = Me!ID

! [CFname $]=$ Me!cFname

![cMname $]=$ Me!cMname

! [CLname $]=$ Me!cLname

![cDesignation $]=$ Me!cDesignation

$![$ cPlant Name $]=$ Me!cPlant Name

![nPlant_type] = Me!nPlant_type

! cPlant_type $]=$ Me!cPlant_type

![CProduct_desp] $=$ Me!cProduct_desp

![cPlant_Profile] = Me!cPlant_Profile

![CMotor_Id $]=$ Me!cMotor_Id

![nMotor_Size] $=$ Me!cMotor_Size

![cMotor_Size] $=$ Me!cMotor_Size

![nAge_of_Motor] = Me!nAge_of_Motor

! [nDesign_Life] $=$ Me!nDesign_Life

![mLabor_Cost $]=$ Me!mLabor_Cost

![nrate_noload $]=$ Me!nrate_noload

![nrate_fullload] $=$ Me!nrate_fullload

![nspeed_rpm] $=$ Me!nspeed_rpm

![npower_kw] = Me!npower_kw

![chk_Thermometer] = Me!chk_Thermometer

![chk_Vibration] = Me!chk_Vibration

![chk_Volt $]=$ Me!chk_Volt

![chk_Amm] $=$ Me!chk_Amm

![chk_Ohm] $=$ Me!chk_Ohm

![chk_PI $]=$ Me!chk_PI

![chk_Watt] $=$ Me!chk_Watt

![chk_Tacho $]=$ Me!chk_Tacho

![vot_v1] $=$ Me!vot_v1

! $[$ vot_v2] $=$ Me!vot_v2

![vot_v3] = Me!vot_v3

! $[$ vot_avg_v] $=$ Me!vot_avg_v

![vot_unbalance] $=$ Me!vot_unbalance

![tt_Ambient temp1] = Me!tt_Ambient temp1

![tt_Insulation_temp1] = Me!tt_Insulation_temp1

![tt_Insulation_class] = Me!tt_Insulation_class

![tt_Bearing_Temp] = Me!tt_Bearing_Temp

! [tt Middle temp] $=$ Me!tt Middle temp

' $* * * * * * * * * * * * * * * * * * * * * * * * * * * * * * * * * * * * * * * * * * * * * * * * * * * * * * 1$

' Temperature Calculation

' $* * * * * * * * * * * * * * * * * * * * * * * * * * * * * * * * * * * * * * * * * * * * * * * * * * * * * * 1$

Dim Temp_Calc As Integer

Temp_Calc $=0$

If Me!tt_Bearing_Temp > Me!tt_Middle_temp Then

Temp_Calc $=$ Me!tt_Bearing_Temp - Me!tt_Middle_temp

If Temp_Calc $>=10$ Then

![tt_Message] = "Bearing"

End If

End If

If Me!tt_Middle_temp > Me!tt_Bearing_Temp Then

Temp_Calc $=$ Me!tt_Middle_temp - Me!tt_Bearing_Temp

If Temp_Calc $>=10$ Then 


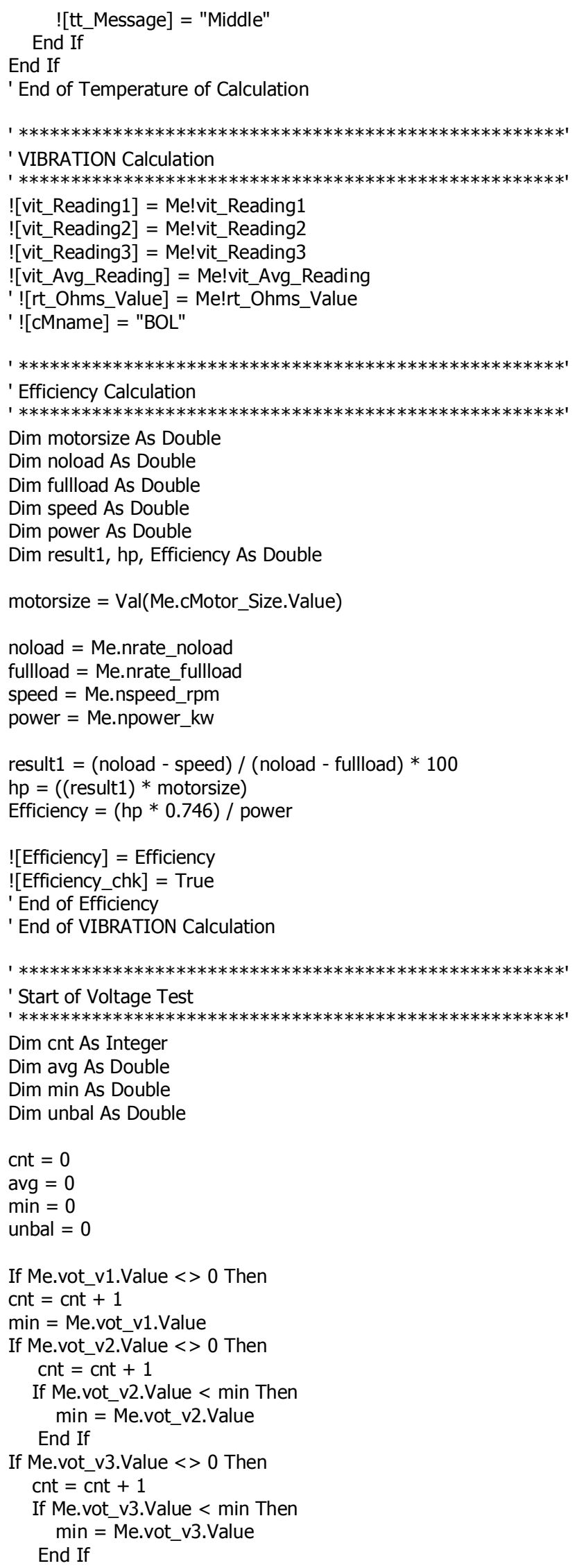




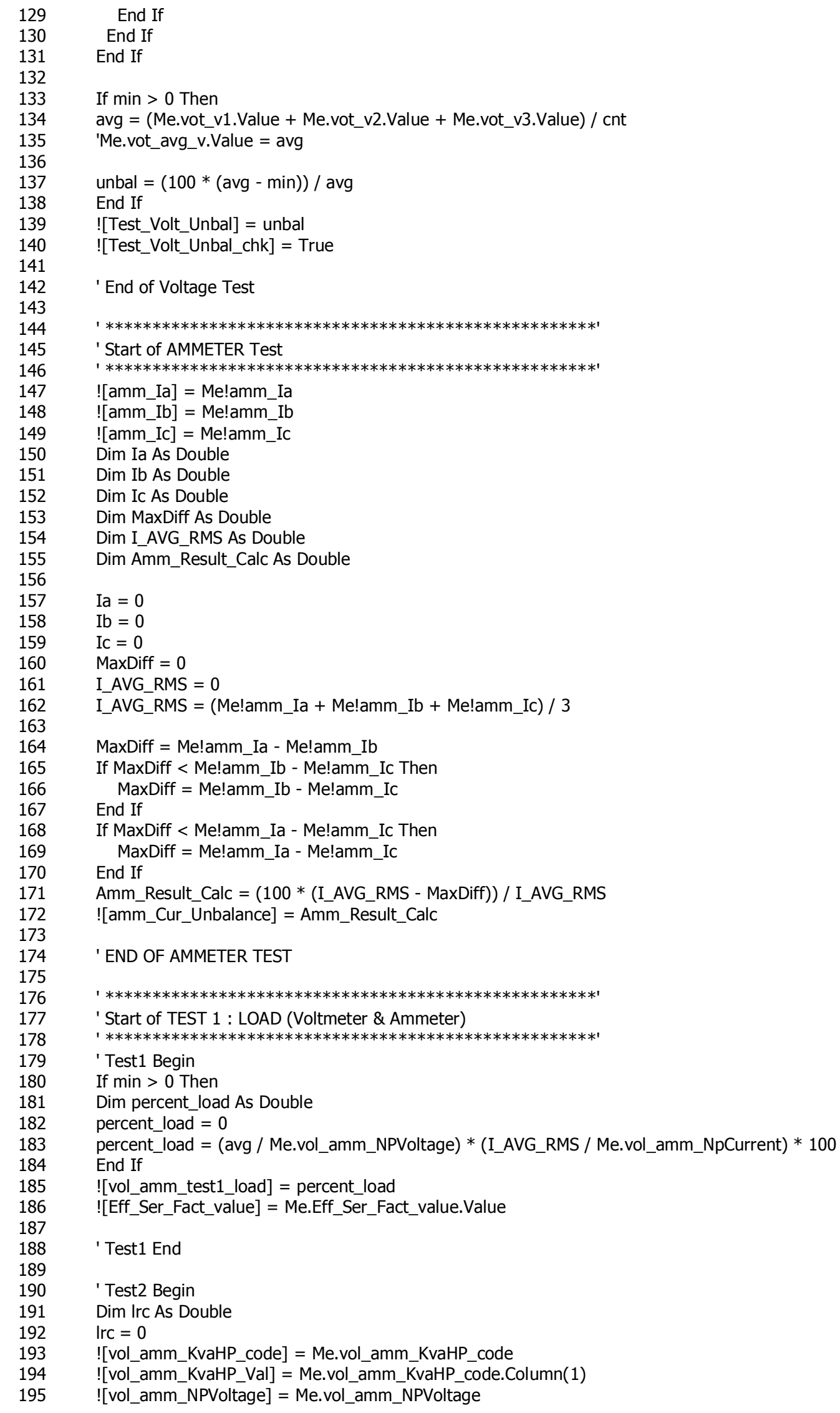




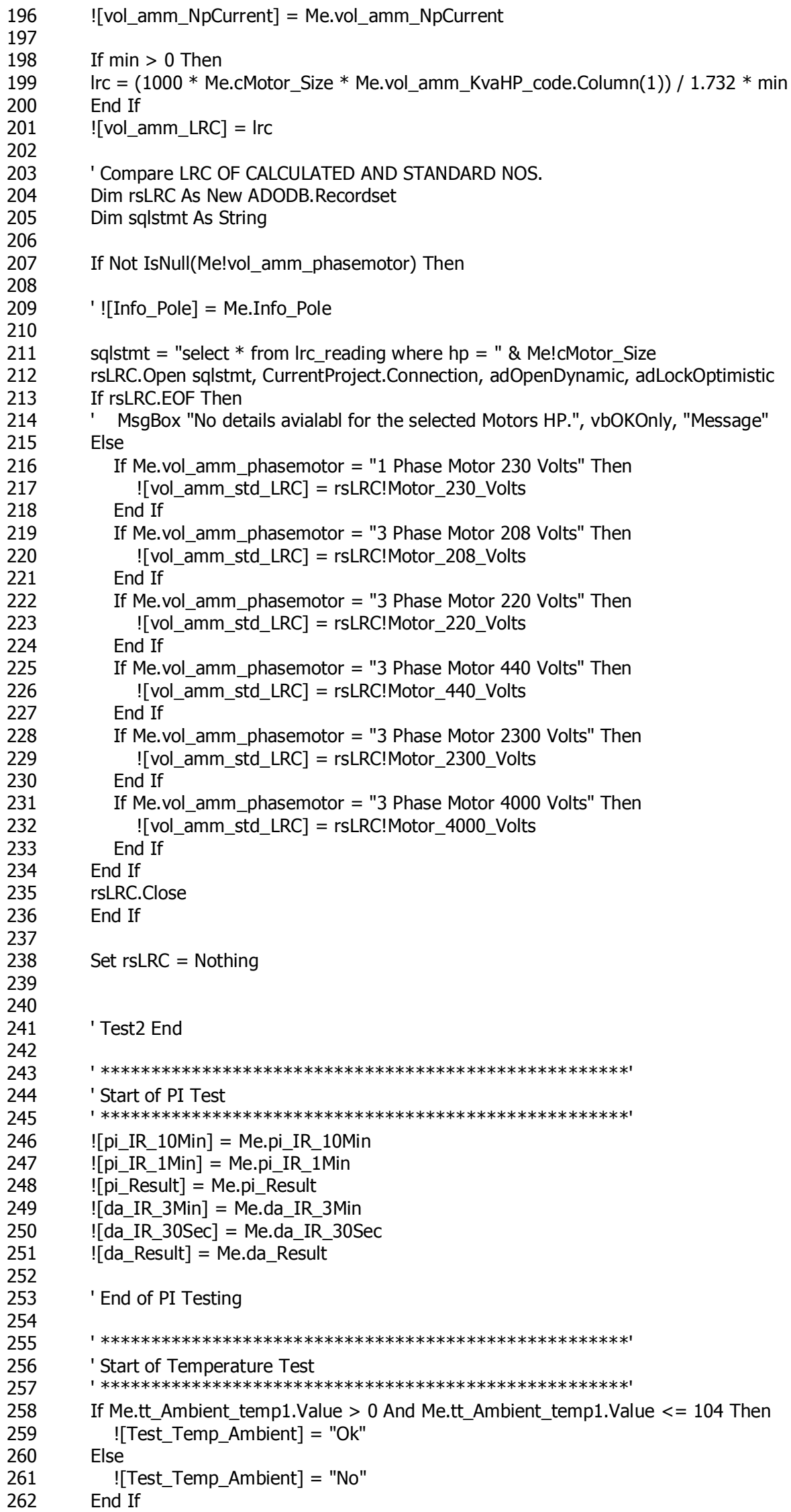




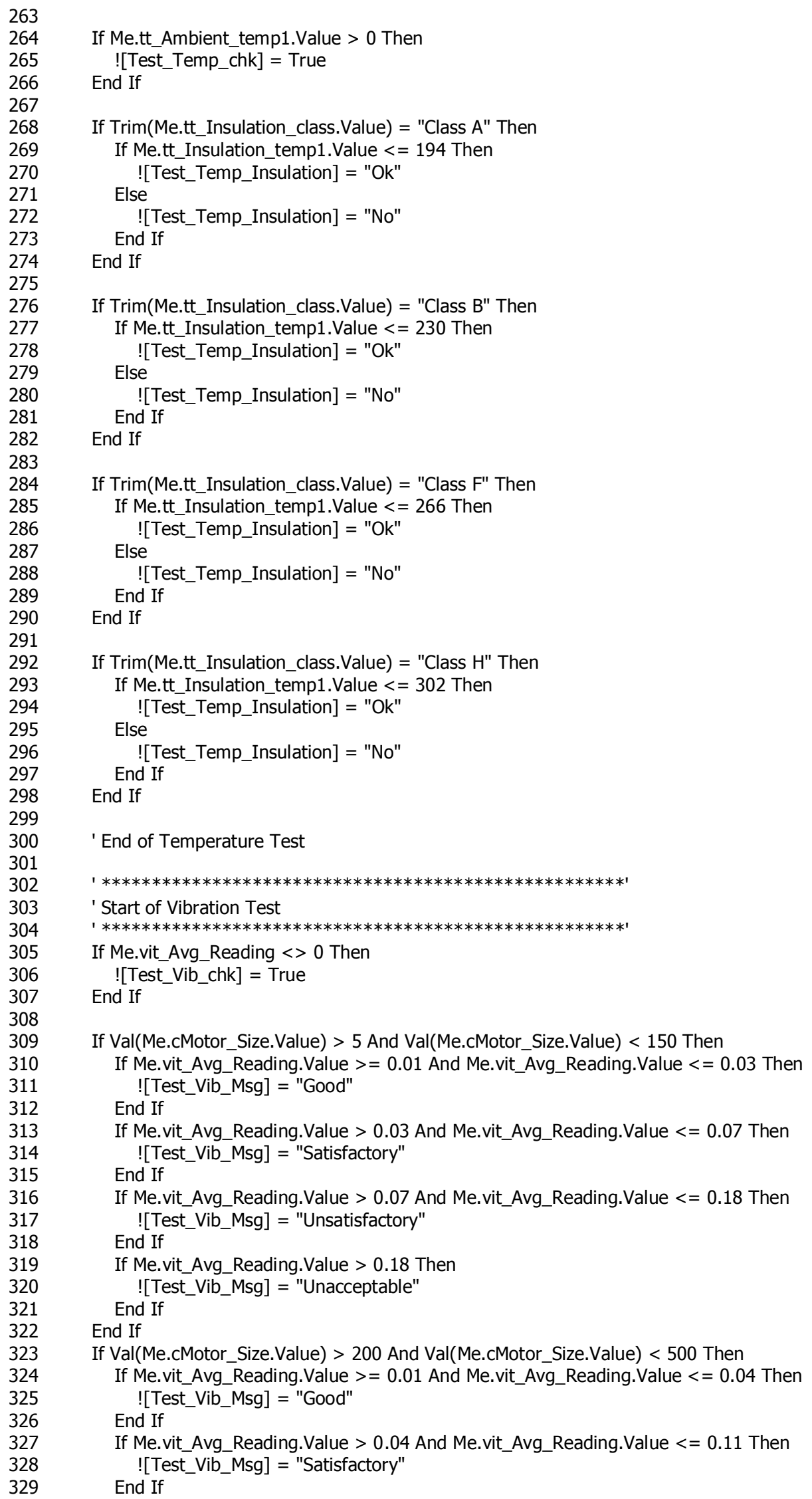




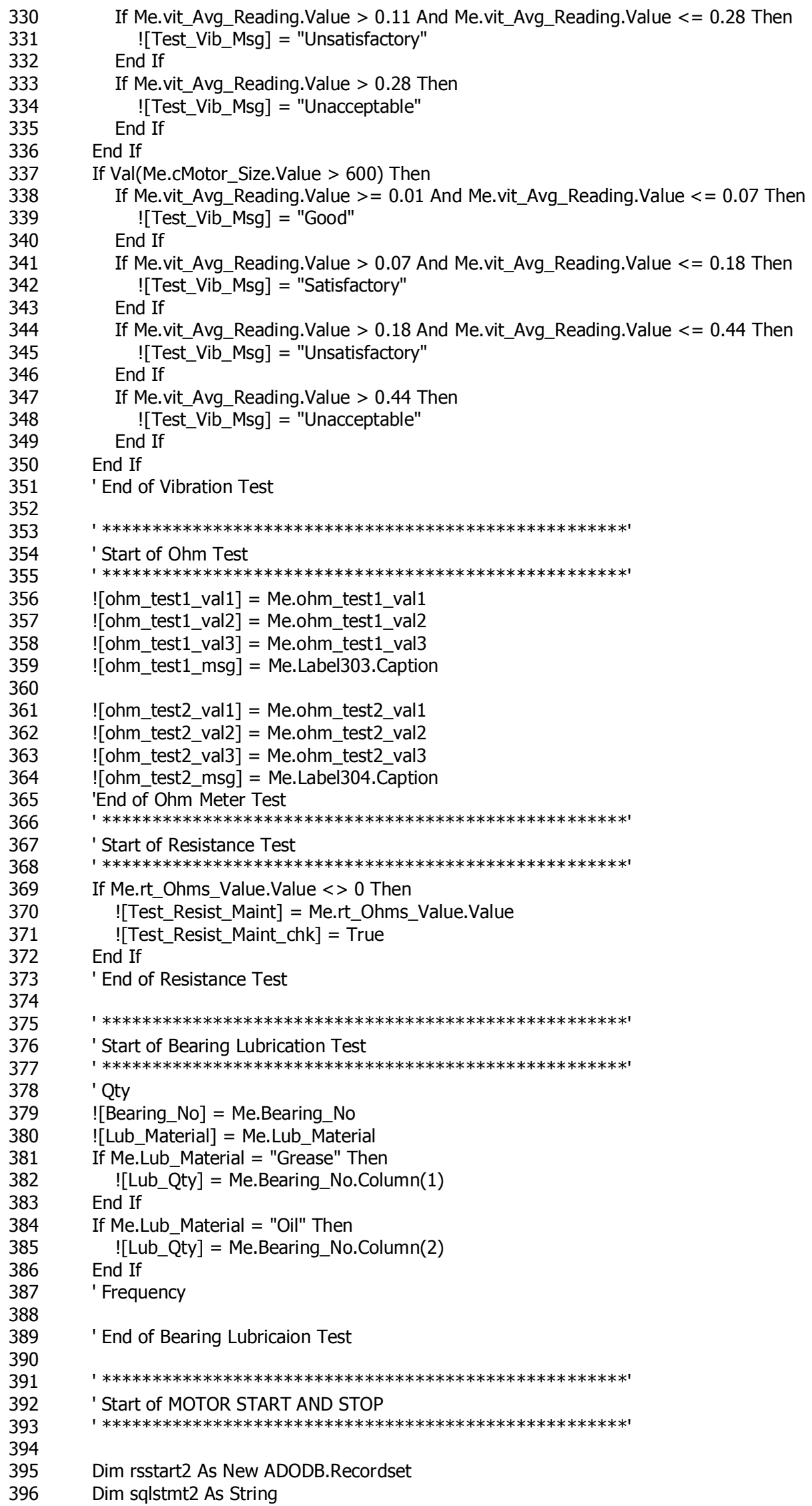




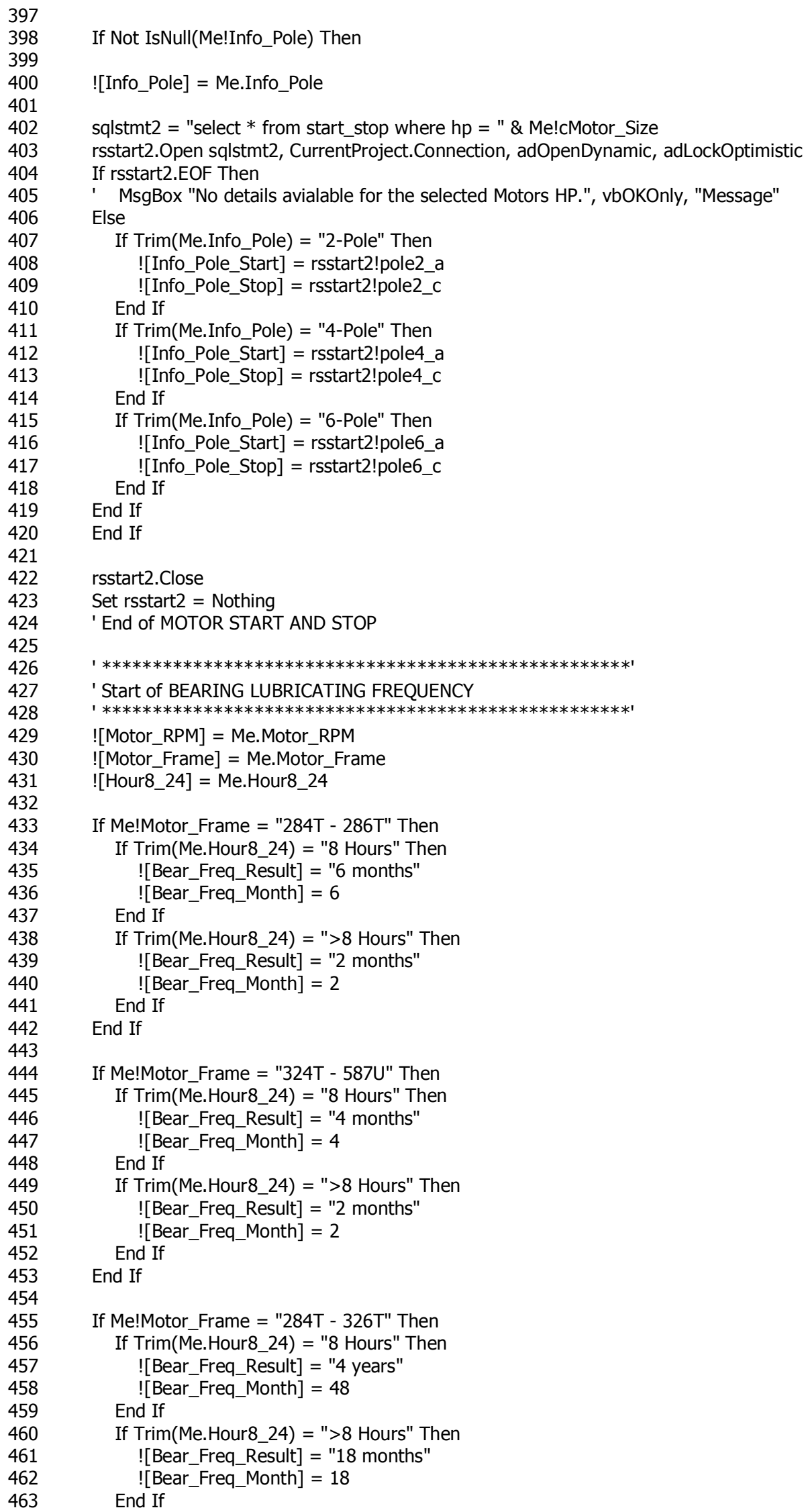




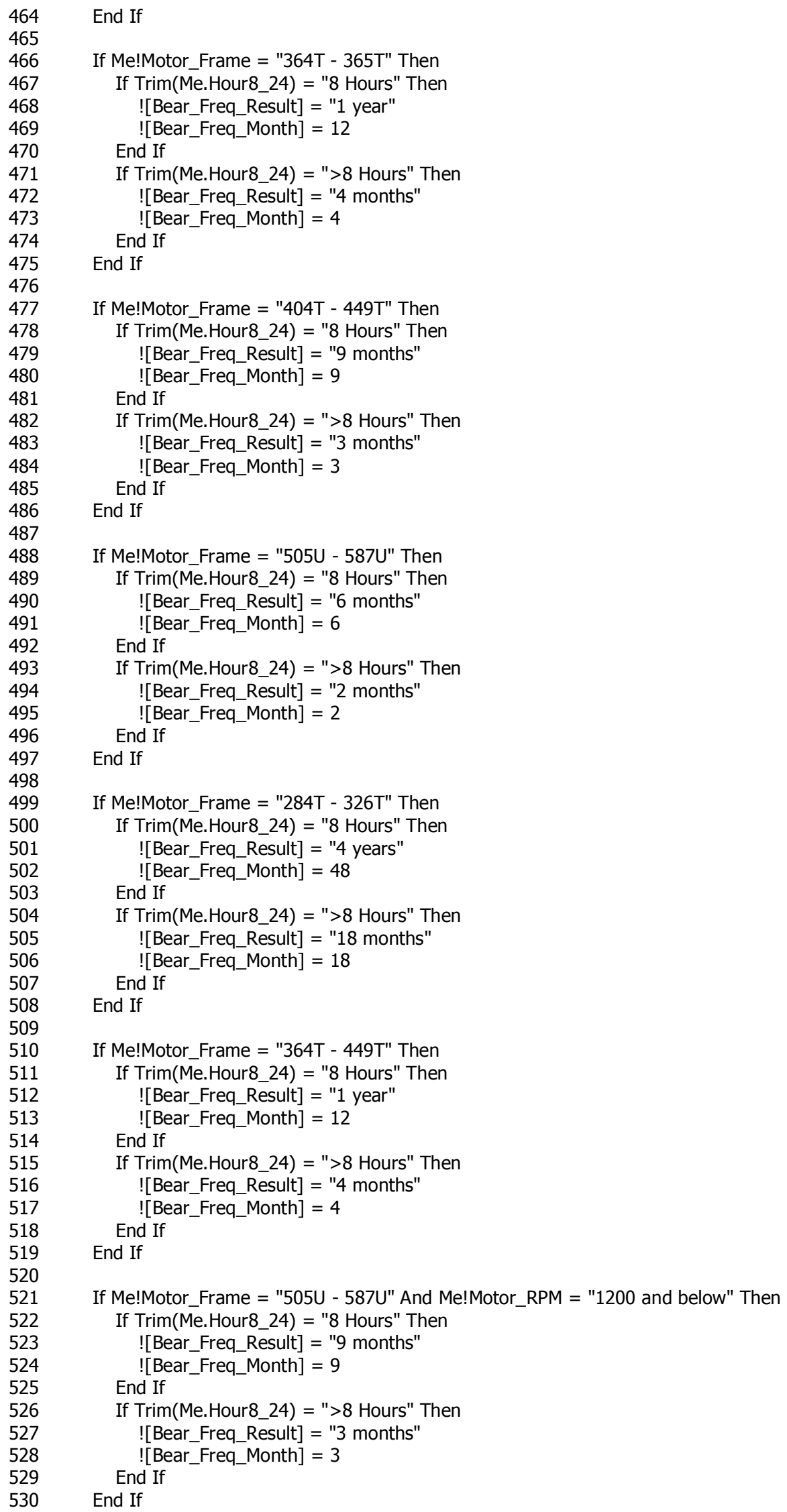




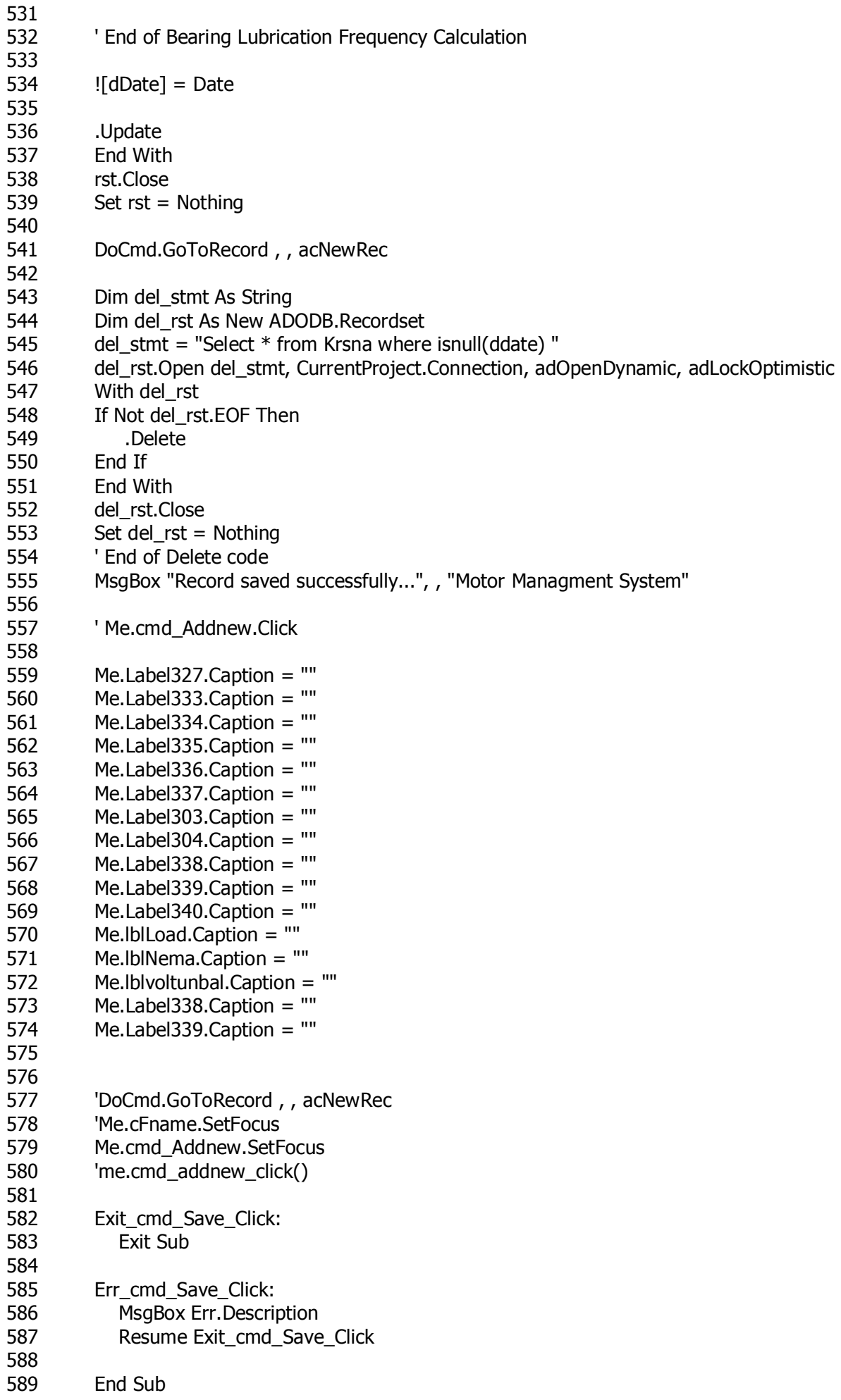




\begin{tabular}{|c|l|}
\hline Code Line & \\
\hline 1 & This is the command button in the form to save the record. Event is click. \\
\hline 2 & Used to catch the error if any occurs \\
\hline 3 & Declare a recordset with ActiveX Data Obects. (ADODB) \\
\hline 4 & We are opening the recordset with the table name (KRSNA) \\
\hline 6 & keeping the rst - recordset open using the WITH STATEMENT \\
\hline 7 & used to append a blank record to save the entered values \\
\hline 8 to 47 & $\begin{array}{l}\text { respective fields in table are assigned with the form objects - values entered / } \\
\text { input }\end{array}$ \\
\hline 48 to 50 & Comment \\
\hline 51 to 66 & used to calculate temperature test result \\
\hline 70 to 75 & to calculate Vibration test and assign respective data to table fields \\
\hline 80 to 101 & efficiency calculation \\
\hline 106 to 143 & voltage calc \\
\hline 147 to 175 & Ammeter calcuation \\
\hline 179 to 242 & Load calc \\
\hline 246 to 253 & PI \\
\hline 356 to 365 & Ohm test \\
\hline 379 to 390 & Bearing calc \\
\hline 395 to 425 & Motor Start and Stop calc \\
\hline 429 to 532 & $\begin{array}{l}\text { Lubrication calcuation, here we are doing manual checking for the Bearing } \\
\text { Frequency values and assinging the duration.. }\end{array}$ \\
\hline 534 & $\begin{array}{l}\text { Used to store the date on which the transaction is made. This is the system } \\
\text { date, This date is used while generation report and for filtering the data. }\end{array}$ \\
\hline 536 & $\begin{array}{l}\text { Dot Update is used to update the record in table.. Means we used Append to } \\
\text { insert a blank record in line no. } 7 \text { and now we hare updating the actual values } \\
\text { from table and the calculated result to the table by giving .UPDATE. This is } \\
\text { SQL syntax }\end{array}$ \\
\hline 537 & Used to Close the WITH STATEMENT \\
\hline 538 & closing the recordset \\
\hline 539 & Freeing the space from recordset \\
\hline 540 to 555 & to delete any blank record if existing in table without DATE data \\
\hline 555 & Message box to confirm the successful entry of record \\
\hline 557 & getting ready for accept another record in form \\
\hline 585 to 557 & to clear all label captions - which is used to display test results \\
\hline 589 & to display the error message if any error occurs. This is in response to line 2 \\
\hline & end of procedure \\
\hline 59
\end{tabular}

Table AI.1: Code Description 


\subsection{Appendix II}

Listed here are the columns, type of data stored in each column and size of tables used in the database for storing the information gathered from the user. In the column names, "c" means character, used for data that is in the text form. " $n$ " means number, used for data that is in the numerical form. The data type indicates the type of data, whether it is text, integer, decimal etc. Size is the length of each data type, choosing the appropriate size will keep the size of the database within limits.

\begin{tabular}{|l|l|l|}
\hline \multicolumn{1}{|c|}{ Column Name } & \multicolumn{1}{c|}{ Type } & \multicolumn{1}{c|}{ Size } \\
\hline ID & Long Integer & 4 \\
\hline cFname & Text & 50 \\
\hline cMname & Text & 50 \\
\hline cLname & Text & 50 \\
\hline cDesignation & Text & 50 \\
\hline cPlant_Name & Text & 50 \\
\hline nPlant_type & Long Integer & 4 \\
\hline cPlant_type & Text & 100 \\
\hline cProduct_desp & Text & 255 \\
\hline cPlant_Profile & Text & 50 \\
\hline nPlant_Size & Long Integer & 4 \\
\hline cPlant_Size & Text & 50 \\
\hline nBudget & Long Integer & 4 \\
\hline cBudget & Text & 50 \\
\hline nMaint_Personnel & Long Integer & 4 \\
\hline cMotor_Id & Text & 50 \\
\hline nMotor_Size & Long Integer & 4 \\
\hline cMotor_Size & Text & 50 \\
\hline nCriiticality & Long Integer & 4 \\
\hline cCriiticality & Text & 50 \\
\hline nAge_of_Motor & Long Integer & 4 \\
\hline nDesign_Life & Long Integer & 4 \\
\hline nRepair_History & Long Integer & 4 \\
\hline nTime_for_Action & Long Integer & 4 \\
\hline mRepair_Cost & Currency & 8 \\
\hline mLabor_Cost & Currency & 8 \\
\hline nrate_noload & Long Integer & 4 \\
\hline nrate_fullload & Long Integer & 4 \\
\hline nspeed_rpm & Long Integer & 4 \\
\hline npower_kw & Single & 4 \\
\hline chk_Thermometer & Yes/No & 1 \\
\hline chk_Vibration & Yes/No & 1 \\
\hline chk_Volt & Yes/No & 1 \\
\hline chk_Amm & Yes/No & 1 \\
\hline chk_Ohm & Yes/No & 1 \\
\hline chk_PI & 1 \\
\hline chk_Watt & 1 \\
\hline
\end{tabular}




\begin{tabular}{|l|l|l|}
\hline \multicolumn{1}{|c|}{ Column Name } & \multicolumn{1}{|c|}{ Type } & Size \\
\hline chk_Tacho & Yes/No & 1 \\
\hline chk_Eff_Ser_Fact & Yes/No & 1 \\
\hline vot_v1 & Long Integer & 4 \\
\hline vot_v2 & Long Integer & 4 \\
\hline vot_v3 & Long Integer & 4 \\
\hline vot_avg_v & Long Integer & 4 \\
\hline vot_unbalance & Long Integer & 4 \\
\hline tt_Ambient_temp1 & Long Integer & 4 \\
\hline tt_Insulation_temp1 & Long Integer & 4 \\
\hline tt_Ambient_temp2 & Long Integer & 4 \\
\hline tt_Insulation_temp2 & Long Integer & 4 \\
\hline tt_Insulation_class & Text & 50 \\
\hline tt_Bearing_Temp & Long Integer & 4 \\
\hline tt_Middle_temp & Long Integer & 4 \\
\hline tt_Message & Text & 50 \\
\hline amm_Ia & Long Integer & 4 \\
\hline amm_Ib & Long Integer & 4 \\
\hline amm_Ic & Long Integer & 4 \\
\hline amm_avg_c & Long Integer & 4 \\
\hline amm_Cur_Unbalance & Single & 4 \\
\hline vol_amm_test1_load & Double & 8 \\
\hline vol_amm_KvaHP_code & Text & 1 \\
\hline vol_amm_KvaHP_Val & Long Integer & 4 \\
\hline vol_amm_phasemotor & Text & 30 \\
\hline vol_amm_NpCurrent & Long Integer & 4 \\
\hline vol_amm_NPVoltage & Long Integer & 4 \\
\hline vol_amm_LRC & Double & 8 \\
\hline vol_amm_std_LRC & Double & 8 \\
\hline ohm_test1_val1 & Text & 15 \\
\hline ohm_test1_val2 & Text & 15 \\
\hline ohm_test1_val3 & Text & 15 \\
\hline ohm_test1_msg & Text & 25 \\
\hline ohm_test2_val1 & Double & 8 \\
\hline ohm_test2_val2 & Double & 8 \\
\hline ohm_test2_val3 & Double & 8 \\
\hline ohm_test2_msg & Text & 25 \\
\hline pi_IR_10Min & Long Integer & 4 \\
\hline pi_IR_1Min & Long Integer & 4 \\
\hline pi_Result & Double & 8 \\
\hline da_IR_3Min & 4 \\
\hline da_IR_30Sece & 4 \\
\hline da_Result & \\
\hline vit_Reading1 & \\
\hline vit_Reading2 & Double & 4 \\
\hline vit_Reading3 & \\
\hline vit_Avg_Reading & 4 Integer & 4 \\
\hline Eff_Ser_Fact_value & 4 \\
\hline
\end{tabular}




\begin{tabular}{|l|l|l|}
\hline \multicolumn{1}{|c|}{ Column Name } & \multicolumn{1}{c|}{ Type } & \multicolumn{1}{c|}{ Size } \\
\hline rt_Ohms_Value & Long Integer & 4 \\
\hline dDate & Date/Time & 8 \\
\hline Info_Pole & Text & 10 \\
\hline Info_Pole_Start & Long Integer & 4 \\
\hline Info_Pole_Stop & Long Integer & 4 \\
\hline Bearing_No & Text & 20 \\
\hline Lub_Material & Text & 7 \\
\hline Lub_Qty & Double & 8 \\
\hline Motor_RPM & Text & 15 \\
\hline Motor_Frame & Text & 15 \\
\hline Hour8_24 & Text & 15 \\
\hline Bear_Freq_Result & Text & 15 \\
\hline Bear_Freq_Month & Integer & 2 \\
\hline Efficiency & Single & 4 \\
\hline Efficiency_chk & Yes/No & 1 \\
\hline Test_Volt_Unbal & Single & 4 \\
\hline Test_Volt_Unbal_chk & Yes/No & 1 \\
\hline Test_Resist_Maint & Long Integer & 4 \\
\hline Test_Resist_Maint_chk & Yes/No & 1 \\
\hline Test_Temp_chk & Yes/No & 1 \\
\hline Test_Temp_Ambient & Text & 2 \\
\hline Test_Temp_Insulation & Text & 2 \\
\hline Test_Vib_chk & Yes/No & 1 \\
\hline Test_Vib_Msg & Text & 20 \\
\hline
\end{tabular}

Table AII..1: Main table of the model database

\begin{tabular}{|l|l|l|}
\hline \multicolumn{1}{|c|}{ Column Name } & \multicolumn{1}{|c|}{ Type } & \multicolumn{1}{c|}{ Size } \\
\hline Kva_HP_Code & Text & 1 \\
\hline Value & Double & 8 \\
\hline
\end{tabular}

Table AII..2: kVA/hp Code

\begin{tabular}{|l|l|l|}
\hline \multicolumn{1}{|c|}{ Column Name } & \multicolumn{1}{|c|}{ Type } & \multicolumn{1}{c|}{ Size } \\
\hline HP & Double & 8 \\
\hline Motor_230_volts & Double & 8 \\
\hline Motor_208_volts & Double & 8 \\
\hline Motor_220_volts & Double & 8 \\
\hline Motor_440_volts & Double & 8 \\
\hline Motor_2300_volts & Double & 8 \\
\hline Motor_4000_volts & Double & 8 \\
\hline
\end{tabular}

Table AII..3: Locked Rotor Current

\begin{tabular}{|l|l|l|}
\hline Column Name & \multicolumn{1}{c|}{ Type } & \multicolumn{1}{c|}{ Size } \\
\hline Bearing_No & Double & 8 \\
\hline Grease & Double & 8 \\
\hline Oil & Double & 8 \\
\hline
\end{tabular}

Table AII..4: Lubrication Quantity 


\begin{tabular}{|l|l|l|}
\hline Column Name & \multicolumn{1}{|c|}{ Type } & \multicolumn{1}{c|}{ Size } \\
\hline HP & Double & 8 \\
\hline Pole2_A & Double & 8 \\
\hline Pole2_C & Double & 8 \\
\hline Pole4_A & Double & 8 \\
\hline Pole4_C & Double & 8 \\
\hline Pole6_A & Double & 8 \\
\hline Pole6_C & Double & 8 \\
\hline
\end{tabular}

Table AII..5: Frequency of starts and stops

\begin{tabular}{|l|l|l|}
\hline Column Name & \multicolumn{1}{|c|}{ Type } & \multicolumn{1}{c|}{ Size } \\
\hline RPM & Text & 255 \\
\hline Motor_Frame & Text & 255 \\
\hline Hours_8 & Text & 255 \\
\hline Hours_24 & Text & 255 \\
\hline
\end{tabular}

Table AII..6: Lubrication Frequency

\begin{tabular}{|l|l|l|}
\hline Column Name & \multicolumn{1}{|c|}{ Type } & \multicolumn{1}{c|}{ Size } \\
\hline Industry & Text & 255 \\
\hline Plant & Text & 255 \\
\hline
\end{tabular}

Table AII..7: Industry 


\subsection{Appendix III}

A brief description on guiding the user in getting the measurements that has to be input into the model

\section{Motor Efficiency:}

Rated speed at no load - Enter the rated speed at no load conditions as given by the designer on the nameplate in rpm

Rated speed at full load - Enter the rated speed at full load conditions as given by the designer on the nameplate in rpm

Measured speed - Measure the speed of the motor using a tachometer and enter the speed in rpm

Measured power - Measure the power of the motor using a wattmeter and enter the power in $\mathrm{kW}$

Insulation Temperature Testing:

Ambient Temperature - Enter the ambient or atmospheric temperature in ${ }^{\circ} \mathrm{F}$

Temperature of Insulation - Measure the temperature of the insulation using an electronic thermometer and enter the reading in ${ }^{\circ} \mathrm{F}$

Insulation Class - Find what the insulation class is from the nameplate and select the right one from the drop down list

Bearing Temperature Testing:

Bearing Temperature - Measure the temperature at the bearing location using an electronic thermometer and enter the reading in ${ }^{\circ} \mathrm{F}$

Temperature at the Middle of Motor - Measure the temperature at the middle of the motor on the external surface using an electronic thermometer and enter the reading in ${ }^{\circ} \mathrm{F}$

\section{Vibration Test:}

Reading 1 - Place the vibration meter at the middle of the motor for about 5 seconds on the external surface and enter the reading in inches/second Reading 2 - Place the vibration meter at the bearing location of the motor for about 5 seconds and enter the reading obtained in inches/second Reading 3 - Place the vibration meter at the stator location of the motor for about 5 seconds and enter the reading obtained in inches/second

Voltage Test:

Voltage Reading 1 - Measure the voltage of phase 1 using a voltmeter and enter the reading in volts 
Voltage Reading 2 - Measure the voltage of phase 2 using a voltmeter and enter the reading in volts

Voltage Reading 3 - Measure the voltage of phase 3 using a voltmeter and enter the reading in volts

Ammeter Test:

Ammeter Reading 1 - Measure the current of phase 1 using an ammeter and enter the reading in Amperes

Ammeter Reading 2 - Measure the current of phase 2 using an ammeter and enter the reading in Amperes

Ammeter Reading 3 - Measure the current of phase 3 using an ammeter and enter the reading in Amperes

Percentage Load Calculation:

Nameplate Voltage - Find the nameplate voltage and enter in volts

Nameplate Current - Find the nameplate current and enter in Amperes

Locked Rotor Current Test:

$\mathrm{kVA} / \mathrm{hp}$ Code - Find the $\mathrm{kVA} / \mathrm{hp}$ code provided on the nameplate and select the appropriate one from the drop down list

Motor Phase and Voltage - Find the nameplate motor phase and voltage and select the appropriate combination from the drop down list

Test for Short to Ground:

Resistance Value 1 - Measure the resistance value at phase 1 using an ohmmeter and enter the reading in ohms

Resistance Value 2 - Measure the resistance value at phase 2 using an ohmmeter and enter the reading in ohms Resistance Value 3 - Measure the resistance value at phase 3 using an ohmmeter and enter the reading in ohms

Test for Short/Open in Windings:

Resistance Value 1 - Measure the resistance reading between phase 1 and phase 2 in the windings using an ohmmeter and enter the reading in ohms

Resistance Value 2 - Measure the resistance reading between phase 2 and phase 3 in the windings using an ohmmeter and enter the reading in ohms

Resistance Value 3 - Measure the resistance reading between phase 3 and phase 1 in the windings using an ohmmeter and enter the reading in ohms

Polarization Index Testing: 
IR at 1 Minute - Measure the insulation resistance at the insulation for duration of 1 minute using a PI Tester and enter the reading in ohms

IR at 10 Minutes - Measure the insulation resistance at the insulation for duration of 10 minutes using a PI Tester and enter the reading in ohms

Dielectric Absorption Testing:

IR at 30 Seconds - Measure the insulation resistance at the insulation for duration of 30 seconds using a PI Tester and enter the reading in ohms

IR at 3 Minutes - Measure the insulation resistance at the insulation for duration of 3 minutes using a PI Tester and enter the reading in ohms

Frequency of Starts and Stops:

Pole - Find the number of poles in motor given on the nameplate and pick the appropriate one from the dropdown list

Bearing Lubrication Quantity:

Bearing Number - Find the number of the bearing on the nameplate and select the right one provided in the dropdown list

Lubricating Material - Select the appropriate lubricating material used to lubricate the bearing

Bearing Lubrication Frequency:

Motor RPM - Enter the motor speed in rpm given on the nameplate

Motor Frame - Find the motor frame given on the nameplate and select the appropriate one from the dropdown menu

Hours per Day - Enter the plant operation profile in hours/day 